\title{
Structure and function of the pigeon visual system
}

\author{
WILLIAM J. DONOVAN \\ Florida State University, Tallahassee, Florida 32306
}

\begin{abstract}
This comprehensive, up-to-date account of vision in the pigeon begins with a description of the eye, its dimensions, and optical properties. The retina is discussed in considerable detail, with particular attention given to: the distribution of the various cell types within and across the retina, the number and the nature of the oil drops in the cones, the highly developed inner plexiform layer, the response characteristics of the ganglion cells, and the damage to cones caused by exposure to light. Lastly, the three major visual pathways are examined neuroanatomically and electrophysiologically. In the second section, several important issues have been emphasized: the putative differences between frontal and lateral vision, visual sensitivity to both discrete and periodic stimuli at various adaptation levels, polarotaxis in the pigeon, the bipartite spectral sensitivity of its retina, hue and saturation discrimination, sensitivity to ultraviolet light, panoramic acuity, and the detection of movement.
\end{abstract}

With the tremendous growth of animal learning research during the past 30 years, the pigeon has emerged as the most frequently studied representative of the avian class. Quite often, an awareness of the sensory abilities of an animal can enhance the quality of experimental design or facilitate the selection of appropriate stimuli. A considerable but scattered literature deals specifically with the visual system of Columba livia. Certain delimited samples of this literature have already been thoroughly discussed elsewhere: neuroanatomical organization by Webster (1974) and ablation-deficit research by Hodos (1976). The present monograph is a complementary, but much more extensive, review. Since it is intended as a reference guide for nonsensory as well as sensory laboratories, technical terms have been defined wherever appropriate. The author hopes that, in formulating a succinct organized account of the research on pigeon vision, readability has not been sacrificed. As is necessary in a review of such broad scope, certain articles have been deliberately omitted from discussion even though they may be relevant to some specialized aspects of pigeon vision. References for these undiscussed articles are included in a supplementary bibliography.

On more than one occasion the question has been posed: Why bother studying vision in the pigeon? If generalizability to man is a sine qua non for justifying scientific inquiry, then this question is indeed difficult to answer. However, if one's interests include sensory processes in a broader evolutionary context,

This report was prepared with the support of Grants 5T01 MH 11218 and 1T32 EY 07029, both from D.H.E.W. A list of permissions received for the reprinting of figures and tables is provided on page 437. The author's present address: Hunter Laboratory, Brown University, Providence, Rhode Island 02912. as modes of adaptation which are specific to each organism's survival needs, then it seems advantageous to select an animal for which the sensory system being considered is highly developed and for which the behavior and habitat are familiar. The pigeon, Columba livia, is an ideal choice according to these criteria and therefore it is not surprising that the pigeon has been investigated so intensively.

\section{STRUCTURE}

\section{Shape and Size}

\section{The Pigeon Eye}

The shape of the pigeon eye, as seen in Figure 1, has been described as two hemispheres of different radii of curvature joined at the ora serrata (Chard \& Gundlach, 1938). The ocular globes are tightly enclosed in their bony sockets and are closely adjacent along the midline, so much so that light entering one eye may also to some extent illuminate the opposite eye (Wolbarsht, Stopp, \& Godson, 1964). Ocular dimensions are provided in Tables $1 \mathrm{a}$ and $1 \mathrm{~b}$.

\section{Optical Properties}

The optical properties of the pigeon's eye have been described (Marshall, Mellerio, \& Palmer, 1973). Values reported for a "typical" eye are based on paraxial optics (less than $10^{\circ}$ off-axis) and 589-nm light. Refractive indices for the ocular media are furnished in Table 2, and cardinal points of the schematic eye in Figure 2. The estimated total refractive power is 126 diopters, as compared to about 65 diopters for the human eye. (A diopter is a measure of the ability to bend light, referring specifically to the reciprocal focal length in meters.) Elsewhere, total refractive power has been estimated at 105 diop- 


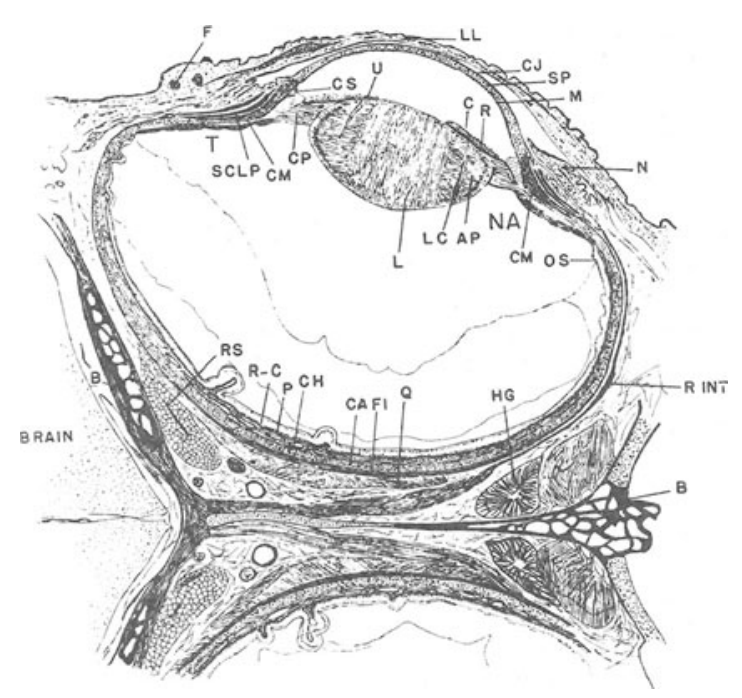

Figure 1. Camera sketch of the left eye of the pigeon at the region of the axis showing the relations of the various parts. F, feather follicle; LL, lower lid; CJ, conjunctiva; SP, substantia propria; M, membrane of Descement; CS, canal of Schlemm; $U$, uvea; $C$, circular fibers of the iris; $R$, radial fibers of the iris; $\mathrm{N}$, nictitating membrane; SCLP, scleral plates; CM, ciliary muscle; $C P$, ciliary processes; $L$, lens; $L C$, lenticular chamber; $A P$, annular pad; OS, ora serrata; RS, superior rectus muscle; R-C, rod and cone layer; $P$, pigment layer; $\mathrm{Ch}$, choroid; $\mathrm{CA}$, cartilage; FI, fibrous tissue; Q, quadratus muscle; HG, Harder's gland; R INT, internal rectus muscle; $B$, bone; $T$, temporal side of the eye; NA, nasal side of the eye. (From Chard \& Gundlach, 1938.)

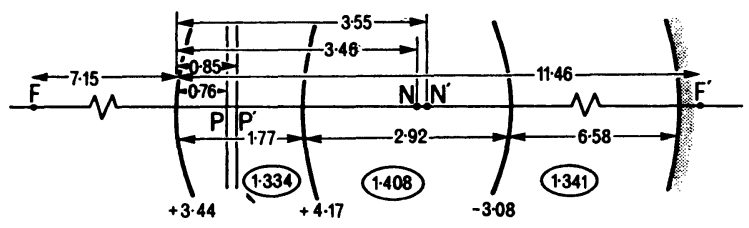

Figure 2. The schematic eye of the pigeon derived from measurements of nine eyes. The pole of the cornea is taken as the origin of the distances in millimeters of the cardinal points along the axis. $P$ and $P^{\prime}$ are the anterior and posterior principal planes, $N$ and $N^{\prime}$ the nodal points, and $f$ and $f^{\prime}$ the foci. The radii of curvature of the refracting surfaces are given in millimeters (in the cartesian sign convention) at the bottom of the diagram. The refractive indices of the ocular media are ringed. The total optical power of the schematic eye is 126 diopters. (From Marshall et al., 1973.)

ters, corneal curvature alone accounting for approximately 85 diopters (Nye, 1973). The effective $\mathrm{f}$ number (ratio of posterior nodal distance to pupillary diameter) for an eye adapted to intense light is 4 as compared to an $\mathrm{f}$ number of 8 for the human eye. Thus, given the same quantity of light impinging on the cornea, the retinal irradiance will be approximately four times greater for the pigeon.

\section{Ocular Media}

The transmittances of the pigeon's ocular media have been measured directly with a spectrophotometer (Govardovskiľ \& Zueva, 1977). As seen in Figure 3, the ocular media are quite transparent even at shorter wavelengths, as previously suggested (D. S. Blough, 1957; Graf \& Norren, 1974). At $350 \mathrm{~nm}$, transmittance is near $70 \%, 85 \%$, and $90 \%$ for the cornea, lens, and vitreous body, respectively. Thus, sensitivity to ultraviolet light (see below) is not precluded by the absorptive characteristics of the ocular media.

\section{The Pupil}

The pigeon's pupil is capable of about a ninefold change in area (Laurens, 1923). When fully dilated, the pupil is round and has a diameter of approximately $5.6 \mathrm{~mm}$. When fully constricted, this pupil shrinks to an elliptical aperture of about $1.7 \times$ $2.0 \mathrm{~mm}$, with the longer axis approximately parallel

Table 1a

Gross measurements of the eye of the pigeon

\begin{tabular}{|c|c|c|}
\hline & 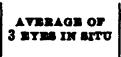 & 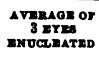 \\
\hline & $\mathbf{m m}$. & mm. \\
\hline Anterior chamber.......... & 1.6 & 1.4 \\
\hline Axial diameter of the lens. & 3.1 & 3.2 \\
\hline Equatorial diameter of the lens.. & 5.4 & 5.7 \\
\hline Posterior chamber. . ............. & 6.0 & 6.3 \\
\hline Axial diameter of the whole eye........ & 10.5 & 11.0 \\
\hline Equatorial diameter of the whole eye............... & 13.0 & 14.0 \\
\hline $\begin{array}{l}\text { Equatorial diameter at the junction of the cornea and } \\
\text { sclera } \ldots \ldots \ldots \ldots \ldots \ldots \ldots \ldots \ldots \ldots \ldots \ldots \ldots\end{array}$ & 6.4 & 6.4 \\
\hline Equatorial diameter at the ora serrats $\ldots \ldots \ldots \ldots \ldots$ & 11.9 & 12.7 \\
\hline Axial distance from the front of the lens to the retina. . & 9.0 & 9.6 \\
\hline
\end{tabular}

Note-From Chard and Gundlach, 1938.

Table $1 \mathrm{~b}$

\begin{tabular}{llll}
\hline \multicolumn{1}{c}{ Parameter } & $\begin{array}{c}\text { Mean } \\
(\mathrm{mm})\end{array}$ & $\begin{array}{c}\text { Standard } \\
\text { deviation } \\
( \pm)\end{array}$ & $\begin{array}{c}\text { Number } \\
\text { of birds }\end{array}$ \\
\hline Radius of cornea & 3.443 & 0.217 & 9 \\
Radius of lens anterior surface & 4.174 & 1.113 & 9 \\
Radius of lens posterior surface & 3.080 & $\mathbf{0 . 3 0 5}$ & 9 \\
Depth of anterior chamber & 1.771 & $\mathbf{0 . 1 5 9}$ & 9 \\
Thickness of lens & 2.924 & $\mathbf{0 . 1 6 9}$ & 9 \\
Distance from lens posterior surface to retina & $\mathbf{6 . 5 7 6}$ & $\mathbf{0 . 3 2 1}$ & 9 \\
Pupillary diameter at 2000 cd $\mathrm{m}^{-2}$. & $\mathbf{2 . 0}$ & $\mathbf{0 . 2}$ & 8 \\
\hline Refractive error by retinoscopy & $\mathbf{2 . 4 D}$ & $\mathbf{0 . 2 D}$ & 9 \\
\hline
\end{tabular}

Note-From Marshall et al., 1973.

Table 2

MEAN REFRACTIVE INDICES AND STANDARD DEVIATIONS OF THE OCULAR MEDIA. The absolute accuracy of the refractometer is about \pm 0.001 . The standard DEVIATIONS IN THIS TABLE ARE THEREFORE MAINLY DUE TO DIFFERENCES BETWEEN SPECIMENS

\begin{tabular}{lccc}
\hline \multicolumn{1}{c}{ Medium } & $\begin{array}{c}\text { Mean refractive index at } 25^{\circ} \mathrm{C} \text { for } \\
\text { light of wavelength } 589 \mathrm{~nm}\end{array}$ & $\begin{array}{c}\text { Standard } \\
\text { deviation } \\
( \pm)\end{array}$ & $\begin{array}{c}\text { Number of } \\
\text { specimens }\end{array}$ \\
\hline Aqueous humour & 1.334 & 0.002 & 4 \\
Vitreous humour & 1.341 & 0.004 & 3 \\
Lens cortex & 1.383 & $\mathbf{0 . 0 0 9}$ & 8 \\
Lens nucleus & 1.409 & 0.010 & 8 \\
Assumed bulk lens & 1.408 & - & - \\
\hline
\end{tabular}

Note-From Marshall et al., 1973. 


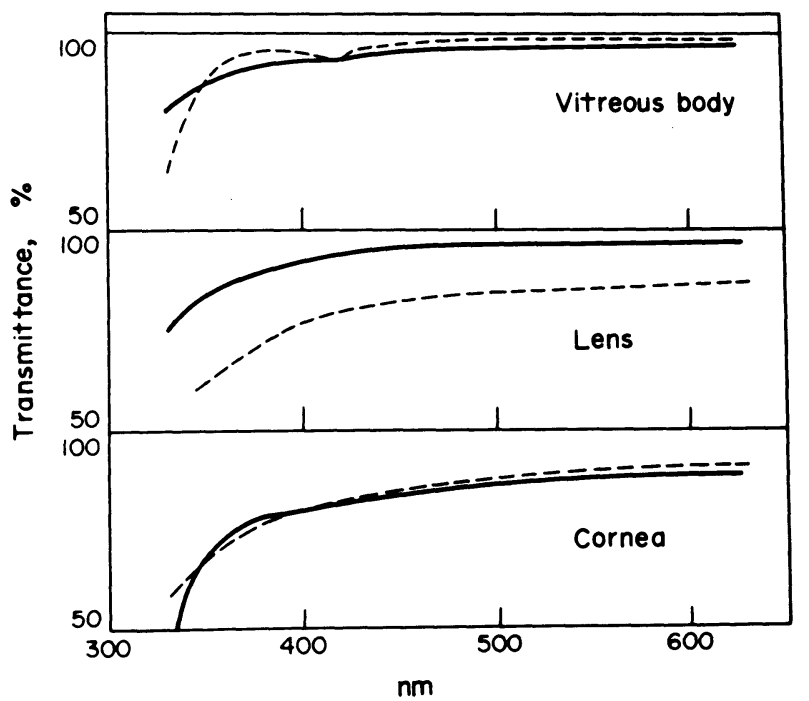

Figure 3. The spectral transmittance of the ocular media in chicken (dashed lines) and pigeon (solid lines). (From Govardovskii \& Zueva, 1977.)

to the beak. The iridial muscles (sphincter and dilatator pupillae) are striated, allowing for rapid constriction (Gundlach, 1934). Full dilation of the pigeon's pupil can be maintained for up to $2 \mathrm{~h}$ under strong illumination (Campbell \& Smith, 1962). The mydriatic agent consists of tubocurarine chloride freshly mixed in a benzalkonium chloride solution.

\section{The Pecten}

Lying directly over the optic papilla (exit point of optic nerve) is a pigmented vascularized organ, the pecten. This multifluted structure, which projects well into the vitreal chamber, presumably nourishes the retina via osmosis (Chard \& Gundlach, 1938). Although the choroid layer is both pigmented and vascularized, there are no superficial or intraretinal blood vessels in the pigeon (Chard \& Gundlach, 1938; Hughes, Jerrome, \& Krebs, 1972).

Barlow and Ostwald (1972) have mapped the primary scotoma (blind spot) associated with the pecten. The pecten projects onto an extensive $\left(10^{\circ} \times 60^{\circ}\right)$, elongated area in the visual field, closely adjacent to the foveal projection. (The calculation of the angle subtended by objects in the visual field is described in the appendix.) In addition, a secondary "shadow" (area of reduced illumination) is cast upon the fovea by the pecten for any light source in the upper (approximately $40^{\circ}$ ) lateral visual field. (This is somewhat surprising since the fovea lies above the pecten on the retina.) Thus, Barlow and Ostwald conclude that the pecten acts as a visor against the sun's glare.

\section{Thickness and Area}

\section{The Retina}

The retina of the pigeon is approximately $.4 \mathrm{~mm}$ thick, of which about $40 \%$ is due to the inner nuclear and inner plexiform layers (Chard \& Gundlach, 1938; Hughes et al., 1972). The total area of the retina has been estimated at $350 \mathrm{~mm}^{2}$ (Binggeli \& Paule, 1969).

\section{Retinal Layers: Cell Topographies}

The thickness of the retina varies with eccentricity, most of the variation attributable to the inner nuclear layer (Galifret, 1968). A quantitative plot of cell density (corrected for shrinkage) vs. vertical eccentricity for the inner nuclear layer (Müller, horizontal, bipolar, and amacrine cell nuclei), the outer nuclear layer (receptor nuclei), and ganglion cell layer is seen in Figure 4. According to Figure 4, there appear to be approximately twice as many receptors, i.e., cells in outer nuclear layer, as cells in the ganglion layer; the cell population of the inner nuclear layer appears approximately 3 to 5 times as dense as that for receptors. Also, there are two areas of high cell density for the inner nuclear layer: between $20^{\circ}$ and $60^{\circ}$ above the posterior pole, and between $5^{\circ}$ and $10^{\circ}$ below. These two regions correspond to the dorsotemporal quadrant (red field) and fovea, respectively.

\section{Fovea}

The fovea, an ovoid depression in the vitreal surface of the retina due to a diminution and/or a lateral displacement of the proximal layers, occupies about a $.5-\mathrm{mm}$ diameter area located slightly ventral and temporal to the optic axis (Chard \& Gundlach, 1938). Thus, the visual axis is inclined from $5^{\circ}$ to $10^{\circ}$ upward and from $7^{\circ}$ to $14^{\circ}$ nasalward with respect

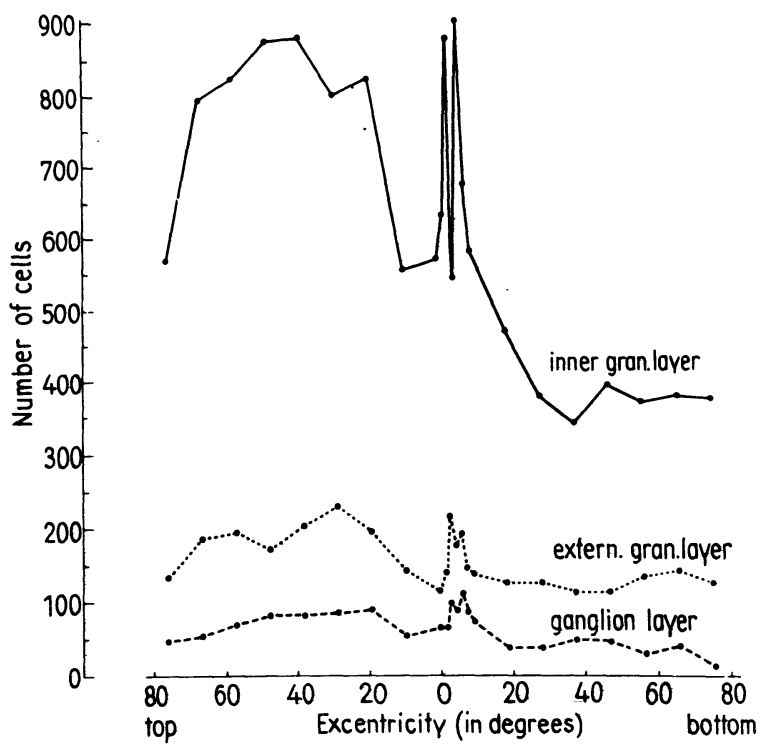

Figure 4. Distribution of cells in the pigeon retina for a nearly vertical section through the fovea. Cell counts (based on $50 \times 50-\mu$ sample areas) are corrected for shrinkage so as to apply to the in vivo retina. Inner and external granular layers correspond to inner and outer nuclear layers. (From Galifret, 1968.) 
to the optical axis, assuming $7^{\circ}$ of visual arc per millimeter on the retina (Galifret, 1968). Generally, the pigeon fovea appears relatively shallow as compared with some other avian species, e.g., the starling (Tansley, 1965) or the hawk (Walls, 1942).

\section{Types of Photoreceptors}

At least three morphologically distinct classes of photoreceptor can be differentiated: single cones, double cones, and rods. The rod is comprised of: an outer segment containing the pigmented lamellae (which are not continuous with the outer segment membrane except at its very base); an inner segment containing an ellipsoid (a cluster of mitochondria); a paraboloid (a sac of cytoplasm rich in endoplasmic reticulum) and a myoid region; a nucleus (subadjacent to the external limiting membrane); and a synaptic pedicle (extending into the outer plexiform layer) (Cohen, 1963; Hughes et al., 1972; Marshall, Mellerio, \& Palmer, 1972).

The single cone is comprised of: a tapered outer segment (here, the lamellae appear at least partially continuous with the outer segment membrane); an inner segment with an oil drop or a "granulecontaining body" at its apex; an ellipsoid; a paraboloid; a myoid region; a nucleus; and a synaptic pedicle (Cohen, 1963). The outer segment diameter is $1-1.5 \mu$ at its base, narrowing to approximately $.2 \mu$ at its apex; its length is 8-20 $\mu$. The inner segment is about $1.5 \mu$ in diameter (Cohen, 1963; Hughes et al., 1972; Marshall et al., 1972). The double cone is made up of a "chief" element which partially surrounds an "accessory" element. The former exhibits the structural characteristics of cones; the latter, however, lacks an oil drop (Bowmaker, 1977). Cohen (1963) has also reported multicolumnar cones whose outer segments contain as many as three separate stacks of lamellae, all partially contiguous with the outer segment membrane.

\section{Oil Drops}

The prominent "red field" in the dorsotemporal retina owes its appearance to a large proportion of oil drops which transmit only long wavelength light. Many of the oil drops in the "yellow field" transmit much or all of the visible spectrum. The oil drops contain carotenoid pigments and act as high-pass blocking filters, absorbing selectively at shorter wavelengths (Bloch \& Maturana, 1971; King-Smith, 1969; Strother, 1963).

Recently, the absorbance spectra of the oil drops have been measured directly by means of microspectrophotometry (Bowmaker, 1977). For the red field, five types of oil drops were found and each resembled a high-pass blocking filter. In single cones, the wavelength at which $50 \%$ of the incident light was transmitted $\left(\lambda_{\mathrm{T} 50}\right)$ was $610 \mathrm{~nm}$ for type "red," $570 \mathrm{~nm}$ for type " $C$," and $473 \mathrm{~nm}$ for type "A." A small fraction of single cones contained "clear" oil drops whose density was still less than .1 log units even at wavelengths as short as $425 \mathrm{~nm}$. In the chief element of the double cones, a type " $\mathrm{B}$ " oil drop was found, and its $\lambda_{\mathrm{T} 50}$ ranged from 522 to $554 \mathrm{~nm}$ depending on the retinal location. Sometimes a prominent "shoulder" in its absorption spectrum was observed near 485-490 nm (see also King-Smith, 1969). There were no oil drops in either the rods or the accessory elements of the double cones. Bowmaker also noted the red oil "microdroplets" in single cones containing the type "red" oil drop. Pedler and Boyle (1969) had previously measured these microdroplets, which range from .02 to $.2 \mu$ in diameter and which occur only in the red field.

For the yellow field, the same five classes of oil drops were observed. However, $\lambda_{\mathrm{T} 50}$ tended to be located at shorter wavelengths: 470,562 , and $600 \mathrm{~nm}$ for A, C, and red oil drops, respectively (see also King-Smith, 1969). Again, the clear oil drops were virtually transparent down to at least $425 \mathrm{~nm}$. In the chief element of the double cones, B-type oil drops were found and $\lambda_{\mathrm{T} 50}$ ranged from 470 to $498 \mathrm{~nm}$, depending on retinal location. Sometimes a "shoulder" appeared in the absorption spectra near $485 \mathrm{~nm}$.

Autofluorescence occurs in the yellow oil drop and, to a lesser extent, in the orange oil drop when they are illuminated with ultraviolet $(365 \mathrm{~nm})$ light (Marc, Note 1). The emission spectrum for the yellow drop peaks at about $625 \mathrm{~nm}$, emmissivity dwindling to $50 \%$ of $\max$ at about $525 \mathrm{~nm}$. The excitation spectrum for this autofluorescence is unknown. Another interesting finding was that the cone types are arranged in interlacing hexagonal arrays and that the oil drops are layered.

The relative distribution of different oil drop types has been shown to be nonuniform for the four retinal quadrants (Bloch \& Maturana, 1971). As seen in Table 3, the dorsotemporal quadrant appears to contain relatively more long-wavelength transmitting oil drops, especially "orange" drops, while the other quadrants contain more "yellow" drops.

Table 3

Percentage of Oil Droplets in the Different Retinal Quadrants of One Fresh Dark-Adapted Pigeon Retina

Oil Droplets

\begin{tabular}{|c|c|c|c|c|}
\hline \multirow[b]{2}{*}{ Retinal Quadrant } & \\
\hline & Red & Orange & Yellow & Greenish \\
\hline Posterior Dorsal & 20 & 47 & 19 & 14 \\
\hline Dorsal & 16 & 9 & 59 & 16 \\
\hline Posterior Ventral & 21 & 9 & 51 & 19 \\
\hline Anterior Ventral & 19 & 2 & 76 & 11 \\
\hline
\end{tabular}

Note-The data were obtained by counting about 500 droplets in different fields of each quadrant (from Bloch \& Maturana, 1971). 
The primary function of the oil drop has been a frequent topic of speculation. Among the various roles hypothesized are that the oil drops are filters influencing spectral sensitivity, that they act en masse as a contrast filter so that objects of a given hue are more readily detected against a given background hue, that the oil drops compensate for chromatic aberration (a characteristic of lenses such that different wavelengths are focused in different planes), and that they store surplus vitamin A as carotenoid pigment.

\section{Photoreceptor Topography}

The density of photoreceptors across the pigeon retina is quite uniform, varying between 100 and 225 cells per 2,500- $\mu^{2}$ area sampled (Galifret, 1968). The relative proportion of different receptor types varies with eccentricity. The dorsal retina is dominated by cones (Schultze, 1866), whereas the retina is rod-free at the fovea (P. M. Blough, 1971). Marshall et al. (1972) report a cone-predominant red field and a rodpredominant ventral retina.

\section{Inner Plexiform Layer}

The disproportionate cell density of the inner nuclear layer suggests the possibility of complex levels of sensory processing in the pigeon retina. Further support has been furnished by Dubin (1970) in his report that the inner plexiform layer contains about 10.8 amacrine synapses for every bipolar synapse and approximately $11.2 \%$ of the former occur in serial configuration (comparable figures reported for the human parafovea are 1.3:1 and 1.9\%, respectively). Unfortunately, Dubin does not locate the area of retina sampled. Yazulla (1974) has systematically sampled the inner plexiform layer, and his counts of amacrine (conventional) vs. bipolar (ribbon) synapses for different retinal areas are shown in Table 4. The amacrine:bipolar synapse ratio, a presumed index of organizational complexity, varies between $4: 1$ and 6.8:1. The percentage of amacrine synapses in serial configuration appears in Table 5. Yazulla reports that the retina is not homogeneous regarding structural complexity, and suggests that the differences reported, e.g., between the red vs. yellow field, may be reflected in the receptive field characteristics of ganglion cells at different retinal locations.

\section{Centrifugal Fibers}

The centrifugal fibers originate in the isthmo-optic nucleus (see Figure 7), which has been estimated to contain almost 10,000 cells, most of which project to the contralateral retina and terminate along the proximal border of the inner nuclear layer (Cowan \& Powell, 1963). These centrifugal fibers appear uniformly distributed across the retina and end in one of two configurations (Maturana \& Frenk, 1965).
Table 4

Counts of Amacrine and Bipolar Synapses and Their Respective Ratios Within the Inner Plexiform Layer at Ten Different Loci

\begin{tabular}{llccc}
\hline & & $\begin{array}{c}\text { Amacrine } \\
\text { (Conventional) } \\
\text { Synapses }\end{array}$ & $\begin{array}{c}\text { Bipolar } \\
\text { (Ribbon) } \\
\text { Synapses }\end{array}$ & $\begin{array}{c}\text { Corrected } \\
\text { Ratio } \\
\text { Amacrine: } \\
\text { Bipolar }\end{array}$ \\
\hline Red & NRF & 506 & 65 & $6.8: 1$ \\
Field & TRF & 508 & 70 & $6.8: 1$ \\
Temporal & PTF & 354 & 86 & $4.0: 1$ \\
Yellow & TYF & 407 & 73 & $4.6: 1$ \\
Field & TPn & 450 & 62 & $6.1: 1$ \\
Nasal & PNF & 422 & 76 & $4.7: 1$ \\
Yellow & NYF & 344 & 74 & $4.1: 1$ \\
Field & NPn & 368 & 71 & $4.3: 1$ \\
Area & Pf & 424 & 82 & $4.5: 1$ \\
Centralis & F & 353 & 69 & $4.1: 1$ \\
\hline
\end{tabular}

Note-Taken from Yazulla (1974). NRF=nasal red field; TRF = temporal red field; $P T F=$ peripheral temporal (yellow) field; TYF = temporal yellow field; TPn = temporal to pecten; $P N F=$ peripheral nasal yellow field; $N Y F=$ nasal yellow field; $N P n=$ nasal to pecten; $P f=$ perifovea $F=$ fovea.

Either the terminal branches converge onto one or a few target neurons as a synaptic nest or they diverge in a fanlike ramification onto groups of cells. Maturana and Frenk (1965) conclude that there are at least 100,000 centrifugal fiber terminals per retina which terminate onto displaced ganglion cells, flat amacrine cells, and small unistratified amacrine cells. Dowling and Cowan (1966) suggest that most of these terminals synapse on the basal portion of amacrine cells at the origin of their main processes.

\section{Ganglion Cell Layer}

The density and diameters of fibers in the optic nerve have been examined with both light and electron microscopy (Binggeli \& Paule, 1969). The majority of these axons were narrower than $1 \mu$ and unmyelinated axons were typically less than $.5 \mu$ wide. The estimated total number of axons per optic nerve was approximately 2.38 million (74\% myelinated) based on counts within 165 areas of $100 \mu^{2}$ extent.

An isodensity map of cells in the ganglion layer is seen in Figure 5. Note that peak density in the fovea is 31,500 cells $/ \mathrm{mm}^{2}$ or about 643 cells/square degree of visual angle. An additional region of high density occurs in the dorsotemporal quadrant. A comparison of the fovea to the far periphery reveals a fivefold decrease in cell density in the ganglion layer. The total number of cells in the ganglion layer per retina has been estimated as 4.8 million, almost half of these assumed to be either "displaced amacrines" or "intraretinal association cells." An additional 4,300 (approximate estimate) "displaced" ganglion cells are located along the proximal border of the inner 
Table 5

Synaptic Diameters, Synaptic Densities, and Percentage of Amacrine Synapses in Serial Configuration

\begin{tabular}{|c|c|c|c|c|c|c|}
\hline & & \multicolumn{2}{|c|}{$\begin{array}{l}\text { Corrected Synaptic } \\
\text { Diameter in } \\
\text { Angstroms }\end{array}$} & \multicolumn{2}{|c|}{$\begin{array}{c}\text { Density } \\
\text { Synapses/ } \\
\text { Microns }^{3}\end{array}$} & \multirow{2}{*}{$\begin{array}{l}\text { \% Amacrine } \\
\text { Synapses in } \\
\text { Serial } \\
\text { Configuration }\end{array}$} \\
\hline & & Amacrine & Bipolar & Amacrine & Bipolar & \\
\hline $\begin{array}{l}\text { Red } \\
\text { Field }\end{array}$ & $\begin{array}{l}\text { NRF } \\
\text { TRF }\end{array}$ & $\begin{array}{l}2031 \\
2012\end{array}$ & $\begin{array}{l}1596 \\
1790\end{array}$ & $\begin{array}{l}1.02 \\
1.01\end{array}$ & $\begin{array}{l}0.15 \\
0.15\end{array}$ & $\begin{array}{r}5.1 \\
10.2\end{array}$ \\
\hline $\begin{array}{l}\text { Temporal } \\
\text { Yellow } \\
\text { Field }\end{array}$ & $\begin{array}{l}\text { PTF } \\
\text { TYF } \\
\text { TPn }\end{array}$ & $\begin{array}{l}1810 \\
2192 \\
2192\end{array}$ & $\begin{array}{l}1726 \\
1517 \\
1682\end{array}$ & $\begin{array}{l}0.84 \\
0.83 \\
0.85\end{array}$ & $\begin{array}{l}0.21 \\
0.18 \\
0.14\end{array}$ & $\begin{array}{l}5.1 \\
8.4 \\
8.4\end{array}$ \\
\hline $\begin{array}{l}\text { Nasal } \\
\text { Yellow } \\
\text { Field }\end{array}$ & $\begin{array}{l}\text { PNF } \\
\text { NYF } \\
\text { NPn }\end{array}$ & $\begin{array}{l}2300 \\
2157 \\
2254\end{array}$ & $\begin{array}{l}1720 \\
1552 \\
1684\end{array}$ & $\begin{array}{l}0.85 \\
0.73 \\
0.70\end{array}$ & $\begin{array}{l}0.18 \\
0.18 \\
0.16\end{array}$ & $\begin{array}{r}9.0 \\
9.9 \\
10.3\end{array}$ \\
\hline $\begin{array}{l}\text { Area } \\
\text { Centralis }\end{array}$ & $\begin{array}{l}\mathrm{Pf} \\
\mathrm{F}\end{array}$ & $\begin{array}{l}2044 \\
2270\end{array}$ & $\begin{array}{l}1487 \\
1600\end{array}$ & $\begin{array}{l}0.76 \\
0.70\end{array}$ & $\begin{array}{l}0.17 \\
0.17\end{array}$ & $\begin{array}{l}9.4 \\
9.3\end{array}$ \\
\hline
\end{tabular}

Note-Taken from Yazulla (1974). NRF = nasal red field; TRF = temporal red field; PTF = peripheral temporal (yellow) field; $T Y F=$ temporal yellow field; $T P n=$ temporal to pecten; $P N F=$ peripheral nasal yellow field; $N Y F=$ nasal yellow field; $N P n=$ nasal to pecten; $P f=$ perifovea; $F=$ fovea.

nuclear layer (Karten, Fite, \& Brecha, 1977). These large cells $(18-30 \mu$ in diameter) are widely spaced over much of the retina but seem particularly scarce near the fovea and near the center of the red field.

\section{Ganglion Cell Response Characteristics}

Since any visual information processed in the retina is ultimately encoded by the ganglion cells, a description of their response properties is essential.

Six categories of ganglion cells have been described based on single-unit microelectrode recordings in the optic nerve (Maturana, 1964; Maturana \& Frenk, 1963):

(1) General edge detectors respond transiently to the onset and offset of a stationary stimulus but yield a strong, sustained discharge to an edge or spot moving within the receptive field (that area of the visual field within which photic stimulation produces a change in the firing rate of the cell). Receptive field diameters range from $3^{\circ}$ down to less than $.5^{\circ}$.

(2) Directional movement detectors prefer a contrast edge of a particular orientation moving in a specific direction, the opposite or null direction of movement producing little or no response. These units have small $\left(.5^{\circ}-1.0^{\circ}\right)$ receptive field diameters.

(3) Convex edge detectors, which have receptive field diameters of only a few minutes of arc, discharge preferentially to convex edges moving through their receptive fields.

(4) Horizontal edge detectors are units for which the optimal stimulus is a horizontal edge moved up or down through the receptive field and extending across the entire receptive field.

(5) Verticality detectors respond to both moving and stationary vertical edges.

(6) Luminosity detectors exhibit discharge rates proportional to the intensity of illumination, and some are selectively sensitive to wavelength.
Holden (1969) has examined the response properties of 27 ganglion cells. All these units had a circular or somewhat elliptical receptive field. Two-thirds of these units responded transiently to the onset and offset of illumination anywhere in their receptive fields, whereas the remaining nine units had an "on-off" center but an "off" surround, i.e., the offset of illumination on the receptive field surround yielded a brief increase in discharge rate. Twentythree units preferred a moving stimulus, 15 of which

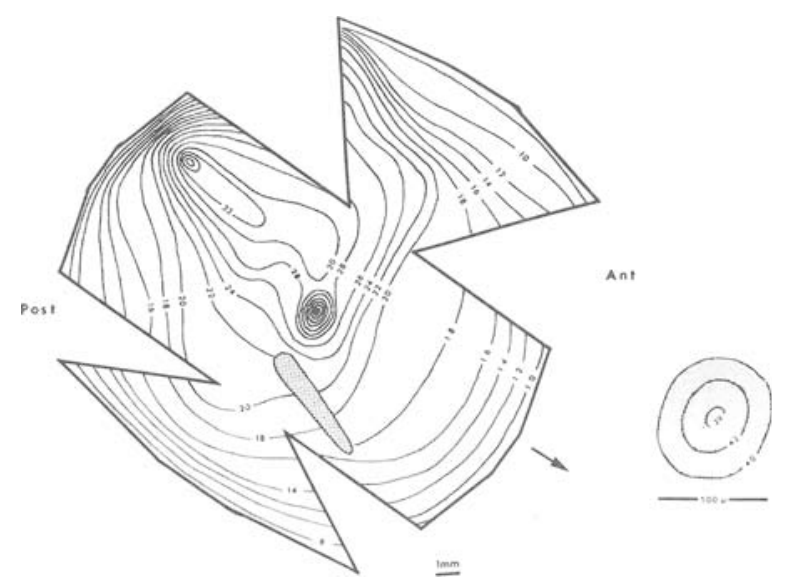

Figure 5. Schematic of a flat mount of the right retina with isodensity lines produced by drawing smooth curves between plotted measured values of cells in the ganglion cell layer. The above values should be multiplied by $10^{3}$ to yield cells $/ \mathrm{mm}^{2}$ in fixed retina. In vivo values can be found by reducing this product by $25 \%$. Multiplying the illustrated values by 15 approximately yields the number of cells per square degree of visual angle in vivo. The arrow indicates the direction of the beak tip (approximately $20^{\circ}$ from the angle of the pecten, the elongated stippled area). An enlarged schema of the fovea centralis shows details of the densities there. Post, posterior or temporal; Ant., anterior or nasal. (From Binggeli \& Paule, 1969.) 
were directionally selective, usually responding maximally to upward or anteriorward movement.

Based on single-unit records from a much larger sample of ganglion cells $(N=359)$, four major types of receptive fields have been delineated (Pearlman \& Hughes, 1976a). Twenty-five percent of these units had an on-off center plus an inhibitory surround. The strength of the surround antagonism was quite variable, as were the relative amplitudes of the on vs. off response. Eleven percent of the ganglion cells had a "pure" on or off center plus an inhibitory surround. Fifteen percent of the units were motionsensitive but did not prefer any particular orientation of a moving edge. Thirty-eight percent of the ganglion cells were directionally selective. For one-third of this group, directional tuning was narrower for larger stimuli. A disproportionately large fraction of the directionally selective units had, as their "null" direction (no response elicited), movement from the anterior to the posterior visual field. Only one directionally selective unit did not respond to movement in the opposite direction.

Extracellular recording has been used to construct averaged discharge frequency histograms in response to various combinations of spot and annular stimulation (Holden, 1977). Most of the units sampled were within $2 \mathrm{~mm}$ of the fovea and were close to the horizontal meridian. Based on responding to flashed spots, 13 on-center, 6 off-center, and 32 on-off-center units were observed. These receptive field centers subtended $.5^{\circ}-2.5^{\circ}$ of visual angle.

Evidence was adduced by Holden for the existence of concentric, antagonistic surrounds. A unit which responded vigorously to a small flashing spot centered on its receptive field often exhibited little or no response to a much enlarged version of the flashed spot. The subsequent addition of a steady spot on the center sometimes led to a response to the large flashing spot, but the longer latency of this response (relative to flash onset and/or offset) indicated that the response probably originated from the surround mechanism. Similarly, in 58 of 61 cells, the response to a flashed annulus was greater in the presence of a steady central spot. A discharge occurred at annulus offset for on-center cells and at annulus onset for off-center cells. Thus on-centers are associated with off-surrounds, off-centers with on-surrounds.

Because the spontaneous discharge rate of pigeon ganglion cells was low, annular stimuli alone were often ineffective for demonstrating surround antagonism, i.e., in the absence of ongoing impulse activity, inhibition by the surround would go unnoticed. Holden created a "driven (nonspontaneous) baseline" by flashing a central spot at a different rate than, i.e., unsynchronized with, a flashing annulus and the sweep rate of the response averager. This trick generally revealed or enhanced the response associated with the surround which appeared as a modulation of the driven baseline such that intervals of surround antagonism showed up as deletions in the baseline whereas periods of surround discharge showed up as discharge peaks in the baseline. On-off cells usually exhibited discharge peaks both at onset and offset of the flashed annuli, whereas on-center cells exhibited discharge peaks at offset only. The outer diameters of the surrounds were generally in excess of $12^{\circ}$ of visual angle. Holden concludes that some pigeon ganglion cells do, indeed, possess a concentric, antagonistic center-surround organization which can coexist with other specialized response characteristics, e.g., directional selectivity.

\section{ERG}

Both the diffuse and localized electroretinographic response of the central retina have been examined (Ogden \& Wylie, 1971). An a-wave (for a thorough discussion of the various components of the ERG, see Brown, 1968) of maximum amplitude has been recorded in the receptor layer where the outer segments enmesh with the pigment epithelium. The b-wave is maximal in the distal half of the inner nuclear layer. Recorded amplitudes of a-waves were more sensitive than those of $b$-waves to the position of the stimulating spot, reflecting the larger summation area inherent in the b-wave. The off-response of the local ERG was identified with the decay of the isolated P III. Electroretinal responses as indices of specific visual functions are discussed below.

\section{Photomechanical Adaptation}

Two types of "photomechanical" changes which occur in the distal retina of many diurnal birds are pigment migration and myoid activity (Walls, 1942). The ciliary processes of the pigment epithelium interdigitate with the photoreceptors, and the pigment within these processes migrates toward the receptors when the retina is illuminated. In addition, light adaptation induces a shortening of the myoid segment of the cone and an extension of the myoid segment in the rod. Two likely consequences of these events are a more complete transition from scotopic to photopic vision and enhanced directional sensitivity of the receptors in that the outer segments are protected from stray light.

Pigment migration has been noted throughout the pigeon's retina, but especially in regions of high rod density (Stort, 1887; cited by Detwiler, 1943). Myoid activity by the cones consisted of contraction in the light and elongation in the dark. Relative changes in length for cones in the yellow, red, and foveal field were in the proportions of 23,32 , and 40 , respectively. Absolute differences in length were not reported.

Cohen (1963) has recently suggested that light adaptation causes outer segments to "attach" to the 
pigment epithelium. Ogden and Wylie (1971) have remarked that the "state of adaptation affects apparent height of the pigment epithelium." A systematic and quantitative description of these photomechanical changes is still lacking, however.

\section{Light Damage}

Although the visual system of a pigeon operates almost exclusively under photopic conditions, prolonged exposure to even moderate intensities can cause severe damage to the cones. Marshall et al. (1972) furnished uniform, diffused illumination through the walls of a pigeon cage. A 6-h exposure to $3,000 \mathrm{~cd} / \mathrm{m}^{2}$ (comparable to a "bright, hazy sky") or a 48 -h exposure to $600 \mathrm{~cd} / \mathrm{m}^{2}$ yielded profound injury to the cones but no damage to the rods. While this degree of vulnerability is surprising, the authors point out that the pigeon doesn't ordinarily view the sky directly and continuously. The absence of rod damage may be due in part to the protection afforded by pigment migration and myoid activity. In view of these results, obvious precautions should be taken by those conducting visual research with pigeons.

\section{Visual Pathways}

The visual neuroanatomy of the pigeon has been studied in considerable detail by the application of ablation-degeneration techniques, single-unit electrophysiology, and, more recently, retrograde transport methods and autoradiography. After a brief sum-

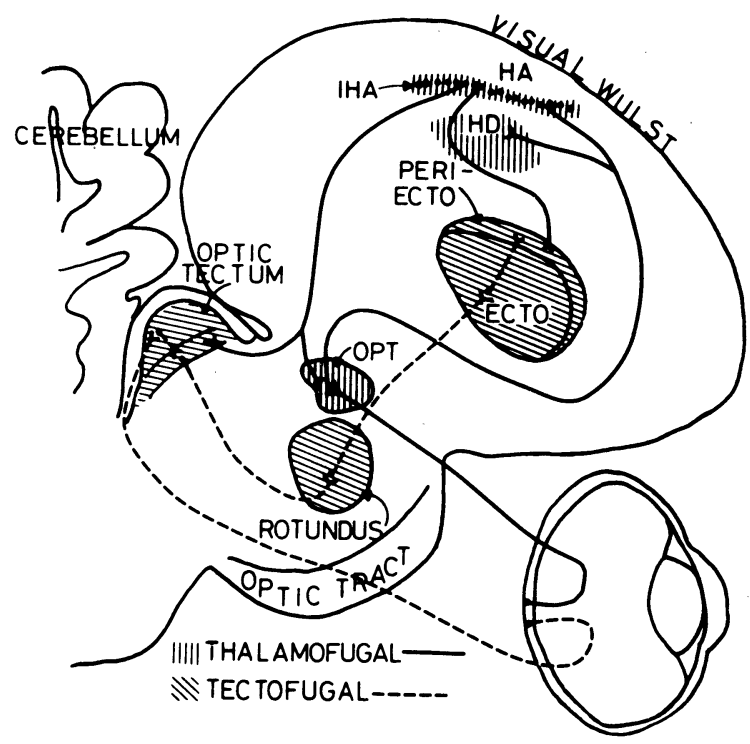

Figure 6. Diagrammatic representation of the tectofugal and thalamofugal visual pathways. Fiber pathways are indicated by continous and broken lines. Cell groups are indicated by crosshatching. ECTO, ectostriatum; HA, hyperstriatum accessorium; HD, hyperstriatum dorsale; IHA, nucleus intercalatus hyperstriati accessorii; OPT, nucleus opticus principalis thalami; PERI-ECTO, periectostriatal belt. (From Hodos, 1976.)

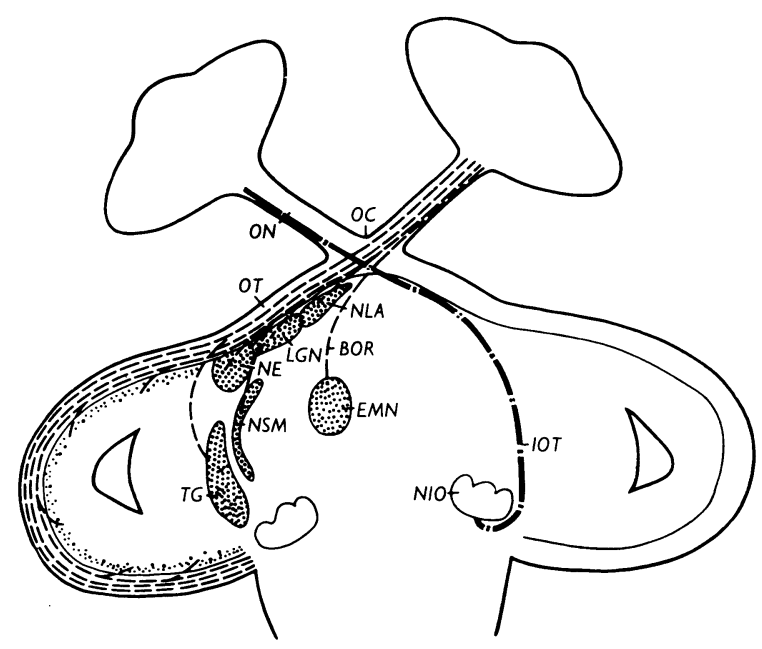

Figure 7. A schematic diagram to show the main features of the retinal projection. The broken lines indicate pathways in which fiber degeneration has been traced (following unilateral eye removal) and the dotted areas nuclei in which terminal degeneration was found. The isthmo-optic nucleus (NIO) and tract (IOT), shown separately on the right, comprise a centrifugal pathway projecting to the retina. OC, optic chiasm; ON, optic nerve; OT, optic tract; NLA, nucleus lateralis anterior; LGN, nucleus geniculatus lateralis; BOR, basal optic root; NE, nucleus externus; NSM, nucleus superficialis synencephali; EMN, ectomamillary nucleus; TG, tectal gray. The unlabeled lateral lobe is the optic tectum. (From Cowan et al., 1961.)

mary of the sites to which the optic nerve fibers project, the visual system will be discussed in terms of three major subdivisions: the tectofugal, thalamofugal, and centrifugal pathways. The response properties at various locations along each will be described. Lastly, the deficits resulting from damage to these pathways will be examined. A diagram of the tectofugal and thalamofugal pathways is presented in Figure 6 and will serve as a reference throughout this section.

\section{Retinal Projections}

The destinations of the optic nerve fibers have been investigated (Cowan, Adamson, \& Powell, 1961) and are diagramed in part in Figure 7. After complete decussation at the optic chiasm, most ascending axons enter the contralateral optic tract. Others exit dorsomedially from the optic chiasm to form the basal optic root. Fibers in the optic tract project primarily to the optic tectum but also to nucleus externus, nucleus superficialis synencephali, and tectal gray. In addition, Repérant (1972) found retinal efferents terminating in nuclei ventrolateralis thalami; decussationis supraopticae ventralis, pars anterior; dorsolateralis anterior, pars lateralis; area pretectalis diffusus; and pretectalis lateralis. Also, a few uncrossed optic nerve fibers were reported as projecting to several ipsilateral thalamic nuclei. Meier, Mihailovic̀, and Cuénod (1974) have demon- 
strated additional projections to nucleus opticus principalis thalami (see below), nucleus geniculatus lateralis, and nucleus lentiformis mesencephali.

Another pathway, originating from the displaced ganglion cells, projects, via the basal optic root, to the ectomamillary nucleus (Karten et al., 1977). Since this pathway will not be discussed further below, it will be noted here that the latter nucleus, in turn, projects to the vestibulocerebellum via the brachium conjunctivum cerebellopetalle, thus completing a bisynaptic pathway from retina to cerebellum. This pathway has been implicated in the control of oculomotor reflexes (Brauth \& Karten, 1977).

\section{Tectofugal Pathway}

Optic tectum. The optic tectum, which receives the plurality of retinal efferents, consists of six main layers (Huber \& Crosby, 1933): stratum opticum (SO), stratum griseum et fibrosum superficiale (SGFS), stratum griseum centrale (SGC), and stratum fibrosum periventriculare (SFP). The SO is comprised of the incoming retinotectal axons which terminate within SGFS (Cowan et al., 1961), primarily in sublayers a through $\mathrm{f}$ (SGFS has 10 cytoarchitectonically distinct sublayers), especially sublayer d (Hayes \& Webster, 1975; Hunt \& Webster, 1975; Stone \& Freeman, 1971).

The retinotectal projection is topographically organized. Electrophysiological mapping has indicated that the superior half of the contralateral visual field is represented on the dorsal surface of the tectum and that the horizontal meridian corresponds to the lateral "edge" separating the dorsal and ventral surfaces of the optic tectum (Bilge, 1971; Hamdi \& Whitteridge, 1954). Moreover, McGill, Powell, and Cowan (1966b) have utilized ablation-degeneration methods to show that superior retina projects to ventral optic tectum (OT), inferior retina to dorsal OT, nasal retina to posterior OT, and temporal retina to anterior OT.

More recently, a detailed retinotopic map of the entire tectal surface has been procured electrophysiologically (Clarke \& Whitteridge, 1976). As previously suggested (Bilge, 1971; Whitteridge, 1961), both the fovea and the red field seem to be disproportionately represented. Specifically, the areal magnification in tectum (surface area vs. area of visual field) is related to the square of the cell density in the ganglion cell layer of the retina. A deliberate search for units representing the red field area of both eyes was unsuccessful.

Tectal response properties. The nature of the information transmitted by the retinotectal pathway has been examined. Duff and Cohen (1975) recorded from 313 single units in SO (presumably ganglion cells) during photic or electrical stimulation of the eye. Estimated conduction velocities were 1.9$12.8 \mathrm{~m} / \mathrm{sec}$. Almost all units transiently increased their discharge rate at the onset of an intense, diffuse light; on-response latency was inversely proportional to stimulus intensity. About half these units also exhibited an off-response especially at high intensities with long (e.g., 4-sec) stimuli. Amplitudes of both on- and off-discharges were positively related to stimulus intensity. Addition of a constant background illumination caused a reduction in these responses. Also recording from superficial optic tectum, Wylie (1962) found two general types of units: center-surround units which were sensitive to stationary flashed spots but usually not to diffuse stimulation, and movement-sensitive units which responded preferentially to moving stimuli and, for some units, to only a given direction of movement, being insensitive to the null $\left(180^{\circ}\right.$ opposite) direction. Even moving stimuli, if they extended far enough into the receptive field surround, were sometimes ineffective.

A growing body of electrophysiological research has dealt with the response characteristics of neurons located within the various laminae of optic tectum. Table 6 attempts to summarize the most salient features reported.

Table 6

\begin{tabular}{llll}
\hline \multicolumn{1}{c}{ Study } & Receptive Field Diameter & \multicolumn{1}{c}{ Characteristics } & Locatio \\
\hline $\begin{array}{l}\text { Hamdi \& Whitteridge, } 1954 \\
\text { Jassik-Gerschenfeld et al., } \\
1970\end{array}$ & $\begin{array}{l}\text { Approximately } 5^{\circ} \\
\text { Average center size was } 4^{\circ} \\
\text { (range } 2-11^{\circ} \text { ) }\end{array}$ & $\begin{array}{l}\text { Latency of 25 msec } \\
91 \% \text { movement-sensitive of } \\
\text { which 35\% were directionally } \\
\text { selective }\end{array}$ & $\begin{array}{l}\text { SGFS of dorsal } \\
\text { SO and SGFS }\end{array}$ \\
Revzin, 1970 & $\begin{array}{l}\text { Less than } 4^{\circ} \\
64 \% \text { larger than } 40^{\circ} \text { in one } \\
\text { dimension }\end{array}$ & $\begin{array}{l}\text { Not reported } \\
75 \% \text { were "wide-field" } \\
\text { movement detectors }\end{array}$ & SO and SGFS \\
& $2-3^{\circ}$ & $\begin{array}{l}\text { Units deeper in this stratum } \\
\text { habituate faster to repetitive } \\
\text { stimuli }\end{array}$ & SGFS
\end{tabular}




\begin{tabular}{|c|c|c|c|}
\hline & $\begin{array}{l}\text { "Larger" rectangular field's } \\
\text { average size }=20^{\circ} \times 70^{\circ} \text { oriented } \\
\text { either vertically or horizontally }\end{array}$ & $\begin{array}{l}\text { Movement detectors, direc- } \\
\text { tionally sensitive units, com- } \\
\text { plex movement detectors; } 70 \% \\
\text { extend as far as the horizontal } \\
\text { meridian from above or below }\end{array}$ & SGC \\
\hline \multirow[t]{4}{*}{ Gusel'Nikov et al., 1971} & $.5-30^{\circ}$ for receptive field centers & Center-surround organization & SO and SGFS in lateral OT \\
\hline & $6-14^{\circ}$ centers & $\begin{array}{l}\text { Little or no surround antag- } \\
\text { onism }\end{array}$ & In other areas of OT \\
\hline & $8-60^{\circ}$ for entire fields & $\begin{array}{l}\text { Weaker surrounds, direction } \\
\text { and velocity of movement } \\
\text { important }\end{array}$ & SAC and SGC \\
\hline & & $\begin{array}{l}\text { Units deeper in OT habituate } \\
\text { faster to repetitive stimuli }\end{array}$ & \\
\hline \multirow[t]{4}{*}{ Holden, 1971} & $1-2^{\circ}$ & $\begin{array}{l}\text { "On" latency of } 50 \mathrm{msec} \\
\text { directionally selective units } \\
\text { found throughout the optic } \\
\text { tectum }\end{array}$ & SO of lateral tectum \\
\hline & $24^{\circ}$ & $\begin{array}{l}\text { Directionally selective units } \\
\text { found throughout the optic } \\
\text { tectum }\end{array}$ & Down to 600 microns \\
\hline & $10-20^{\circ}$ & $\begin{array}{l}\text { Directionally selective units } \\
\text { found throughout the optic } \\
\text { tectum }\end{array}$ & Between $600-1,200$ microns \\
\hline & $\begin{array}{l}\text { As long as } 150^{\circ} ; \text { vertically } \\
\text { oriented rectangular strips }\end{array}$ & $\begin{array}{l}\text { Directionally selective units } \\
\text { found throughout the optic } \\
\text { tectum }\end{array}$ & 1,500 microns down \\
\hline \multirow[t]{2}{*}{$\begin{array}{l}\text { Jassik-Gerschenfeld, et al., } \\
1972\end{array}$} & $1-55^{\circ}$ & $\begin{array}{l}6 \% \text { had center-surround } \\
\text { organization; } 72 \% \text { were move- } \\
\text { ment-sensitive, the majority } \\
\text { exhibiting an inhibitory } \\
\text { surround; orientation and } \\
\text { contrast had little effect; } \\
\text { deeper units fatigue more } \\
\text { quickly; } 21 \% \text { directionally } \\
\text { selective }\end{array}$ & $\begin{array}{l}77 \% \text { between } 500-1,400 \\
\text { microns; remainder above } \\
500 \text { microns (SO and part of } \\
\text { SGFS) }\end{array}$ \\
\hline & "Larger" & $\begin{array}{l}\text { Only movement-sensitive } \\
\text { units }\end{array}$ & Below 1,000 microns \\
\hline \multirow[t]{3}{*}{ Hughes \& Pearlman, 1974} & $\begin{array}{l}\text { Ranged from less than } 2^{\circ} \text { up to } \\
30^{\circ}\end{array}$ & $\begin{array}{l}\text { Circular or oval receptive } \\
\text { fields; many responsive to } \\
\text { stationary stimuli, some only } \\
\text { to movement }\end{array}$ & SO and SGFS (sublayers $a-h$ ) \\
\hline & From $7.5^{\circ}$ to greater than $45^{\circ}$ & $\begin{array}{l}\text { Again, mostly rounded fields } \\
\text { but also some irregularly } \\
\text { shaped; most units are move- } \\
\text { ment sensitive }\end{array}$ & SGFS (sublayers $\mathrm{i}-\mathrm{j}$ ) \\
\hline & From $4^{\circ}$ to greater than $45^{\circ}$ & Same as in previous category & SGC, SAC, SGP, and SAP \\
\hline \multirow[t]{5}{*}{$\begin{array}{l}\text { Jassik-Gerschenfeld, et al., } \\
1975\end{array}$} & $\begin{array}{l}\text { Receptive field size tended to } \\
\text { increase with depth in the tectum }\end{array}$ & $\begin{array}{l}36 \text { directionally selective } \\
\text { units, } 108 \text { movement-sensitive } \\
\text { units }\end{array}$ & SGFS \\
\hline & & 44 movement-sensitive units & SGC \\
\hline & & 20 movement-sensitive units & SAC \\
\hline & & 10 movement-sensitive units & SGP \\
\hline & & 9 movement-sensitive units & SAP \\
\hline
\end{tabular}

Several further observations can be made based on single-unit records from tectal neurons. In an electrode penetration perpendicular to the surface of optic tectum, receptive fields project to approximately the same location in the visual field; successively deeper neurons exhibit longer latencies and more rapid fatigue when stimulated repeatedly (Hamdi \& Whitteridge, 1954) as well as larger receptive fields (Jassik-Gerschenfeld, Guichard, \& Tessier, 1975). In general, the velocity range to which motion-sensitive units respond is between $5^{\circ}$ and $300^{\circ} / \mathrm{sec}$ (Frost \& Di Franco, 1976). Woods and Frost (1977) found 
that the size of the "bandwidth" of directions to which units will respond varies substantially. A maximal response is often elicited by stimuli moving from the posterior to the anterior visual field. The rate of adaptation to or recovery from repetitive stimulation differs among these motion-sensitive units. Some exhibit differential adaptation to various directions of movement. Some abruptly increase in responsiveness when the direction of motion is altered (dishabituation). Thus, the determination of the directional selectivity profile of a particular unit can be contaminated by residual adaptation from prior stimulation.

Tectal efferents and rotundal afferents. Among the many projections of the optic tectum (Hunt \& Künzle, 1976), a major thalamic target is the nucleus rotundus (NR), which appears to receive most of its input from the ipsilateral optic tectum (Karten \& Revzin, 1966). (Hunt and Künzle, 1976, also report an interhemispheric tectorotundal pathway.) This tectal projection originates primarily in SGC (Revzin, 1970; Revzin \& Karten, 1966/1967) and is highly organized in that cells from different strata in SGC innvervate separate subdivisions of NR (Benowitz \& Karten, 1976). The latter authors also describe a "massive" projection from SGC to contralateral nucleus geniculatus lateralis. Other sources of input to NR are nucleus subpretectalis; nucleus interstitiopretectalis-subpretectalis; and nucleus reticularis superior thalami, pars dorsalis. Different regions in NR appear to be innervated by each of these nuclei.

Several interhemispheric tectotectal projections have been proposed. The major intertectal pathway involves the ventral supraoptic decussation (Voneida \& Mello, 1975). Target neurons appear confined to the deeper layers of the optic tectum. The tectal and/or posterior commissures also constitute an intertectal pathway (Robert \& Cuénod, 1969a, 1969b).

Nucleus rotundus. Single-unit recordings have established that about $75 \%$ of NR units are sensitive to movement anywhere within their large (e.g., $160^{\circ}$ horizontal $\times 90^{\circ}$ vertical), sharply delimited receptive fields (Revzin, 1967, 1970). Even small moving stimuli are effective, provided their velocity is sufficient (greater than $5 \% / \mathrm{sec}$ ). Generally, response amplitudes were proportional to target velocities (up to approximately $275^{\circ} / \mathrm{sec}$ ). About $25 \%$ of these "wide-field" units were directionally selective: $15 \%$ preferred "radial" movement, i.e., toward vs. away from the bird; $5 \%$ preferred "fore-aft" movement, i.e., parallel to midsagittal plane; $5 \%$ preferred vertical (up-down) movement, especially of horizontal edges; and 2\% preferred "complex" movement.

DeBritto, Brunelli, Francesconi, and Magni (1975) have focused specifically on NR units which, in turn, project to ectostriatum (see below). All 36 units had substantial spontaneous discharge rates $(10$ spikes/ sec) and responded to stimuli moved in any direction. Seventy-three percent of these units also responded to diffuse light. Receptive fields range from $90^{\circ}$ to $120^{\circ}$. The authors describe these units as simple movement and/or luminance detectors.

Granda and Yazulla (1971) have discovered a functional segregation of units (45 sampled) such that most excitatory units were located in dorsal NR, inhibitory units in ventral NR. Within each of these two groups, units were classified as "phasic," "tonic," or "sustained," depending on the duration and onset of the response relative to a brief $(.5-1.0-\mathrm{sec})$ diffuse $\left(60^{\circ}\right)$ stimulus.

Ectostriatum. The major thalamotelencephalic link in the tectofugal pathway (see Figure 6) is the projection of nucleus rotundus to the "core" of ectostriatum (E) via tractus thalamofrontalis pars lateralis (Revzin \& Karten, 1966/67). The cells in the ectostriatal core may, in turn, innervate the surrounding cells of the periectostriatal belt (Karten \& Hodos, 1970). Revzin (1970) has found that $95 \%$ of units in $\mathrm{E}$ are "wide-field" movement detectors similar to those in NR. Moreover, Kimberly, Holden, and Bamborough (1971) observed that $86 \%$ of the ectostriatal units from which they recorded were directionally selective, usually preferring anteriorward or upward movement. Some units responded best to radial movement, i.e., toward or away from the bird. Benowitz and Karten (1976) have examined labeled cells in nucleus rotundus following injections of horseradish peroxidase in ectostriatum. Several cytoarchitectonically distinct areas in NR appear to project to discrete regions of $\mathrm{E}$, supporting the notion of multiple channels within this tecto-rotundoectostriatal pathway.

\section{Thalamofugal Pathway}

Thalamic nuclei. The nucleus opticus principalis thalami (OPT) refers collectively to three nuclei: dorsolateralis anterior, pars lateralis (DLL), lateralis anterior (LA), and dorsolateralis anterior (DLA) (Karten, Hodos, Nauta, \& Revzin, 1973). Based on histological and electrophysiological evidence, only these nuclei both receive retinal input and project to "Wulst"' (see below) (Meier et al., 1974; Miceli, Peyrichoux, \& Repérant, 1975; Mihailovic̀, Perisic̀, Bergonzi, \& Meier, 1974).

Crossland $(1970,1972)$ has recorded from thalamic units, some of which gave a sustained response to stationary stimuli, others yielding only a transient response. The latter were movement-sensitive and usually directionally selective. DLL units often preferred posteriorward movement and exhibited a bimodal distribution of receptive field sizes (ranges: $6^{\circ}-18^{\circ}$ and greater than $26^{\circ}$ ). DLA $A_{m c}$ units usually responded to stationary stimuli, had large receptive fields without any surrounds, and were sometimes 
$(26 \%)$ color coded. Units in nucleus geniculatus lateralis had smaller receptive fields $\left(4^{\circ}-8^{\circ}\right)$ with strong antagonistic surrounds and typically preferred anteriorward movement.

DeBritto et al. (1975) have examined 52 OPT units which could be antidromically or orthodromically fired from one or both Wulsts. These units exhibited little spontaneous activity and were most responsive to movement. Sixty-nine percent were directionally selective. Three were orientation-selective when tested with bar stimuli. Receptive fields ranged from $2^{\circ}$ to $10^{\circ}$. The authors suggest that these OPT units mediate pattern analysis.

Jassik-Gerschenfeld, Teulon, and Ropert (1976) recorded from 110 units in DLL. Fifty-six percent were on- or off-center units for which either a sustained or transient change in discharge rate accompanied stimulation. Sixteen percent were classified as on-off center units, based on static flashed stimuli, but they also responded vigorously to movement in any direction. Twenty-eight percent of the DLL units responded exclusively to movement but still with no directional preference. For all three categories, a wide range of receptive field sizes was evident.

Hyperstriatum. The major thalamotelencephalic link in the thalamofugal pathway (see Figure 6) is the projection of OPT to the "Wulst" or hyperstriatum via the lateral forebrain bundle (Karten et al., 1973; Meier et al., 1974; Powell \& Cowan, 1961). Some units in Wulst appear to be driven by the ipsilateral eye $(26.4 \%)$ or binocularly $(21.2 \%)$, interhemispheric communication depending on the integrity of the supraoptic decussation (Karten et al., 1973; Meier et al., 1974; Perisic̀, Mihailovic̀, \& Cuénod, 1971). OPT fibers innervate the posterior Wulst (dorsolateral telencephalon), especially intercalatus hyperstriatum accessorium (IHA). Cells in ventral DLL provide input mainly to ipsilateral Wulst, whereas dorsal DLL cells project bilaterally.

The Wulst includes, besides IHA, hyperstriatum dorsale (HD), hyperstriatum intercalatus suprema (HIS), and hyperstriatum accessorium (HA). Revzin (1969) recorded from 220 units in HIS and found topographically organized columns perpendicular to the HIS-HA border. Receptive fields which ranged from less than $2^{\circ}$ up to $10^{\circ}$ were circular or elliptical and generally preferred moving stimuli. As electrodes advanced lateromedially, receptive field size decreased.

The Wulst appears to project to virtually all retinorecipient cell groups, and to some bilaterally, e.g., nucleus geniculatus lateralis (Bagnoli, Francesconi, \& Magni, 1977; Karten et al., 1973; Meier et al., 1974). In addition, Wulst sends fibers to other telencephalic sites, including the periectostriatal belt where, apparently, the tectofugal and thalamofugal pathways converge.

\section{Effects of Damage to the Tectofugal and Thalamofugal Pathways}

Even small lesions in the optic tectum produce a noticeable impairment in the discrimination of intensity differences (D. H. Cohen, 1967). Larger tectal lesions yield very severe and often permanent deficits when tested with the following series of discriminative tasks: (1) bright vs. dim square, (2) horizontal vs. vertical bar, (3) upright vs. inverted triangular solid, (4) upright vs. inverted triangular outline. (This battery of tests will be referred to, from this point on, as the "coarse intensity and pattern tasks"; Hodos \& Karten, 1974.)

Based on the coarse intensity and pattern tasks, NR lesions result in severe impairment followed by prolonged reacquisition (Hodos \& Karten, 1966). The initial acquisition of these visual discriminations is likewise severely retarded by NR damage (Hodos \& Fletcher, 1974). No postoperative deficit is observed following NR lesions when combined with damage to nucleus geniculatus lateralis pars ventralis. When, in addition, nucleus subpretectalis is damaged, the usual deficit associated with NR lesions is observed (Hodos \& Bonbright, 1975). Based on a more sensitive test of intensity discrimination, NR lesions result in moderate threshold elevations followed by full recovery. When combined with OPT lesions, recovery is incomplete and resembles the degree of recovery following lesions in OPT alone (Hodos \& Bonbright, 1974). When tested on a simple color discrimination, pigeons with NR lesions drop to chance performance but gradually recover to their preoperative levels (Hodos, 1969). Ectostriatal lesions yield severe deficits, as assessed with the coarse intensity and pattern tasks, followed by prolonged recovery (Hodos \& Karten, 1970).

Extensive lesions in OPT or in IHA yield little or no deficit based on the coarse intensity and pattern tasks (Hodos, Karten, \& Bonbright, 1973). However, joint lesions of the tectofugal and thalamofugal pathways (NR and OPT) yield greater deficits than either alone (see, also, Jarvis, 1974). Damage to Wulst impairs brightness and pattern but not color discrimination (Pritz, Mead, \& Northcutt, 1970). However, with a delayed matching-to-sample paradigm based on a simple color discrimination, severe and permanent deficits result from an extensive Wulst ablation combined with moderate destruction of hyperstriatum ventrale (Pasternak, 1977). Lastly, intensity difference thresholds are elevated following lesions which involve IHA, HIS, and HA (subdivisions of Wulst) but subsequently return to their preoperative levels (Pasternak \& Hodos, 1977).

Even with this terse summary of the ablationdeficit research (for further details, see Hodos, 1976), it is evident that the differences between the tecto- 
fugal and thalamofugal pathways do not suggest a simple functional dichotomy. Lesions in the former pathway generally result in more substantial decrements in performance on all tests of visual discrimination. In many cases, partial or total recovery in performance is observed. The methods for assessing losses in sensory capacity may be too insensitive or too nonspecific to reveal permanent deficits. Moreover, sufficient functional overlap between these pathways and others may exist so that one system may compensate in time for initial deficits due to damage in another system.

\section{Centrifugal Pathway}

The centrifugal system (see Figure 7) consists of successive projections from retina to optic tectum, from superficial tectum (SGFS) to the isthmo-optic nucleus (ION) and from ION to the retina (proximal border of the inner nuclear layer) via the isthmooptic tract (Cowan \& Powell, 1963; Galifret \& Condé-Courtine, 1968; McGill, 1964). Ablationdegeneration evidence suggests that retinotopy is preserved throughout this pathway so that each quadrant of the retina receives centrifugal input from the same area of ION to which it projects indirectly via the tectum (McGill, Powell, \& Cowan, 1966a, 1966b). The ION contains somewhat less than 10,000 cells (Cowan \& Powell, 1963).

Holden and Powell (1972), recording from units in ION, found that $43 \%$ were sensitive to small (less than $4^{\circ}$ ) stimuli moving in any direction; another $43 \%$ were classified as "posterior-minimum" due to their lack of response to posteriorward movement (their preferred direction was not clearly defined); and an additional $13 \%$ were directionally selective (83\% of which preferred anteriorward movement).

By means of a reversible cooling technique (cryogenic probe on ION), Pearlman and Hughes (1976a, 1976b) have evaluated the influence of the centrifugal feedback on the response properties of retinal ganglion cells. When the centrifugal input is removed, receptive fields shrink and responsivity is reduced for about $75 \%$ of the ganglion cells tested. Motionsensitive and directionally selective units were much more likely to show this response decrement when ION was cooled. Referring to the centrifugal fibers' terminations on amacrine cells, the authors conclude that the "removal of efferent (ION) influences leads to enhancement of an inhibitory mechanism that extends throughout the receptive field." To the extent that movement-sensitive and directionally selective units are achieved by a mechanism utilizing amacrine cells, these types of units would, naturally, be most affected by deactivating the centrifugal fibers.

The converse experiment, that of artificially increasing centrifugal "feedback" to the retina, has been performed in the chick (Miles, 1970). Miles electrically stimulated the isthmo-optic tract. The most significant effect was an enhancement of the response characteristic of each receptive field center. Ganglion cells were rendered more responsive and less selective regarding stimuli which could elicit responding. Miles concluded that IOT stimulation suppressed the influence of the surround, i.e., disinhibited the receptive field center.

\section{Effects of Damage to the Centrifugal Pathway}

Shortess and Klose (1977) employed a reaction time task to demonstrate increases in latencies of a keypecking response following lesions in the isthmooptic tract. In addition, orientation discrimination (vertical vs. horizontal gratings) at low contrast and luminance levels became worse. In view of the mild deficits observed, the authors suggest that the centrifugal system plays a minor, supplemental role in the visual process. However, its most likely function, modulating sensitivity to movement, has yet to be rigorously evaluated. Rogers and Miles (1972) have suggested that this feedback system mediates visual guidance of motor behavior. Holden (1966) has speculated that it permits suppression of either eye singly, or of vision in both lateral visual fields during binocular vision in the frontal field, or suppression of vision during head and eye movements. Miles (1972) has conjectured that the centrifugal system prevents confusion between selfproduced movements and motion extrinsic to the birds. A valuable contribution at this point would be an assessment of motion sensitivity both before and after ablation of the centrifugal pathway.

\section{FUNCTION}

\section{Visual Fields}

\section{Spatial Range of Operation}

Panoramic vision in the pigeon is achieved both by a large (approximately $180^{\circ}$, according to Chard $\&$ Gundlach, 1938) monocular visual field and by the lateral placement of the two eyes whose optical axes form an angle of approximately $145^{\circ}$ (Goodson, 1969), which includes an estimated $25^{\circ}$ of overlap, i.e., binocular field, when the eyes are fully converged (Chard \& Gundlach, 1938; Galifret, 1968). The eye and head movements exhibited by the pigeon would, in effect, extend this panorama.

\section{Accommodation}

Accommodation, the adjustment of refractive power for focusing objects at varying distances, is accomplished primarily by controlling the degree of curvature of the corneal bulge (Gundlach, Chard, \& Skahen, 1945). Corneal curvature is jointly determined by three striated ciliary muscle groups 
(Crampton's, Brücke's, and Müller's) and the scleral ossicles (a set of bony plates which surrounds the ocular globe approximately at the ora serrata). A range of approximately 17 diopters is thereby provided. The role of the lens in accommodation has not yet been determined.

\section{Eye Movements}

Two types of response have been observed when vertically striped patterns rotated about the restrained pigeon (Fite, 1968). When step changes in the velocity of the pattern occurred, "stare nystagmus" developed which entailed head and eye movements of irregular periodicity and amplitude, the frequency of these movements depending on the number of contours in the rotating pattern. When pattern velocity was gradually increased, "look nystagmus," i.e., very cyclical head movements of uniform amplitude, ensued; frequency and amplitude of the nystagmus depended on pattern velocity.

When the head as well as the body was restrained, an optokinetic response (OKR), consisting of both a fast (saccadic) and a slow (tracking) eye movement, was elicited by the rotating stripes (Goodson, 1969). Neither foveal lesions nor extensive retinal lesions abolished the OKR. As the velocity of the rotating pattern was increased, step increases in "slippage rate," i.e., discrepancy between pattern velocity and tracking velocity, occurred. More accurate tracking was exhibited for a vertical pattern moving from the posterior to the anterior visual field. With bodily restraint only, monocularly viewing pigeons also make about four times as many head movements to anteriorward than to posteriorward movement (Corballis \& Luthe, 1973).

Eye movements, while limited in extent (horizontal mobility confined to $15^{\circ}$ of arc; Goodson, 1969), occur in several forms. Oculomotor activity has been monitored by directing a focused beam onto a corneamounted mirror (Nye, 1969). The reflected beam stimulated two photomultiplier tubes to a greater or lesser degree depending on the horizontal and/or vertical angular deviation of the eye. At least four types of eye movements were revealed: $30-\mathrm{Hz}$ bursts of oscillatory movement with an amplitude of several degrees (found to be accompanied by eyeblinks so that the cornea is, in effect, "polished"); impulse movements of as much as $2^{\circ}$ with no oscillation; slow drifts suggestive of tracking with rates of $1^{\circ}-5^{\circ} / \mathrm{sec}$; rarely, a "flick," i.e., a rapid (less than $20-\mathrm{msec}$ ) change in the direction of gaze.

\section{Frontal vs. Lateral Vision}

In most psychophysical studies, visual stimuli have been presented with no explicit restriction as to how the pigeon would view them (cf. P. M. Blough, 1973; Corballis \& Luthe, 1973). With regard to this practice, it is important to consider the notion that the pigeon eye is nonuniform regarding its form and, in some respects, its function. Differences in refraction for the frontal vs. lateral visual field have been discovered (see below), as have differences in the topography of various types of oil drops, in the extent of photomechanical changes, and in the density of the various retinal neurons and in their organizational complexity (see above). In terms of function, photopic spectral sensitivity appears to vary considerably as a consequence of where, in the visual field, the stimuli are presented (see below). In addition, other, presumably non-sensory, differences may limit performance on sensory tasks. Nye (1973) found that pigeons were unable to acquire a behavioral (keypeck) discrimination between a uniform field and either a stationary or moving bar pattern when these were viewed binocularly (identical stimuli in both lateral visual fields) but successively. Subsequently, pigeons were trained on color and luminance problems in which the stimuli were again presented binocularly, but successively, on a panoramic screen. As the identical stimuli were moved further away from the anterior midline and each other, performance deteriorated markedly. Nye suggested that "pigeons do not possess the neural capability required to learn to use information contained in laterally located stimuli to directly control pecking behavior." However, this appears to be an overstatement, at least for some gross discriminations. For example, Bloch and Maturana (1971) employed brief $(200-\mathrm{msec})$, peck-initiated flashes of wide-band chromatic stimuli at different locations in the visual field. The pigeons, although taking considerably longer to learn to distinguish among these stimuli when viewed in the posterior visual field, eventually attained a high degree of correctness.

The notion that the pigeon is myopic ("nearsighted") in its anterior binocular field and hyperopic ("far-sighted") in its lateral monocular field has been proposed by Catania (1964), based primarily on anecdotal evidence. Millodot and P. M. Blough (1971) have evaluated this notion both with retinoscopy and by examining serial sections of frozen pigeon eyes. With the latter method, distances from the center of the lens to various points along the retina were compared. The observed differences in refractive state (maximum variation of about 4 diopters) suggested that the superior nasal retina is associated with a myopic refractive error which, perhaps, is shared to a smaller extent by the superior temporal retina.

Marshall et al. (1973) have also measured the pigeon eye retinoscopically. For 589-nm light, a slight hyperopia (2.4 diopters) was exhibited along the vertical axis. The range of such measurements was 4 diopters, which corresponds roughly to the thick- 
ness of the pigeon retina. The superior retina, while not systematically explored, was observed to be somewhat more myopic.

Nye (1973) computed third-order polynomial functions to fit the cornea, lens, and retina as seen in horizontal sections of frozen pigeon eyes. Then, based on these functions, ray paths were traced backward through the eye to calculate the object surface of best focus. The pigeon's eye was relatively more myopic in the anterior and posterior directions, i.e., at angles greater than $40^{\circ}$ from the optic axis. However, even for the central $80^{\circ}$ in the lateral visual field, the object surface was sometimes found to be within $4-5 \mathrm{~cm}$ from the pupil.

In summary, while the pigeon seems somewhat more "near-sighted" for both the anterior and posterior portions of its inferior visual field, this does not necessarily mean that objects nearby in the lateral visual field are out of focus, especially when one considers the large range of accommodation available to the pigeon.

\section{Dark Adaptation}

\section{Visual Sensitivity}

Following a 5-min exposure to a moderately intense level of illumination $\left(1.3 \times 10^{3} \mathrm{~cd} / \mathrm{m}^{2}\right)$, the visual threshold of the pigeon, when measured behaviorally in the dark, undergoes a gradual diminution (D. S. Blough, 1956). After about $30 \mathrm{~min}$ of testing, when the estimated threshold appears to be asymptotic, a substantial negatively accelerated decrease commences. This duplex dark-adaptation function (D. S. Blough, 1956; Ikeda, 1965) suggested that the reacquisition of maximum sensitivity (absolute threshold = $8 \times 10^{-5} \mathrm{~cd} / \mathrm{m}^{2}$ ) can require as long as $70 \mathrm{~min}$. A decrease in either the intensity or duration of light adaptation results in more rapid subsequent dark adaptation. A red test stimulus reveals only the initial (cone) segment of threshold change. One surprising feature of these dark-adaptation functions is their prolonged time course relative to those measured for humans. It is difficult to judge whether this is due to a specific difference in the pigeon's visual system, e.g., slower pigment regeneration kinetics or the coexistent limitation of photomechanical changes, or to the testing procedure used. The tracking procedure (D. S. Blough, 1956), while affording a moment-tomoment account of visual sensitivity, has the disadvantage of necessitating an almost constantly present, albeit dim, test stimulus, thereby permitting an unknown degree of light adaptation (cf. Passe, 1977). One further disadvantage of the tracking method is the difficulty of obtaining reliable threshold estimates during the initial few minutes of dark adaptation when sensitivity change is presumably quite rapid. In humans, as much as a $2 \log$ unit change in threshold can occur within seconds after a photopic adapting light is extinguished (Baker, 1953), so a large sement of the total sensitivity change in the pigeon may have gone unmeasured.

\section{Incremental Sensitivity}

The ability to discriminate small intensity differences is often expressed as a Weber fraction, i.e., the ratio of a just-discernible intensity increment vs. some reference intensity. While acknowledging considerable inter- and intrasubject variability in his psychophysical measurements, Mentzer (1966) reports a Weber fraction of .78 for a background luminance of $1.72 \mathrm{~cd} / \mathrm{m}^{2}$. Shumake, Hatfield, and Smith (1966), employing a wide range of background luminances (1.6 to $48.4 \mathrm{~cd} / \mathrm{m}^{2}$ ), estimated Weber fractions of $.89, .73$, and .36 for three birds. However, intrasubject reliability was limited in that separate increment threshold determinations at each background luminance differed by as much as .3 log units. A qualitative electrophysiological correlate of these changes in incremental sensitivity is observed in the tectal evoked potential whose magnitude is inversely proportional to the background intensity and is directly proportional to the test flash intensity (Samson \& Young, 1973).

Hodos and Bonbright (1972) used a discrete-trial successive comparison procedure to measure intensity "decrement thresholds." On some trials, a reference luminance of $318 \mathrm{~cd} / \mathrm{m}^{2}$ was viewed on the observing (center) key. On other trials, a dimmer (variable amount of attenuation) stimulus was presented. As little as a $.125 \log$ unit difference, on the average, was enough for the pigeon to select the correct sidekey choice on $75 \%$ of trials. This threshold intensity difference corresponds to a Weber fraction of .25 . Such a small Weber fraction is surprising because the successive-comparison method requires the subject to "remember" the reference luminance level as well as to compare it with other levels (cf. Shumake et al., 1966).

\section{Brightness Scaling}

Brightness scaling has been accomplished by means of a discrete trial, maintained discrimination procedure in which training trials are interspersed with testing trials (Boakes, 1969). The pigeons were initially taught to peck one of two side keys based on whether a "bright" $\left(1,878 \mathrm{~cd} / \mathrm{m}^{2}\right)$ or a "dim" $\left(23.6 \mathrm{~cd} / \mathrm{m}^{2}\right)$ stimulus had been viewed on the observing (center) key. During testing, stimuli of intermediate luminance were occasionally presented. Intertrial intervals $(8 \mathrm{sec})$ were spent in darkness. The relation between center-key luminance and relative frequency of pecking a given side key was described by a power function albeit with considerable variability regarding the exponent of best fit. For eight subjects, the median exponent was .24 , which is 
roughly equivalent to the value estimated for humans (Onley, 1960). The median intensity for which this brightness interval was "bisected," i.e., either side key pecked with equal likelihood, was $369 \mathrm{~cd} / \mathrm{m}^{2}$ (range: $\left.210-439 \mathrm{~cd} / \mathrm{m}^{2}\right)$, which falls between the geometric mean $\left(210 \mathrm{~cd} / \mathrm{m}^{2}\right)$ and the arithmetic mean $\left(952 \mathrm{~cd} / \mathrm{m}^{2}\right)$ of the training luminances. As the author has pointed out, the generality of the observed brightness scaling function to other ranges of intensity remains an empirical question.

\section{Flicker Sensitivity}

Early evidence of the pigeon's ability to detect flicker at very high frequencies was provided by electroretinography (Dodt \& Wirth, 1953). Using intense illumination (reported maximum was $8,000 \mathrm{~m}$-cd but with no details regarding measurement) and square-wave stimuli, critical fusion frequency (CFF) was as high as $140 \mathrm{cps}$ (apparently based on visual inspection of the ERG). In a later behavioral study, CFF was shown to be directly proportional to log intensity (Ferry-Porter law) over at least a 2-log-unit range (Hendricks, 1966). Moreover, CFF was still increasing linearly at the highest luminance employed $\left(134 \mathrm{~cd} / \mathrm{m}^{2}\right)$. Indeed, with a much higher intensity $\left(9.6 \times 10^{4} \mathrm{~cd} / \mathrm{m}^{2}\right)$ and short (.10) pulse-to-cycle fraction (PCF is the proportion of time during which light is actually present), behaviorally measured CFF approaches 150 cps (Powell, 1967; Powell \& Smith, 1968) as compared to an upper limit of approximately $70 \mathrm{cps}$ for the human observer. The finding that at even smaller PCF values $(.05, .025)$ CFF declines may be attributable to the concomitant decrease in the time-averaged luminance. One possible explanation of why shorter PCFs are more likely to be resolved as flicker has been suggested by Frost (1972), who reported that "increased sensivity to light offset may

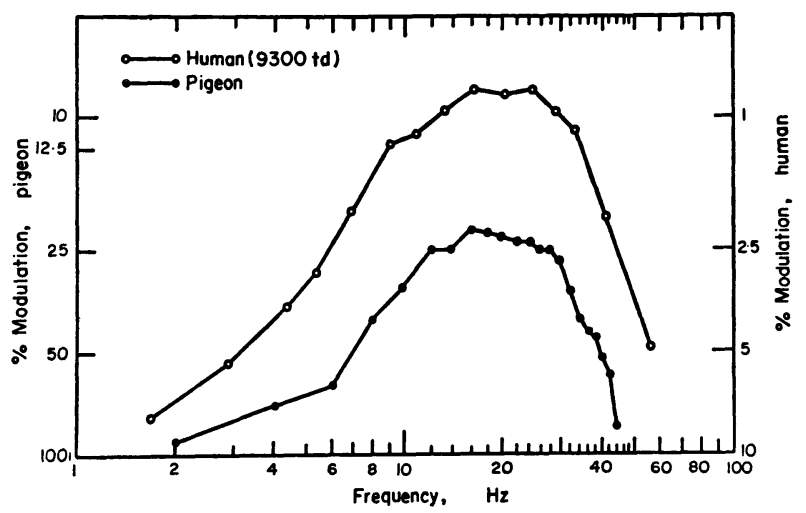

Figure 8. Average de Lange function from six pigeons (filled circles). Averaged illuminance for a human observer was $350 \mathrm{Td}$. The de Lange function for a human observer (replotted from Kelly, 1961) at 9,300 Td is shown for comparison (open circles). (From Graf, 1973.)

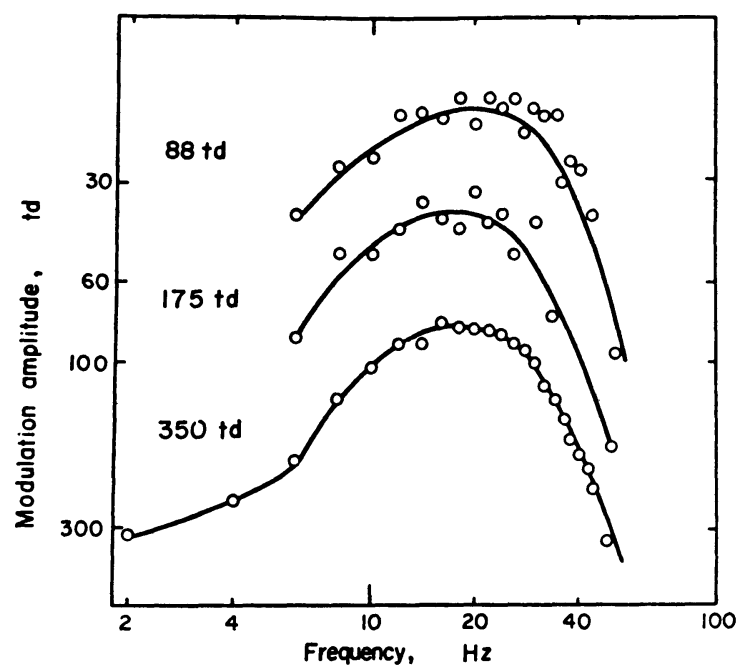

Figure 9. Absolute modulation sensitivity for three levels of average illuminance, 350, 175, and 88 Td. (From Graf, 1973.)

be largely responsible for the higher CFF found in the light-adapted eye," since only the d-wave (ERG wave correlated with stimulus offset) shows an increase due to light adaptation. Presumably, with shorter PCFs and, thus, longer dark periods within each cycle, this off-effect of the ERG would be less likely to be masked by the on-effect (a-wave) to the light pulse of the subsequent cycle. However, it may be more productive to pursue such theorizing in terms of the response of individual ganglion cells, rather than in terms of a gross index of retinal activity such as the ERG.

An alternative approach to the study of flicker perception has involved the measurement of the modulation threshold, i.e., the lowest amplitude of a sinusoidal fluctuation about some time-averaged luminance (TAL) which yields a criterion response. Modulation sensitivity has been investigated at several TALs and over a moderate frequency range $(2-44 \mathrm{cps})$ (Graf, 1973). As seen in Figure 8, the psychophysical functions for humans and pigeons, compared at different average intensities in order to compensate for the difference in $\mathrm{f}$ numbers for the two eyes (see section on optical properties), bear a marked resemblance. However, it is somewhat puzzling that, throughout most of the frequency range examined, modulation thresholds for the pigeon are at least a log unit higher, despite its previously demonstrated aptitude for resolving flicker well beyond the fusion limit for humans.

Comparing the pigeon's modulation sensitivity at different TALs, as in Figure 9, one notes a fair degree of similarity among the three functions, with greater variability appearing in the low-intensity data. Two features of these functions which contrast with the findings for humans are: the absence of a shift in the frequency at which modulation sensitivity is 
maximum (toward higher frequencies at more intense TALs) and the lack of coincidence of these functions along a common high-frequency asymptote. This latter discrepancy, if borne out by further empirical study, would indicate that the temporal response of the pigeon's visual system is nonlinear even at high frequencies, i.e., threshold modulation amplitude would depend not only on the frequency of modulation, but also on the adaptation level.

\section{Purkinje Shift}

\section{Spectral Response}

The relative detectability of various wavelengths differs markedly for the light-adapted vs. the darkadapted pigeon. This "Purkinje shift" has been demonstrated with regard to: pupillary constriction (Laurens, 1923), the massed retinal discharge (Granit, 1942), the tectal evoked potential (Galifret, 1961), and behavioral thresholds during dark adaptation (D. S. Blough, 1957). This change is to be expected, since vision is mediated by rods at dim (scotopic) light levels and by cones at bright (photopic) light levels (Schultze, 1866).

\section{Scotopic Sensitivity}

The presence of the photopigment rhodopsin in the rods of the pigeon retina has been established by its extraction (Bridges, 1962; Sillman, 1969), by the bleaching kinetics and spectral sensitivity of early receptor potential (Govardovskiǐ \& Zueva, 1977), and by rod microspectrophotometry (Bowmaker, 1977; Liebman, 1972). The absorbance of rhodopsin agrees well with the pigeon's scotopic spectral sensitivity function (D. S. Blough, 1957; Donner, 1953; Graf \& Norren, 1974; Ikeda, 1965).

\section{Photopic Sensitivty}

Component spectral mechanisms. The determination of the number and nature of cone mechanisms has required the identification of each of several cone photopigments, as well as each of several oil drops, and, ultimately, the particular pigment/oil-drop combinations which constitute distinct classes of cones.

Govardovskil and Zueva (1977) recorded the early receptor potential (ERP) from the isolated (in vitro) pigeon retina as it was illuminated antidromically, i.e., light traversed the retina in the receptor-toganglion cell direction, thereby avoiding the oil drops. The amplitude of the ERP, which is linearly related to photopigment concentration, was employed to study both the bleaching kinetics and the spectral sensitivity of the various cone pigments. Both methods indicated the presence of at least three visual pigments with $\lambda_{\max } \mathrm{s}$ at 467,507 (presumably rhodopsin), and $562 \mathrm{~nm}$. [Throughout this paper the term " $\lambda_{\max }$ " shall designate the wavelength at which various visual
Table 7

Oil Drops and Visual Pigments in the Pigeon Retina

\begin{tabular}{|c|c|c|c|c|c|}
\hline \multirow{2}{*}{\multicolumn{2}{|c|}{ Oil droplet }} & \multirow{3}{*}{$\begin{array}{c}\begin{array}{c}\text { Outer } \\
\text { segment }\end{array} \\
\begin{array}{c}\text { Pigment } \\
\lambda_{\max } \\
(\mathrm{nm})\end{array}\end{array}$} & \multicolumn{2}{|c|}{$\begin{array}{l}\text { Oil droplet-visual } \\
\text { pigment combination }\end{array}$} & \multirow{3}{*}{$\begin{array}{c}\text { Approx } \% \ddagger \\
\text { of total } \\
\text { cones }\end{array}$} \\
\hline & & & \multirow[b]{2}{*}{$\begin{array}{c}\text { Effective } \\
\lambda_{\max } \\
(\mathrm{nm})\end{array}$} & \multirow{2}{*}{$\begin{array}{l}\text { Band width } \\
\text { at half peak } \\
\text { height } \\
\left(\mathrm{cm}^{-1}\right)\end{array}$} & \\
\hline Type & $\begin{array}{l}\lambda_{\text {Tso }} \\
\text { (nm) }\end{array}$ & & & & \\
\hline & & & Red Sector & & \\
\hline Red & 610 & 567 & 619 & 1417 & 23 \\
\hline C & 570 & 514 & 575 & 1712 & 27 \\
\hline \multirow[t]{2}{*}{ B } & 554 & 567 & 589 & 2376 & 30 \\
\hline & (522) & (567) & (570) & (3124) & \\
\hline \multirow{3}{*}{$\begin{array}{l}A_{r} \\
A_{b} \\
\text { Clear }\end{array}$} & 476 & 567 & 567 & 4157 ) & \\
\hline & 476 & 460 & 485 & $2561\}$ & 20 \\
\hline & $?$ & $567 ?$ & $\begin{array}{c}567 ? \\
\text { Yellow Sector }\end{array}$ & 4526? & \\
\hline \multirow{6}{*}{$\begin{array}{l}\text { Red } \\
\text { C } \\
B \\
A_{4} \\
A_{z} \\
\text { Clear }\end{array}$} & 600 & 567 & 613 & 1592 & 12 \\
\hline & 562 & 514 & 567 & 1785 & 12 \\
\hline & $499 \dagger$ & 567 & 567 & 3608 & 51 \\
\hline & 470 & 567 & 567 & 4299 ? & \\
\hline & 470 & 514 & 525 & $3537\}$ & 25 \\
\hline & $?$ & $?$ & $?$ & $?$ & \\
\hline
\end{tabular}

functions (photochemical, electrophysiological, or behavioral) exhibit maximum sensitivity but shall not necessarily imply a unitary mechanism subserving these functions.] The latter method revealed an additional pigment with $\lambda_{\max }=413 \mathrm{~nm}$. The photopigment with $\lambda_{\max }=562 \mathrm{~nm}$, "iodopsin," had previously been extracted from the pigeon retina by P. K. Brown (Wald, 1958) and measured with a microspectrophotometer (Liebman, 1972).

Bowmaker (1977) has measured the absorbance spectra of both the photopigment and the oil drop in each of 103 cones. Three photopigments were identified: P460 $\left(\lambda_{\max }=460 \mathrm{~nm}\right)$, P514, and P567. The predominant pigment, P567, was found in cones containing a "Red" type oil drop (see section on oil drops), in both elements (chief and accessory) of the double cones, and in some cones with an " $A$ " type oil drop. P514 occurred in cones with a " $C$ " oil drop and some cones containing an " $\mathrm{A}$ " oil drop (but only in the yellow retinal field). P460 was found only in the red retinal field in cones possessing an "A" type oil drop. Due to the small size of their outer segments, only one cone containing a "clear" oil drop was measured with regard to its pigment which, in this one case, was P567. These pigment data and the previously discussed oil-drop data are summarized in Table 7. Composite spectral sensitivities of the cone/oil-drop combinations were based on the assumptions that cone outer segments are $20 \mu$ long and have an end-on absorbance of .3 log units. $A_{r}, A_{g}$, and $A_{b}$ in the table refer to the type $A$ oil drop when combined with P567, P514, and P460, respectively.

Composite spectral sensitivities for the six putative classes of cones in the red and yellow retinal fields are depicted in Figures 10 and 11, respectively. In both cases, the absorbance functions marked "clear" 


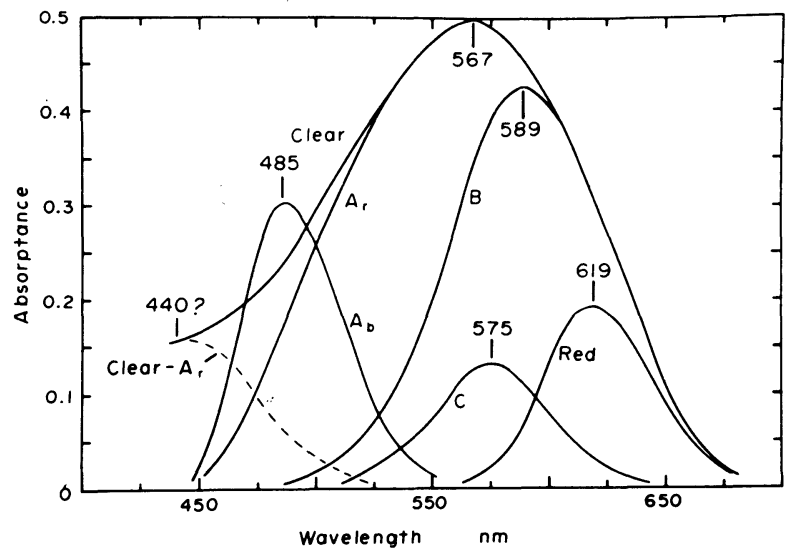

Figure 10. Calculated absorbance for the pigment/oil-drop combinations in the six recognized cone types in the red sector of the pigeon retina, assuming an end-on absorbance of $\mathbf{. 3 0}$ for the cone outer segments. Clear, absorbance of a cone having the clear oil drop with $P 567$ in the outer segment; $A_{r}$, type $A$ drop with P567; $A_{b}$, type $A$ drop with P461; B, type B drop $\left(\lambda_{T 50} 554 \mathrm{~nm}\right)$ with P567; C, type C drop with P514; Red, red drop with P567. The dashed line indicates the possible response, maximal at about 430-440 $\mathrm{nm}$, derived by interaction between the "clear" and "type A," cones. (From Bowmaker, 1977.)

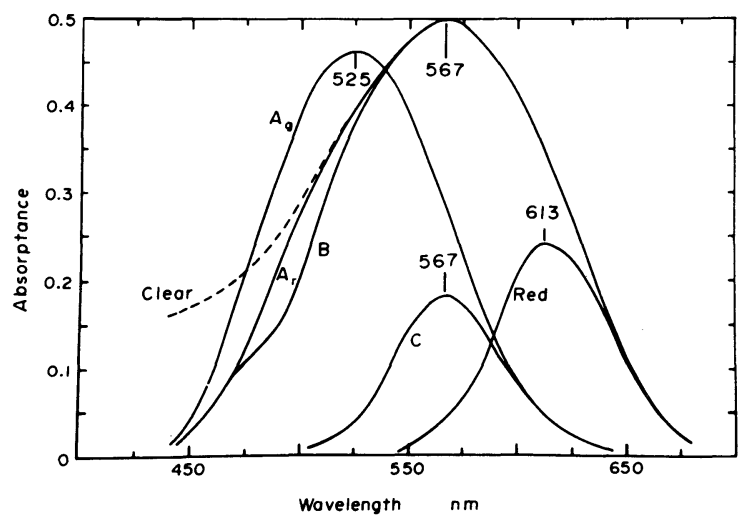

Figure 11. Calculated absorbance for the pigment/oil-drop combinations in the six recognized cone types in the yellow sector of the pigeon retina, assuming an end-on absorbance of $\mathbf{. 3 0}$ for the cone outer segments. Clear (---), possible absorbance of a cone having the clear oil drop with P567 in the outer segment; $A_{r}$, type A drop with P567; $A_{g}$, type A drop with P514; B, type B drop with P567; C, type $C$ drop with P514; Red, red drop with P567. (From Bowmaker, 1977.)

$\left(\lambda_{\max }=567 \mathrm{~nm}\right)$ should be regarded as speculative in view of the paucity of relevant data. The mechanism postulated for the red field (Clear- $\mathbf{A}_{r}$ ), which is sensitive to short wavelengths by virtue of an interaction between mechanisms which, by themselves, respond primarily to long wavelengths, is completely hypothetical and attempts unsuccessfully to account for a demonstrated sensitivity to short wavelengths as will be discussed below.

That the cone pigment P514 was "missed" by Govardovskil and Zueva (1977) is understandable in that their methods might not distinguish it from rhodopsin whose absorbance spectrum would exhibit considerable overlap with that of P514. The shortwavelength pigment P413, which they found but Bowmaker (1977) did not, is given additional credibility by studies of spectral sensitivity before and after chromatic adaptation (Graf \& Norren, 1974; Norren, 1975). Electroretinographic responses to flickering monochromatic stimuli were evoked at a criterion amplitude by adjusting intensity. In addition, the phase lag between the stimulus waveform and the ERG waveform was measured. As seen in the top panel of Figure 12, long-wavelength chromatic adaptation selectively abolishes long-wavelength

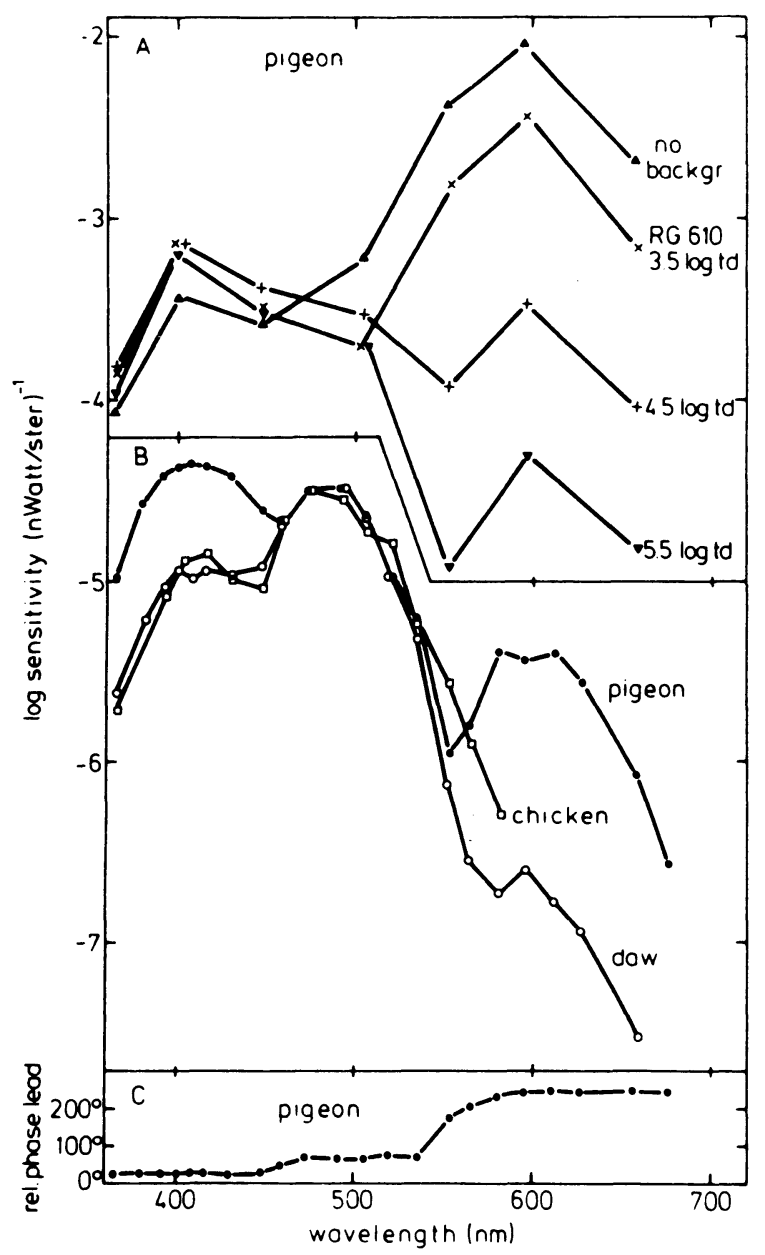

Figure 12. (A) Spectral sensitivity of the pigeon based on a 1- $\mu \mathrm{V}$ criterion response. A red background (Schott, RG 610) of variable illuminance was employed. (B) Relative spectral sensitivity of pigeon, chicken, and daw measured in the presence of a 5.5-logTd red background. The position of the curves with respect to the vertical axis was chosen to produce a best mutual fit in the region $460-540 \mathrm{~nm}$. (C) Relative phase lead of the response with respect to the stimulus for the pigeon. The phase lead is constant in three regions: $360-450 \mathrm{~nm}, 460-540 \mathrm{~nm}$, and 580-680 $\mathrm{nm}$. In each region, this is a necessary condition for one receptor system to determine the response. (From Norren, 1975.) 
sensitivity, leaving short-wavelength sensitivity relatively unaffected. Averaged data, shown in the middle panel, were obtained after intense longwavelength adaptation. For the pigeon, as well as for two other avian species, well-defined peaks of spectral sensitivity occur near 415 and $480 \mathrm{~nm}$. In the bottom panel, three plateaus are discernible in the phase lag function, indicating a constant phase difference from $360-450 \mathrm{~nm}, 460-540 \mathrm{~nm}$, and 560-680 nm. Collectively, these data strongly suggest two short-wavelength photopic mechanisms with $\lambda_{\max } \mathrm{s}$ near 415 and $480 \mathrm{~nm}$. At least one pigment, with $\lambda_{\max }$ no longer than $415 \mathrm{~nm}$, may be inferred since: short-wavelength sensitivity survives bleaching by long-wavelength light and, thus, does not depend on an absorption sideband of a long-wavelength pigment or an interaction between long-wavelength mechanisms; and any explanation in terms of oil droplets is vitiated by the fact that they shift spectral sensitivity distributions only toward longer wavelengths.

Overall sensitivity. Traditionally, color has been regarded as a three-dimensional phenomenon, the joint perception of hue, saturation, and brightness. Most investigations of color vision deal with hue or saturation and, thus, need to equate stimuli for brightness. Photopic spectral sensitivity describes the variation in threshold as a function of wavelength and, therefore, assuming all stimuli at threshold are equally bright, allows for the desired adjustment. A thorough knowledge of the pigeon's spectral sensitivity, then, would seem to be a prerequisite to understanding the more complex aspects of its color vision.

The first thorough behavioral assessment of photopic spectral sensitivity was achieved by D. S. Blough (1957). Thresholds during the "cone plateau" of dark adaptation were measured with monochromatic lights for three pigeons and appear in Figure 13.

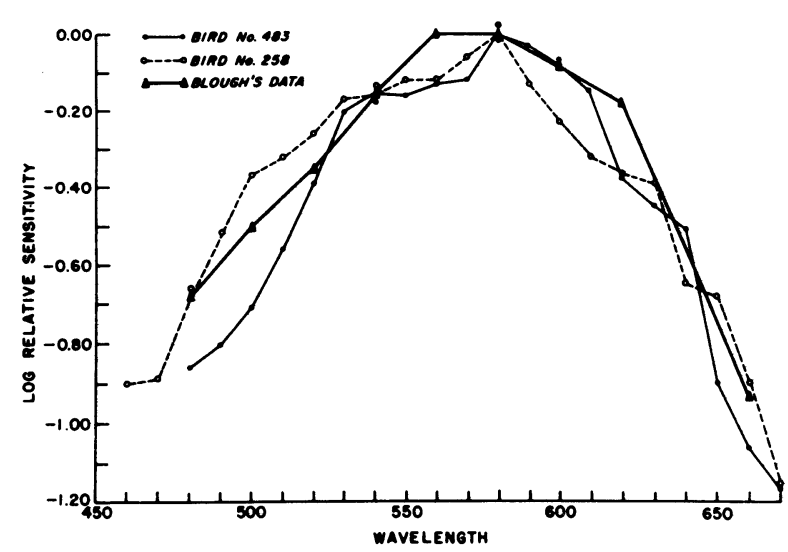

Figure 13. Relative spectral sensitivity of two pigeons determined with flicker photometry. The average data from four pigeons obtained during dark adaptation (D. S. Blough, 1957) also are shown. (From Graf, 1969.)

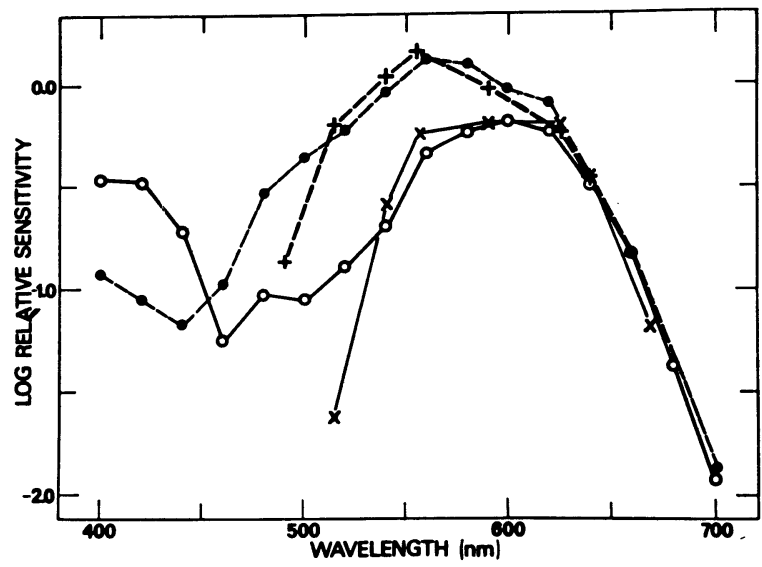

Figure 14. Spectral sensitivity functions. Open circles, Yager and Romeskie (1975); filled circles, D. S. Blough (1957); $X$ s and $+s$ for red and yellow field tectal units, respectively (King-Smith, personal communication cited by Muntz, 1972). The functions have been adjusted to coincide for wavelengths longer than $640 \mathrm{~nm}$. (From Yager and Romeskie, 1975.)

The general shape of the sensitivity function was later replicated behaviorally by the technique of flicker photometry (Graf, 1969), as seen in the same figure. The widespread use of D. S. Blough's sensitivity data to adjust stimuli differing in wavelength so as to be equiluminous is called into question by recent reports of differences in spectral sensitivity as a function of location in the visual field.

Single-unit recordings from optic tectum (by KingSmith; see Muntz, 1972) have suggested that cells representing the red field (dorsotemporal retina) exhibit a sensitivity function displaced toward longer wavelengths $\left(\lambda_{\max }=585 \mathrm{~nm}\right)$ when compared with that of cells associated with the yellow field $\left(\lambda_{\max }\right.$ $=560 \mathrm{~nm}$ ), as seen in Figure 14. In view of the distribution of oil drops in the retina and the fielddependent changes in their absorbance spectra, such a displacement seems quite reasonable. Also seen in this figure are the behaviorally determined photopic spectral sensitivity functions from D. S. Blough (1957) and Romeskie and Yager (1976a; Yager \& Romeskie, 1975). When plotted to coincide for wavelengths of $640 \mathrm{~nm}$ and longer (a reasonable adjustment in that all reported oil drops exhibit negligible density over this spectral region), a marked discrepancy is observed which resembles the difference reported for tectal cells.

Romeskie and Yager attribute D. S. Blough's results to the fact that his pigeons viewed stimuli which were located somewhat above the response keys they were required to peck, whereas Romeskie and Yager presented stimuli upon the response keys themselves. Presumably, the resulting sensitivity functions would apply to the yellow field and to the red field, respectively. While this red vs. yellow field interpretation seems plausible, it is important to 
recognize that viewing conditions in these experiments were never explicitly restricted. Moreover, the behavioral topography of a keypecking pigeon would seem to guarantee against a strict angular correspondence between eye position and the response key (see Hodos, Leibowitz, \& Bonbright, 1976). A careful reassessment of spectral sensitivity with viewing explicitly restricted to each field is needed.

Adaptation conditions can have a dramatic effect on measurements of photopic spectral sensitivity. Ikeda (1965) recorded electroretinographic responses to a flickering test stimulus located in the lateral (foveal) visual field. A background, provided by a tungsten filament lamp of unspecified emissivity, was used to insure a photopic level of adaptation. The resulting spectral sensitivity function (based on a criterion ERG amplitude), with $\lambda_{\max }=547 \mathrm{~nm}$, contrasts noticeably with previous behavioral measurements (D. S. Blough, 1957). A large part of this discrepancy might be due to the chromatic adaptation introduced by Ikeda's background light, in which longer wavelengths were probably overrepresented. In color-vision research, it would seem especially desirable to specify the spectral character of the adaptation conditions employed (e.g., Romeskie \& Yager, 1976a).

The spatial properties of test stimuli can also be an important consideration. P. M. Blough, Riggs, and Schafer (1972) presented either a uniformly flickering field, or a grating whose alternate bars flickered in counterphase, in the lateral visual field. The spectral sensitivity functions were similar in shape and range but were centered at 576 and $587 \mathrm{~nm}$, respectively. The alternating grating, with its constant spaceaveraged luminance, probably reduces the relative contribution to the ERG of those receptor classes which exhibit relatively greater areal summation. This might account for the difference in spectral sensitivity.

Ultraviolet sensitivity. The human visual system is normally insensitive to ultraviolet radiation, due in large part to the absorption characteristics of its ocular media. The pigeon, whose optics are relatively clear at short wavelengths, does respond to UV. Pigeons have been shown to acquire a behavioral discrimination signaled by the addition or omission of a UV band of energy $\left(\lambda_{\max }=366 \mathrm{~nm}\right)$ in conjunction with an always present 520-nm light (Wright, 1972a). Furthermore, in a bipartite-field hue discrimination task, performance was generally better when UV was presented in only one hemifield than when UV was either included or omitted from both hemifields, indicating a relatively localized effect on hue. An alternative explanation in terms of diffuse fluorescence would seem untenable. Kreithen and Eisner (1978) have used a conditioned heart-rate response to demonstrate that UV sensitivity is maximum between
325 and $360 \mathrm{~nm}$ and that thresholds are well below the level of UV provided by sunlight. The basis for this sensitivty, however, remains in doubt. Marc (Note 1) has discovered that the yellow oil drops, when irradiated with $365 \mathrm{~nm}$, fluoresce considerably with an emission spectrum that overlaps the action spectra of several putative long-wavelength cone mechanisms. Such fluorescence could furnish relatively localized visual stimulation. Alternatively, ultraviolet radiation may be absorbed by a shortwavelength photopigment or even a side-band of a longer-wavelength-sensitive photopigment.

Tentative models of spectral sensitivity: The red vs. the yellow field. A careful analysis by Bowmaker (1977), which takes into acount most of the current information, has yielded separate models to explain the spectral sensitivites associated with the red and the yellow fields of the pigeon. The key assumption is that the overall spectral sensitivity represents the sum of the sensitivities of each cone type (i.e., each pigment/oil-drop combination) weighted strictly according to its relative frequency. Frequencies of the various cone types are based on counts of the different oil-drop varieties in the red and yellow retinal fields (Waelchi, 1883). The yellow-field spectral sensitivity function appears in Figure 15 and is a weighted sum for four cone types. Two other cone types have been excluded: P567 plus "A" oil drop for unstated reasons and the "clear" drop-containing cone due to its unknown pigment. Despite these

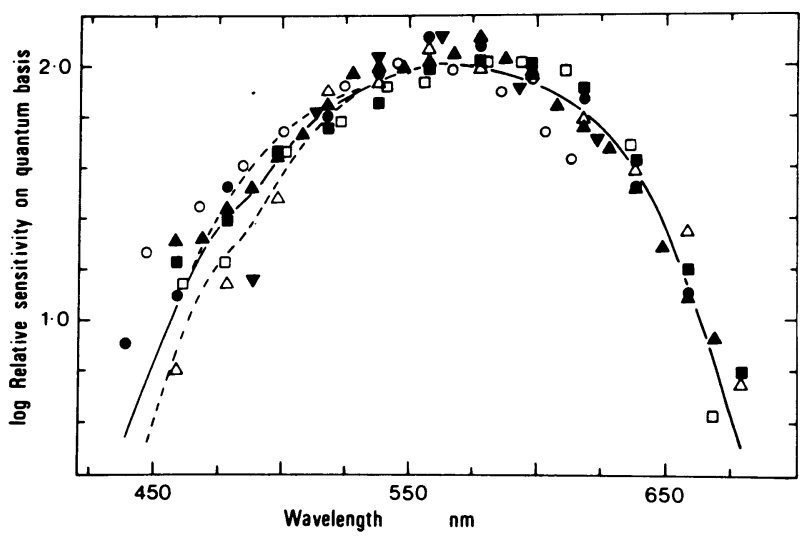

Figure 15. Photopic sensitivity of the pigeon. - , spectral sensitivity for the yellow sector of the retina derived from the absorbance of the red-, $\mathbf{C}-$, B-, and $\mathbf{A}_{\mathrm{g}}$-type cones (Figure 11) summed in the ratio 1.2:1.2:5.1:1.0, respectively (Table 7).----, effect of using the different transmission characteristics of the B-type drops in the yellow sector. Symbols are experimentally determined photopic sensitivities: closed square, from Granit (1942); open square, from Donner (1953); closed circle, from D. S. Blough (1957); open circle, from Ikeda (1965); closed triangle, from Graf (1969); open triangle, from P. M. Blough et al. (1972); closed inverted triangle, from King-Smith quoted by Muntz (1972). The experimental data have been displaced in the vertical axis to obtain the greatest coincidence on the two limbs of the curve. (From Bowmaker, 1977.) 
omissions, this composite sensitivity function agrees closely with much of the previous data on spectral sensitivity, provided one allows for some differences at the shorter wavelengths due to the demonstrated variability in the absorptive properties of the " $\mathrm{B}$ " oil drop. The red-field spectral sensitivity function appears in Figure 16. The solid-line function is derived from three cone types and matches the sensitivity function for single tectal units. The addition of a fourth cone type furnishes a function consistent with spectral sensitivity as measured behaviorally under conditions which favor reliance on the red field. Again, the same two cone types have been omitted from the model.

While these two models represent a significant advance in our understanding of the basis of spectral sensitivity in the pigeon, several questions remain. The pigment contained by the cones with "clear" oil drops is still quite uncertain. It is possible that this pigment could have an absorbance spectrum located at very short wavelengths. Evidence for such a pigment exists (Govardovskil \& Zueva, 1977; Graf \& Norren, 1974; Norren, 1975). This combination of a pigment sensitive to short wavelengths and a clear oil drop would account for the pigeon's sensitivity to very short wavelengths (D. S. Blough, 1957; Wright, 1972a; Yager \& Romeskie, 1975).

Another concern about the present version of these models is the omission of several cone types in the formulation of these composite sensitivity curves. For example, a contribution by the accessory element of the double cone (no oil drop) has apparently been

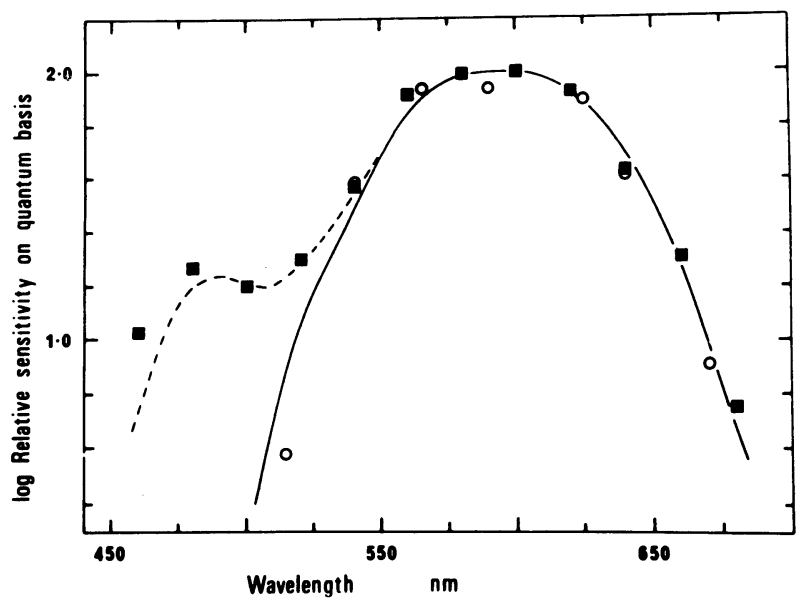

Figure 16. Photopic sensitivity of the red sector of the pigeon retina. - $\longrightarrow$, spectral sensitivity for the red sector derived from the absorptance of the red-, $\mathrm{C}$-, and B-type cones (Figure 10) summed in the ratio 2.3:2.7:3.0, respectively (Table 7).--.-, the effect of the addition of the A + P461-type cones with a weight of 1.0. $\square$, data from Romeskie and Yager (1976). $O$, tectal units measured by King-Smith quoted by Muntz (1972). (From Bowmaker, 1977.) overlooked. Two other cone types were also excluded (see above). For the cones that were included in these models, the weighting functions employed may not be completely accurate. More complete data on the distribution of the various oil drops across the retina are needed. In spite of these "loose ends," Bowmaker's models agree remarkably well with the behavioral and electrophysiological data from other studies.

\section{Hue Discrimination}

\section{Color Vision}

Even though an organism may possess multiple spectral mechanisms, it cannot be inferred to have color vision unless it can actually be shown to distinguish stimuli on the basis of their wavelength content. One of the earliest studies of the pigeon's ability to differentiate, as opposed to merely detect, monochromatic stimuli was conducted by Hamilton and Coleman (1933). Wavelength, intensity, and colorimetric purity were varied independently, and a modified Lashley jumping stand was used to elicit differences in behavior associated with different stimulus conditions. The hue-discrimination function, which ranged from 475 to $700 \mathrm{~nm}$, exhibited two minima, suggesting trichromatic vision within this spectral region.

The converse approach to examining the extent to which the wavelength continuum can be differentiated is to measure the extent to which generalization occurs. A pigeon trained to peck for food in the presence of a specific wavelength typically will also peck when other wavelengths, in the same region of the spectrum, are presented (Guttman \& Kalish, 1956).

Generalization gradients were obtained in this manner by P. M. Blough (1972) for monochromatic stimuli equated approximately for luminance according to the data of D. S. Blough (1957). These generalization functions differed as a function of training wavelength regarding slope and symmetry, presumably reflecting spectral variation in hue discriminability. For example, the gradient obtained from birds originally trained with $600 \mathrm{~nm}$ is narrow and symmetric, indicating that slightly shorter and slightly longer wavelengths are highly and equally distinctive. In contrast, the gradient for $510 \mathrm{~nm}$ is asymmetric, with a gradual slope for the shorter-wavelength side and a much steeper slope for the longer-wavelength side, suggesting finer discriminability in the latter case. Based on an arbitrary relative response probability criterion (50\%), a hue-discrimination function was derived from the generalization data and appears in Figure 17 (solid-line function). The two minima (at 600 and $535 \mathrm{~nm}$ ), occurring in spectral regions where sensitivity to wavelength differences is highest, are indicative of trichromatic vision within the spectral range examined $(510-645 \mathrm{~nm})$. 


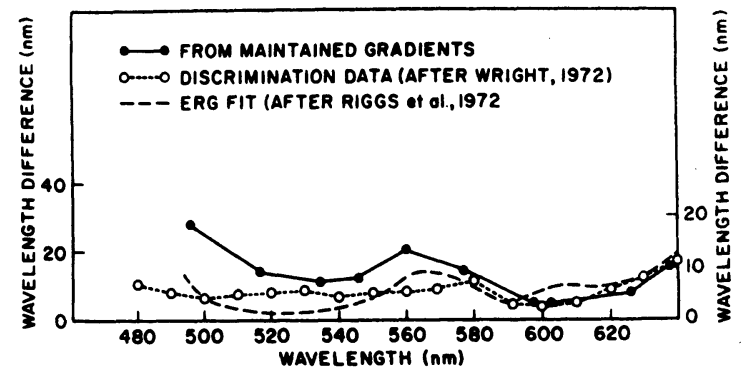

Figure 17. Comparison of three "wavelength discrimination" functions obtained with different methods. P. M. Blough data (maintained gradients) are scaled on left ordinate; Wright data are scaled on right. ERG data have arbitrary scales and are adjusted to facilitate comparison. (From P. M. Blough, 1972.)

Electroretinographic responses to changes in wavelength have been elicited with a vertical grating subtending $40^{\circ}$ in the lateral visual field (Riggs, Blough, \& Schafer, 1972). Two interdigitated sets of bars were exchanged repetitively (counterphase alternation), such that adjacent bars were alternately illuminated with each of two wavelengths equated for luminance based on the previous data of P. M. Blough et al. (1972). Largest amplitudes were observed when a short wavelength (below $525 \mathrm{~nm}$ ) was alternated with a long wavelength (above $585 \mathrm{~nm}$ ). Within the spectral range from 495 to $600 \mathrm{~nm}$, reciprocal relative response magnitudes for a fixed-wavelength difference $(15 \mathrm{~nm})$ were plotted so as to be comparable with two psychophysical wavelength discrimination functions, as seen in Figure 17. Minima, reflecting high responsivity, are seen near 525, 590, and $615 \mathrm{~nm}$, indicating tetrachromacy within this spectral region (495-660 nm).

Signal detection theory has also been used to investigate wavelength discrimination (Wright, 1972b). Either identical or disparate monochromatic stimuli were projected onto a bipartite field. A two-alternative forced-choice procedure revealed nearly linear relationships between $d^{\prime}$ (an index of discriminability) and wave number (reciprocal wavelength) difference. The slopes of the fitted regression lines correspond to the detectability of wavelength differences in each region of the spectrum. Based on equal-detectability criteria $\left(\mathrm{d}^{\prime}=2.0\right)$, threshold wavelength differences vs. wavelength are seen in Figure 17. Minima occur at $600 \mathrm{~nm}$ and, to a much smaller extent, at 540-550 and $500 \mathrm{~nm}$, suggesting tetrachromacy within this spectral range $(470-660 \mathrm{~nm})$.

As Wright points out, two of the observed minima (545 and $600 \mathrm{~nm}$ ) are consistent with crossover points (denoting color boundaries) found in behavioral color-naming functions (Wright \& Cumming, 1971; discussed below). Also, previously reported generalization gradients (D. S. Blough, 1961; Guttman \& Kalish, 1956) had steeper slopes near the presently reported minima. Wright also reviewed some relevent electrophysiological data. The action spectra of some ganglion cells have been found to peak at $540-550 \mathrm{~nm}$, and/or 590-610 nm and sometimes have had a small elevation at $500 \mathrm{~nm}$, although this may have been due to rod activity (Donner, 1953). Several units in nucleus rotundus have exhibited bimodal spectral sensitivity functions peaking at 540 and $600 \mathrm{~nm}$ (Granda \& Yazulla, 1971). For some opponent-color units in nucleus rotundus, the wavelength most effective in decreasing the rate of discharge was $590 \mathrm{~nm}$, that most effective in increasing the rate of discharge was $430 \mathrm{~nm}$, and the cross-over wavelength (discharge unaffected) was $515 \mathrm{~nm}$; for some other units, these wavelengths were 440, 540, and $490 \mathrm{~nm}$, respectively (Yazulla \& Granda, 1973).

Although some measure of agreement exists among these electrophysiological and psychophysical results, a considerable amount of variability is also evident, e.g., regarding the actual shape of the hue discrimination function (see Figure 17). It is unclear whether these discrepancies are due to poor resolution by the techniques employed, or to the unusually complex nature of hue discrimination in what may be a hexachromatic system.

One issue that has not been addressed in these studies of hue discrimination is the possible influence of oil drops. Walls and Judd (1933) have suggested that the oil drops may selectively enhance chromatic contrast for a given part of the spectrum. Such an effect would not be surprising in view of the apparent differences in spectral sensitivity for the red vs. yellow field. In the three psychophysical studies available (P. M. Blough, 1972; Schneider, 1972, discussed below; Wright, 1972b), test stimuli were primarily viewed by the red field and best hue discrimination occurred near $600 \mathrm{~nm}$. In contrast, the one electroretinographic study which employed the yellow field (Riggs et al., 1972) found maximum sensitivity to wavelength differences near $525 \mathrm{~nm}$. An investigation of this possibility of a red vs. yellow field dichotomy regarding hue discrimination is needed and should explicitly restrict viewing to the red or yellow field.

\section{Perceptual Color Space}

A two-dimensional color space has been constructed for the pigeon in order to graphically describe its perception of hue differences throughout the spectrum (Schneider, 1972). On each trial, a bipartite field was projected onto a response key. Each of the two hemifields was illuminated with 1 of 15 monochromatic stimuli so that all possible pairs occurred. After executing an observing response, the pigeon then pecked one of two side keys to indicate "match" or "no match." The statistical technique of multidimensional scaling was then used to generate the function, seen in Figure 18, in which the distance between any two loci is proportional to the distinguishability of the corresponding wavelengths. 


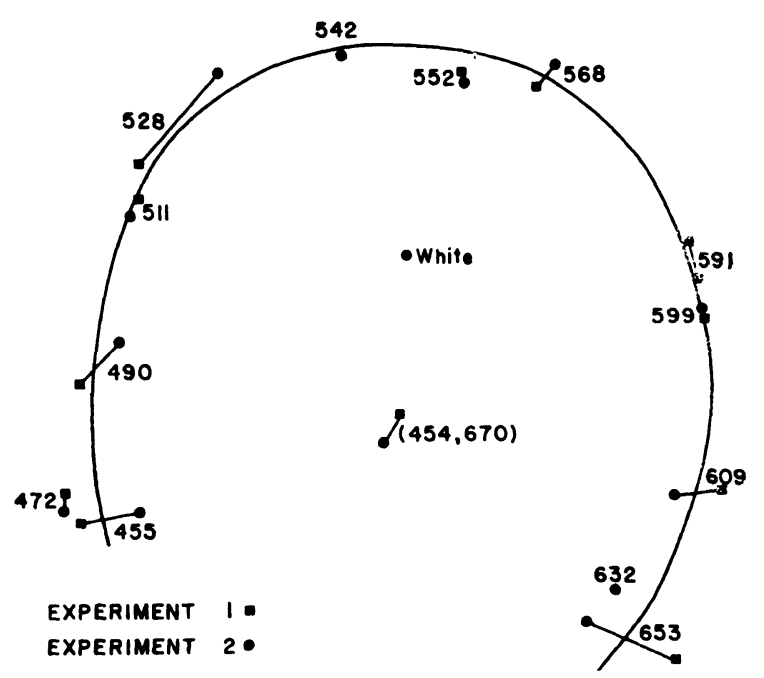

Figure 18. A two-dimensional color space for the pigeon. The distance between any two wavelengths corresponds to their distinguishability. (From Schneider, 1972.)

This horseshoe-shaped funtion shows that hues are more easily distinguished when a midspectral wavelength is compared with either an extremely short or long wavelength than when wavelengths from both the spectral extremes are compared. On this basis, the author suggests that there is a "perceptual similarity" between these long and short wavelengths (see, also, Wright \& Cumming, 1971). However, pigeons do distinguish between these spectral regions when tested behaviorally (Muntz, 1972). In addition, electroretinographic evidence indicates maximal discriminability for a comparison between wavelengths from both the spectral extremes (Riggs et al., 1972). In any case, this color space is consistent with the hue-discrimination data of Wright (1972b) in that regions near 600,540 , and $500 \mathrm{~nm}$ are noticeably expanded. The spectral point least dissimilar to "white" (color temperature $=3,000^{\circ} \mathrm{K}$ ), $552 \mathrm{~nm}$, presumably appears relatively desaturated, as does the nonspectral "purple" (454 nm mixed with $670 \mathrm{~nm})$.

\section{Rayleigh Matching}

In humans, a Rayleigh match exists when a mixture of red and green monochromatic light cannot be distinguished from a monochromatic yellow due to the equal quantum catch in each case by the cone pigments involved. A generalization paradigm has been used to obtain a Rayleigh match for the pigeon (J. Cohen, 1967). Trained initially to peck at a mixture of 567 and $640 \mathrm{~nm}$, subjects were later tested for generalization with various monochromatic stimuli, ranging from 547 to $660 \mathrm{~nm}$. As one might expect, based on human data, a gradient centered at an intermediate wavelength (approximately $603 \mathrm{~nm}$ ) was obtained. However, additional peaks, although considerably smaller, were observed at the training wavelengths. The author interprets these results as evidence that the pigeon's visual system is not only capable of "synthesizing" the compound 567/640-nm stimulus indicated by the main $603-\mathrm{nm}$ peak, but also of "analyzing" the mixture into its components, as indicated by the secondary peaks at the training wavelengths. If verified by further research, this purported analytic capacity would represent a very basic difference in the color vision of pigeons as compared to that of humans, requiring a much more complex neural organization. One possible experimental flaw which could account for the unexpected peaks at the training wavelengths would be the failure to have achieved a uniform mixture. Although "hot spots" (i.e., localized areas of $567 \mathrm{~nm}$ alone or $640 \mathrm{~nm}$ alone) were not detectable to human observers, a careful reexamination of this tentative finding seems warranted in view of its importance.

\section{Color-Naming}

A matching-to-sample paradigm has been used to delineate the spectral regions perceived by the pigeon as distinct colors (Wright \& Cumming, 1971). Originally, the birds were trained to peck an observing key when illuminated with monochromatic light $(512,572$, or $655 \mathrm{~nm})$ and then to peck the side key illuminated with light of the same wavelength. During testing, novel "probe wavelengths" appeared on the observing key and the relative proportion of side-key pecks to each of the three training wavelengths was measured. The general pattern of this "color naming," as seen in the lower panel of Figure 19, partitions the spectrum into a region below $540 \mathrm{~nm}$, a region between 540 and $595 \mathrm{~nm}$, and a region above $595 \mathrm{~nm}$, reflecting the frequencies with which the short-, middle-; and long-wavelength training stimuli were chosen.

The two "crossover wavelengths," 540 and $595 \mathrm{~nm}$, at which the color-naming functions intersect, were shown to be consistent despite changes in the wavelengths of the three training stimuli $(473,555$, and $633 \mathrm{~nm}$ were also used: dashed functions). However, when these crossover wavelengths themselves were employed as two of the three color names available, acquisition of matching-to-sample behavior was prolonged and the color-naming data were quite variable and disorderly. While the hues associated with 540 and $595 \mathrm{~nm}$ border disparate spectral colors, it is not surprising that they prove ambiguous as color names.

Wright and Cumming make an interesting comparison between the present data and Donner's spectral sensitivity measurements for isolated ganglion cells, as seen in Figure 19 (top). Instead of the expected coincidence between sensitivity peaks and color-naming peaks, the former appear to coincide with the cross- 

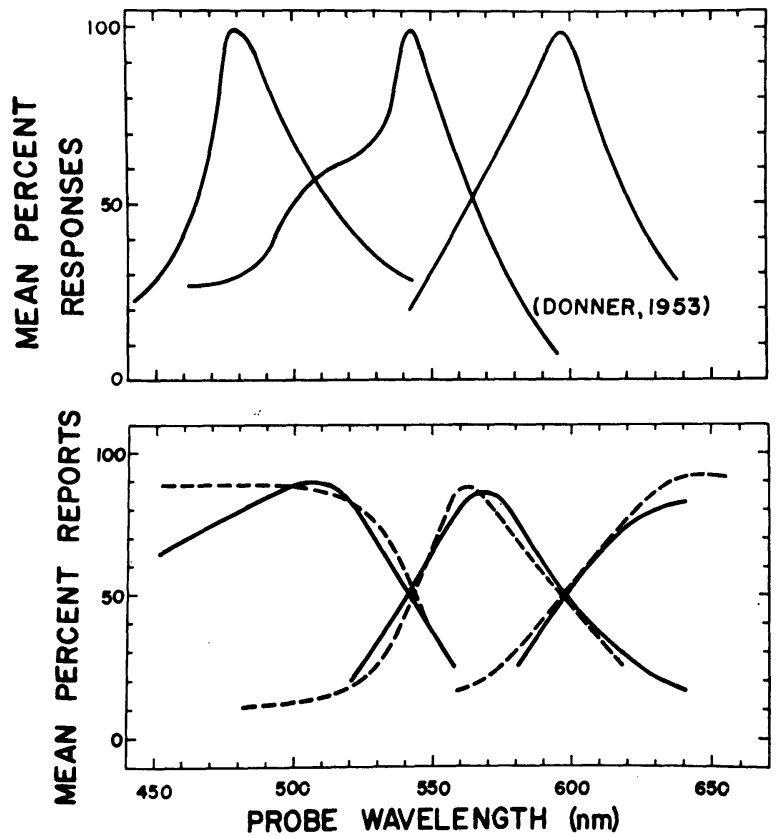

Figure 19. Response curves for ganglion cells of the pigeon retina (upper panel) and mean color-naming curves (lower panel). For the latter, the solid and the dashed functions were obtained with two different sets of training wavelengths: 512,572 , and $655 \mathrm{~nm}$, and 473,555 , and $633 \mathrm{~nm}$, respectively. (From Wright \& Cumming, 1971.)

over wavelengths of the color-naming functions. The apparent correspondence between the maxima of the color-naming functions and the intersections of the sensitivity spectra is questionable in that the latter have all been arbitrarily normalized to the same $100 \%$ value.

Another unexpected outcome mentioned by Wright and Cumming is that, for sample wavelengths from the long (above $630 \mathrm{~nm}$ ) or short (below $500 \mathrm{~nm}$ ) end of the spectrum, the matching color name chosen was often from the opposite spectral extreme, suggesting a resemblance between long and short wavelengths (see also Schneider, 1972). While some evidence exists against such a resemblance (see above), further study of this possibility is needed. For example, what would have happened in Wright and Cumming's experiment if the pigeons had had a shorter wavelength (e.g., $400 \mathrm{~nm}$ ) available as a color name?

\section{Saturation}

A colored stimulus is perceived not just in terms of its hue and brightness, but also in terms of its saturation, i.e., the apparent "purity" of its color. In order to study saturation in the pigeon, P. M. Blough (1975) used both generalization and discrimination procedures in which "white" (color temperature $=3,050^{\circ} \mathrm{K}$ ) served as the training stimulus and $\mathrm{S}+$, respectively. In comparison with this long- wavelength rich "white," the shortest wavelengths (below $525 \mathrm{~nm}$ ) were perceived as the most saturated, while wavelengths between 575 and $600 \mathrm{~nm}$ appeared least saturated.

At absolute photopic threshold, a monochromatic stimulus, although detected by cones, may appear colorless. The additional intensity required before its color is perceived has been designated the "achromatic interval." Light-adapted pigeons have been tested with a two-alternative forced-choice procedure in which the birds had to distinguish between an achromatic and a monochromatic stimulus of equal luminance (Romeskie \& Yager, 1976b). Spectral sensitivity functions based on both these chromatic thresholds and on achromatic thresholds (Romeskie \& Yager, 1976a) were then compared so as to derive the achromatic interval, as in Figure 20. (The authors refer to the difference between the two functions as the "photochromatic interval," a term which usually refers to the difference between photopic and scotopic spectral sensitivity.) Generally, the magnitude of this interval is greatest for the spectral region which exhibits the least saturation, as is the case for human vision.

\section{Hue Shifts}

For human vision, hue, saturation, and brightness are not independent, but interactive, as evidenced by the Bezold-Brücke hue shift in which, for a fixed wavelength, hue varies as a function of intensity. Such a hue shift has recently been demonstrated in
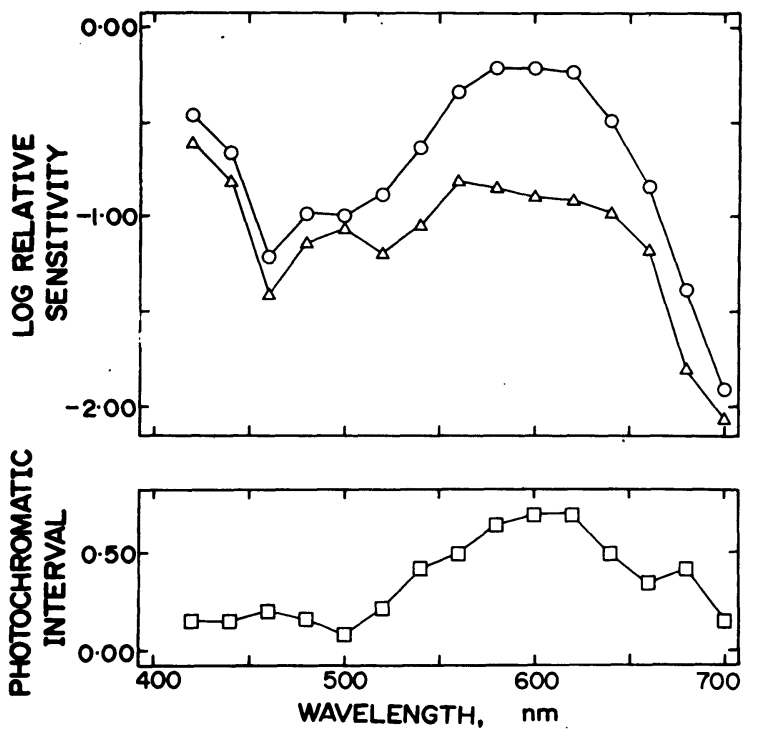

Figure 20. (Top) Circles, achromatic spectral sensitivity function; triangle, chromatic spectral sensitivity function. Both curves mean of two pigeons. (Bottom) Spectral photochromatic interval function (the difference between the two functions above). (From Romeskie \& Yager, 1976b.) 
the pigeon (Wright, 1976). Birds were trained extensively in a hue-discrimination task in which the two halves of a bipartite field were illuminated by either identical or different wavelengths (matched regarding luminance). Infrequently (on $2 \%$ of trials), the luminance of one hemifield was altered ( $\pm .3 \log$ unit), so that the bipartite field was nonuniform both for wavelength and luminance. The resulting performance (presumably based on hue and not brightness) was then used to estimate the comparison wavelength which, hypothetically, would have yielded the same level of accuracy as observed for the actual comparison wavelength (accompanied by the luminance increment/decrement). At low intensities, functions relating these hypothetical wavelengths to intensity tend to converge at 530 and $630 \mathrm{~nm}$. At high intensities, the midspectral functions converge toward $550 \mathrm{~nm}$, whereas the functions at the spectral extremes diverge. Invariant points, i.e., wavelengths for which hue is independent of intensity, are located at $530,550,600$, and $630 \mathrm{~nm}$. Of course, one cannot rule out the possibility of a fifth invariant point at some shorter wavelength.

Wright points out several interesting parallels between these data and previous studies (see above). Two of the invariant points (540 and $600 \mathrm{~nm}$ ) correspond to minima in the pigeon's hue-discrimination function and, approximately, to crossover wavelengths in its color-naming functions. Also, one invariant point, $600 \mathrm{~nm}$, is approximately the wavelength for which the achromatic interval is maximal and is near the wavelength of least saturation. These coincidences are not fortuitous, Wright argues, but reflect the interdependence of hue, saturation, and brightness. A fuller understanding of the relationships among these dimensions, however, will have to await more detailed information about the neural organization of opponent-process mechanisms which subserve hue discrimination. For example, based on a small sample of opponent units in nucleus rotundus, the crossover wavelengths of response spectra were observed to shift as much as $10-20 \mathrm{~nm}$ toward longer wavelengths as intensity was increased (Yazulla \& Granda, 1973). Such shifts might represent a physiological correlate of hue-brightness interaction.

\section{Afterimages}

One phenomenon usually attributed to the opponent nature of color coding in the visual system is that of complementary afterimages. Pigeons were taught to peck a white key on a multiple schedule in which "green" (these color names refer to the hue perceived by a human observer and should not imply a similar appearance to the pigeon; emission spectra for these wide-band chromatic stimuli were not reported) houselight signaled an opportunity to earn grain (Williams, 1974). "Red," "yellow," or “white” houselight signaled a period of extinction. Two levels of intensity were employed for each color of houselight. Color of houselight was changed every $30 \mathrm{sec}$ with the restriction, during training, that white never followed red. In the test phase, this restriction was lifted, with the result that much responding occurred during white when it had been preceded by red, although not quite as much as when the green houselight $(\mathrm{S}+)$ itself was presented. That this enhancement of responding during white-following-red was due to a ("green") complementary afterimage is strongly supported by the fact that almost all responses were confined to the first 5 to $10 \mathrm{sec}$ of the 30 -sec white light. This could be readily explained by the fading of the afterimage. One possible physiological correlate of such an afterimage has been suggested by Yazulla and Granda (1973). Several opponent units, which they isolated in nucleus rotundus, displayed a delayed afterdischarge following a brief short-wavelength stimulus; these same units exhibited an increased discharge rate during long-wavelength stimulation. Thus, such units could mediate a color aftereffect.

\section{Limiting Factors}

\section{Visual Acuity}

The ability of a visual system to resolve fine spatial details is limited by many factors. The size of the eye, often designated by its posterior nodal distance, will determine how large a retinal image is formed. This image will be more or less degraded depending on the optical quality of the eye. In addition, eye movements could "blur" the image by rapidly shifting it with respect to the retina. The density of the retinal mosaic, denoted by the interreceptor distance, limits the resolution of the image by averaging the light within, at least, the cross-sectional area of each receptor. Furthermore, the density of the ganglion cell mosaic and the associated size distribution of receptor field centers reflect the degree of convergence from receptor to ganglion cells with its concomitant loss in spatial information. Additional losses due to processing at "higher" visual centers would be expected. Several of the most important factors mentioned above appear in Table 8 with estimates for both pigeon and man.

\section{Far-Field Acuity and the Near Point of Accommodation}

Early studies of acuity typically involved a discrimination between horizontal vs. vertical gratings in which the measured response was movement toward the "correct" stimulus. Estimates of minimum separable visual angle differed considerably: $.5 \mathrm{~min}$ (Gundlach, 1933) vs. 2.9 min (Hamilton \& Goldstein, 1933) vs. 3.3 min (Chard, 1939). The near point of accommodation (the minimum distance for which 
Table 8

Some Factors Which Limit Acuity in the Pigeon and in the Human

\begin{tabular}{lll}
\hline & \multicolumn{1}{c}{ Pigeon } & \multicolumn{1}{c}{ Human } \\
\hline Retinal distance per minute of visual angle (microns) & 2.38 & 4.9 \\
Posterior nodal distance $(\mathrm{mm})$ & 8 (Marshall et al., 1973) & 16.8 (Le Grand, 1968) \\
Minimum intercone distance (microns) & $3.67 *$ (Nye, 1968a) & 2.5 (Polyak, 1957) \\
Visual angle subtended by a single cone (min) & 1.54 & .51 \\
Maximum ganglion cell density (per mm $\left.{ }^{2}\right)$ & $15.75 \times 10^{3 * *}$ & $147 \times 10^{3}($ Polyak, 1957) \\
Visual angle subtended by a single ganglion cell (min) & 3.36 & .53 \\
\hline
\end{tabular}

*This estimate has been corrected for shrinkage (about 10\%) associated with histological preparation. **Calculated from data in Binggeli and Paule (1969). Peak cell density (for all types of cells) for the ganglion cell layer occurs at the fovea and is $31.5 \times 10^{3} / \mathrm{mm}^{2}$ (in vivo). For the entire retina, about half the cells in the ganglion cell layer are actually ganglion cells. Thus, a rough approximation of peak ganglion cell density is $(.5)\left(31.5 \times 10^{3} / \mathrm{mm}^{2}\right)$.

acuity no longer improves with a further increase in viewing distance) was roughly estimated to be between 30 and $40 \mathrm{~cm}$, presumably for lateral (monocular and foveal) vision, although viewing orientation was unrestricted in these studies. Due to serious methodological shortcomings (psychophysical procedures which often yielded unreliable data, grating stimuli calibrated neither for contrast nor overall luminance, small and sometimes selected samples of data), these early results should be viewed with caution.

\section{Acuity and Viewing Distance}

The effect of viewing distance on visual acuity has been examined with a discrete-trial, two-alternative, forced-choice procedure (P. M. Blough, 1971, 1973). At each end of a two-alley runway of variable length $(13,26,53$, or $73 \mathrm{~cm})$, a response key was located, through which a very small (angular subtense = $12 \mathrm{~min}$ ) grating pattern or a uniform field was observed. Testing was done both with free-viewing and with vision restricted by goggles to the frontal field. Acuity was generally worse with the goggles, especially at longer distances. The marked intersubject differences among the acuity vs. distance functions preclude any estimate regarding the near point of accommodation. However, it does appear that, with the frontal goggles, there is little or no improvement in acuity with distances, suggesting that the "frontal near point" may already be exceeded at a viewing distance of $13 \mathrm{~cm}$. For the far-field, freeviewing condition, spatial frequency thresholds ranged from .357 to .125 cycles/min, corresponding to minimum separable angles of 1.4 to $4.0 \mathrm{~min}$ of arc. Additional testing at short viewing distances but with an enlarged stimulus field $\left(8^{\circ}\right)$ indicated that acuity improved with an increase in target size. This would account for the high degree of resolution reported by Nye (1968; see below).

\section{Role of the Fovea in Acuity}

Acuity has been measured before and after lesions of the central retina in order to assess the importance of the fovea (P. M. Blough, 1973). The only sub- stantial postlesion decrement in acuity occurred for a lesion midway between the fovea and the dorsotemporal edge of the optic disk. Based on these primarily negative findings, P. M. Blough concluded that the fovea of the pigeon is nonessential for static acuity.

\section{Near-Field Spatial Sensitivity}

Near-field binocular spatial modulation sensitivity has been measured with a sinusoidal grating subtending $58^{\circ}$ (Nye, 1968). A discrete-trial, twoalternative, forced-choice procedure was utilized. Spatial frequency and amplitude of modulation (contrast) were varied. Spatial modulation transfer functions (MTFs), based on two different threshold criteria (statistically defined), appear in Figure 21.

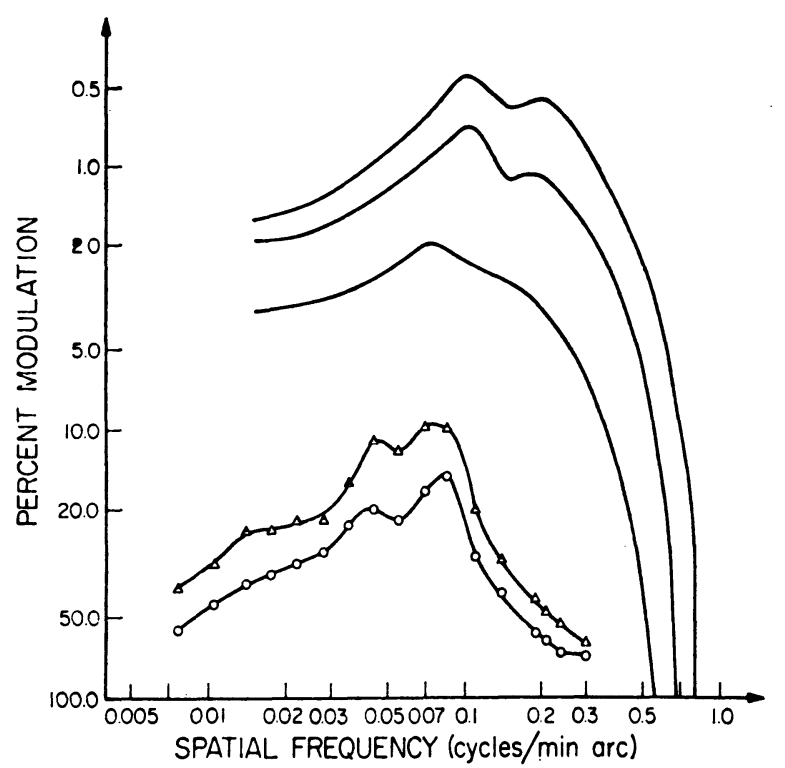

Figure 21. The average MTF data for six pigeons is shown with data points. Open circles indicate modulation levels for criterion $p=.01$. Triangular points give modulation levels for criterion $p=.05$. Pigeon retinal illuminance was $150 \mathrm{Td}$. Curves without data points show MTFs for a human observer replotted from Patel (1966). Retinal illumination levels are from top: $1,000,100$, and 10 Td. (From Nye, 1968.) 
Peak sensitivity coincides with a frequency of about .07 cycles/min, which corresponds to a visual angle of $7 \mathrm{~min}$. Due to the negatively accelerated slope of these MTFs at high frequencies, it is difficult to specify an upper limit of spatial resolution for the pigeon. A conservative estimate might be .33 cycles/ min, which corresponds to a minimum separable angle of $1.5 \mathrm{~min}$. As with two of the human functions, the pigeon's sensitivity functions are doublepeaked, due to a dip between .02 and .06 cycles $/ \mathrm{min}$. Nye suggests that this dip may be due to involuntary eye movements. Nye also argues that the response to spatial contrast may be nonlinear, in that functions relating probability of better-than-chance responding to modulation amplitude were steeper for intermediate than for either the lowest or highest spatial frequencies. However, these slope differences may be merely an artifact due to the use of a natural rather than a logarithmic scale to describe the various modulation values. At the extreme frequencies where sensitivity is lowest, modulation thresholds are high, and seemingly large increments or decrements in percent modulation would, in fact, represent moderately small changes in log modulation.

One difficulty with the study of near-field acuity in an unrestrained animal is how to specify the size of the stimuli. Hodos et al. (1976) used high-speed cinematography to estimate the viewing distance of pigeons. The angular subtense $\left(14^{\circ}\right)$ and spatial frequency of their diagonal high-contrast gratings were then calculable in the usual manner (see appendix). These authors also make the interesting observation that the pigeon gradually closes its eyes when executing a keypeck. At the time of beak-key contact, its eyes are usually fully closed. For the acuity measurements, grating luminance was varied over a 3-log-unit range while the ambient light level was held constant. As seen in Figure 22, visual acuity improved with increasing luminance of the gratings over a 2.5-log-unit range, but deteriorated somewhat at a slightly higher luminance. Acuity at intermediate luminances agrees fairly closely with previously reported thresholds under far-field viewing conditions. Optimum resolution involved the detection of an angle of $1.92 \mathrm{~min}$, suggesting poorer acuity than that estimated by Nye (1968), who, however, employed a significantly larger $\left(58^{\circ}\right)$ grating pattern. In the present study, the resolution limits for two human subjects (for viewing distances of 360 or $497 \mathrm{~mm}$ ) were .32 and $.41 \mathrm{~min}$.

\section{Movement Sensitivity}

The ability to detect a change in the relative position of certain features of the environment depends on the velocity and direction of displacement, the contrast between moving and stationary features, and the size (or spatial frequency) of the moving stimuli.

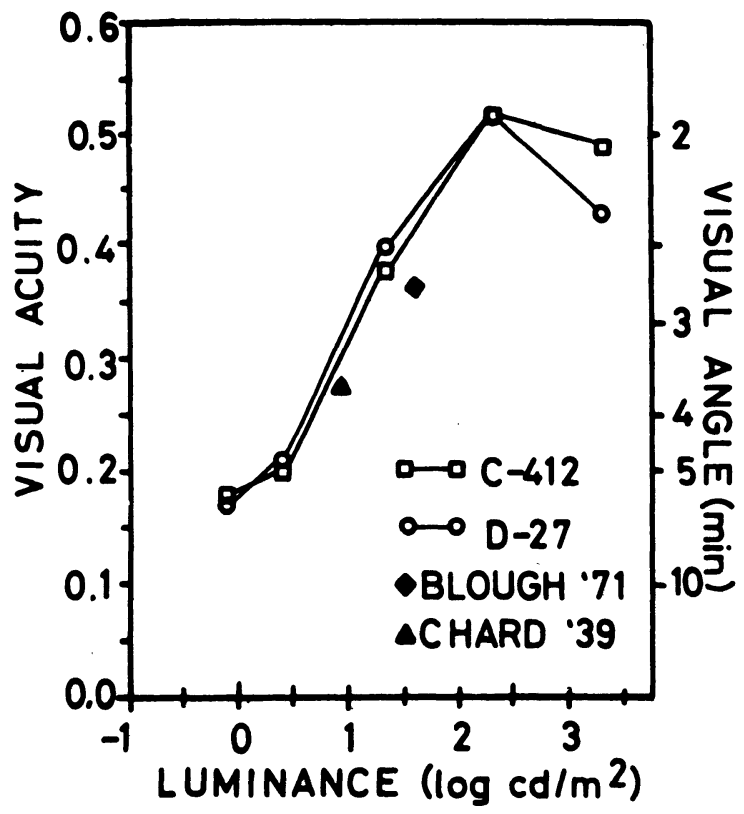

Figure 22. Visual acuity (1/visual angle) plotted as a function of stimulus luminance for each subject. Also shown are estimates from the literature of far-field visual acuity at specified luminances (P. M. Blough, 1971; Chard, 1939). (From Hodos et al., 1976.)

The sensitivity of the pigeon to both apparent and real movement has been examined (Siegel, 1970, 1971). Birds were initially trained to discriminate between the presence and the absence of movement and then tested for generalization at various speeds. For extremely high or low rates of motion, responding was similar, presumably indicating a failure to perceive movement. Conversely, for intermediate speeds, responding was similar, indicating movement detection. Whether motion was apparent or real made little difference. In a control condition, testing with an alternating bar pattern (adjacent bars modulated sinusoidally in counterphase) yielded little or no generalization, indicating that stimulus control of the bird's behavior was not based merely on "flicker" or local changes in luminance of the grating pattern. Additionally, when the motion-producing gratings were defocused, subjects still responded to either real or apparent movement, again indicating the unimportance of any line or pattern cues per se.

Minimum velocity thresholds for movement detection have been measured in two ways (Hodos, Smith, \& Bonbright, 1976). High-contrast line patterns of low spatial frequency were used to achieve rotary motion of radial stripes or linear motion of horizontal stripes. Mean minimum detectable velocities were $5.64^{\circ}$ and $4.39^{\circ} / \mathrm{sec}$, respectively. As the authors point out, these velocity thresholds are much higher than those estimated for human subjects, which, under optimal conditions, are on the order of several minutes of visual angle per second. In addition, acquisition by the pigeons of an operant dis- 
crimination based on the presence or absence of movement was prolonged and performance was highly erratic.

In view of the importance of movement to the survival of the pigeon, e.g., for flight and for predator avoidance, a highly developed motion sensitivity would seem essential. Indeed, much of the electrophysiological literature reviewed above suggests a pervasive influence of movement on response properties throughout the visual system (Frost \& DiFranco, 1976; Holden, 1969; Kimberly et al., 1971; Maturana \& Frenk, 1963; Revzin, 1967, 1970). Perhaps the "poor" performance of the pigeon in the experiment above is indicative not of an insensitivity to movement but rather of the inappropriateness of the minimum velocity threshold as an index of such sensitivity. Under different conditions, e.g., with higher velocities and/or targets of higher spatial frequency viewed in the lateral visual field, movement may be more readily detected. Single-unit recordings in optic tectum suggest an operating range for movementsensitive cells of $5^{\circ}-300^{\circ} / \mathrm{sec}$. A more informative approach to the study of movement sensitivity might be to select representative velocities from within this range and then measure dynamic contrast sensitivity as a function of spatial frequency. In this way, the relative contribution of each of these major parameters to the detectability of motion may be ascertained.

\section{Detection of Polarized Light}

One of several current theories which attempts to account for the legendary homing ability of pigeons assumes that pigeons are able to discriminate the plane of polarization of skylight and to use this information in conjunction with a biological "clock" as a navigational compass. In an early behavioral study (Montgomery \& Heinemann, 1952), pigeons failed to acquire an operant discrimination between orthogonally polarized monochromatic (blue) stimuli. More recently, cardiac conditioning has been used to demonstrate that at least some pigeons are capable of differentiating between linearly polarized lights whose axes of polarization are either rotating or stationary (Kreithen \& Keeton, 1974). However, this finding, although interesting in its own right, does not address the question most germane to homing, i.e., can a pigeon discriminate between fields of polarized light whose axes of polarization are different but stationary? Convincing evidence of such an ability has recently been adduced.

An operant chamber "in-the-round" was arranged so that one of four response keys was located every $90^{\circ}$ around the periphery (Delius, Perchard, \& Emmerton, 1976). An overhead light source, highly diffused and subsequently linearly polarized, illuminated the chamber during each trial. One of two orthogonal axes of polarization was randomly pre- sented as the discriminative stimulus for each trial and indicated at which of the two sets of oppositely located response keys reinforcement (for pecking) was available. Several precautions were implemented in order to prevent discrimination based on extraneous cues, e.g., polarization-dependent variations in the reflection of light. For example, occasionally, an additional diffusing mask was interposed between the polarizer and the chamber. All seven pigeons tested exhibited statistically significant levels of performance within 40-360 test trials (and an unspecified number of correction trials). Also, polarization discrimination remained accurate over a 1.5-log-unit photopic intensity range, deteriorating to a chance performance level after an additional .5-log-unit reduction of luminance to $17 \mathrm{~cd} / \mathrm{m}^{2}$.

In a second experiment, averaged electroretinographic responses to flashes of linearly polarized light were obtained for several axes of polarization. Reliable differences in the shape (but not the amplitude) of the b-wave of the ERG were observed and could not be duplicated by merely changing intensity. This effect on the ERG waveform was more noticeable when the inferior retina was stimulated which is consistent with the notion of sky polarization patterns as the "natural" cue used in homing. The authors suggest that the unique structural properties of the double cone may subserve the discrimination of different orientations of polarization. In the chicken retina, double cones are arranged so that if one were to visualize arrows pointing from the chief elements to the accessory elements, these arrows would be oriented predominantly along one of two orthogonal axes and could point in either direction (Morris, 1970).

\section{DISCUSSION}

While the visual systems of man and pigeon share many similar features, it is interesting to consider in what ways they are dissimilar. For example, the processing of visual information even within the retina is organized and executed differently. The pigeon retina is more "complex" in that the opportunity for lateral interactions, especially within the inner plexiform layer, are considerably more abundant. As a consequence, some ganglion cells even exhibit directional selectivity, a property which is elaborated at a later stage in the human visual pathway. In addition, the pigeon (but not the human) possesses the centrifugal pathway, a feedback loop by which lateral interaction within the proximal retina is modulated by neural activity at later stages in the visual pathway.

Central (extraretinal) visual analysis also proceeds somewhat differently in the pigeon. Beginning with a virtually complete decussation of the optic nerves, information from each eye remains relatively segregated. While a few interhemispheric projections have 
been reported, no large-scale convergence, as in the striate cortex of the human, has been found. In view of the lateral placement of the pigeon's eyes, this degree of monocularity may seem unsurprising. However, $25^{\circ}$ of overlap exists within the pigeon visual field. Furthermore, single units which receive binocular input have been discovered in hyperstriatum. Thus, the possibility of binocular vision or even stereopsis in the anterior visual field cannot yet be discounted. Whether, in the case of the lateral visual fields, both eyes are employed independently and simultaneously remains in question.

Although it does appear that the human is capable of finer spatial discrimination (under optimal conditions) than the pigeon, it is perhaps misleading to conclude that human acuity is "superior." One major consideration should be how acuity varies with respect to the visual field. In the human, resolution is far better at the fovea than elsewhere. In contrast, the pigeon fovea seems virtually nonessential, foveal lesions yielding little or no decrement in acuity. In fact, the comparatively high degree of development across the entire pigeon retina would seem to indicate substantial acuity throughout most of the visual field. If this is the case, then acuity is not necessarily "worse" for the pigeon but, rather, less specialized for foveated features of the environment. Moreover, Lockhart (Note 2) has suggested that the pigeon fovea is, in fact, specialized, not for fine spatial discriminations (as in the human), but for movement and directional sensitivity via extensive lateral interaction within the retina. Indeed, that the entire pigeon visual system may be more attuned to motion than to fine details is suggested by the notable rarity of orientation specificity and ubiquity of movement specificity among the properties of single cells.

In view of the acute color vision derived from the relative activity of three classes of cones in the human, it is puzzling to find that the pigeon employs as many as six varieties of cones. (This does not necessarily imply that the pigeon is a hexachromat in that fewer than six monochromatic primaries may be necessary to achieve a mixture which is indistinguishable from any given color.) As in the human, the analysis of color information appears to be based on opponent processes which, perhaps, are more diverse in the pigeon, resulting in the greater number of threshold minima in its hue-discrimination function. Lockhart (Note 2) has determined that, while pigeon horizontal cells are probably too small to make intracellular recording technically feasible, those of the blue jay are not. In that opponent processes are thought to originate at the outer plexiform layer, information regarding the spectral properties of these cells would be very elucidating.

While many hues are distinguishable to the human eye, only four "psychologically unique" colors seem to exist: red, yellow, green, and blue. Assuming that the pigeon also experiences unique colors, one might ask whether they are associated with similar parts of the spectrum. Based on color-naming data, this does not appear to be the case. Two of the peaks in the pigeon data, 500 and $565 \mathrm{~nm}$, correspond roughly to blue-green and greenish-yellow, respectively, for the human. Also, one of the crossover wavelengths for the pigeon, $540 \mathrm{~nm}$, appears quite green to the human. Thus, while it may be impossible to know just what "colors" are perceived by the pigeon, they do not seem to coincide with human colors in terms of where in the spectrum they are most conspicuous.

Admittedly, this discussion has been rather onesided in that the differences between the human and pigeon visual systems have been emphasized. Additional abilities/features of the pigeon, not shared by the human, have been described in the text: the red and yellow retinal fields, UV sensitivity, detection of polarization, sensitivity to high flicker frequencies, etc. It is the opinion of this author that, while the similarities between these visual systems are even more numerous, it is these discrepancies which furnish the most insight into the visual world of the pigeon.

Appendix I

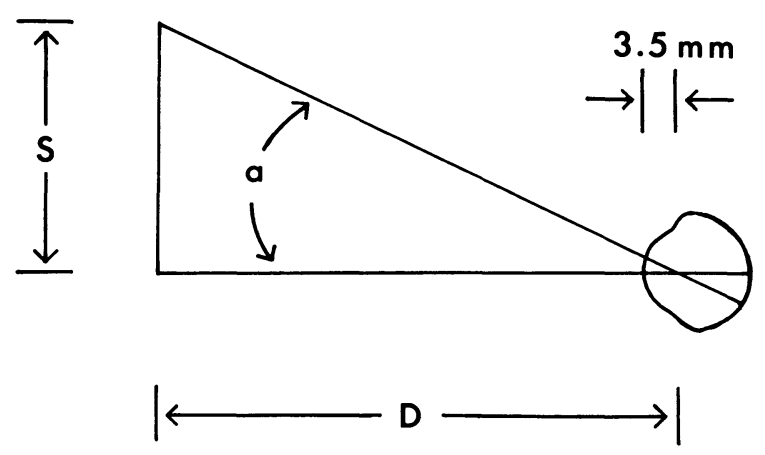

Figure 23. Calculation of the angle, a, subtended by an object in the pigeon's visual field. $S$, size of the object; $D$, distance from the object. Apply the formula: Tan a $=\mathrm{S} / \mathrm{D}$. Then refer to a table of trigonometric values to determine a. The posterior nodal point is located approximately $3.5 \mathrm{~mm}$ behind the foremost point of the cornea. For near objects, this distance should be included in $\mathbf{D}$.

\section{REFERENCE NOTES}

1. Marc, R. E. Personal communication, June 28, 1976.

2. Lockhart, M. Horizontal cells in pigeon retina. Paper presented at the annual meeting of the Association for Research in Vision and Ophthalmology, Sarasota, Florida, April 1976.

\section{REFERENCES}

Bagnoli, B., Francesconi, W., \& Magni, F. Visual Wulst influences on the optic tectum of the pigeon. Brain, Behavior \& Evolution, 1977, 14, 217-237. 
BAKER, H. D. The instantaneous threshold and early dark adaptation. Journal of the Optical Society of America, 1953, 43, 789-803.

Barlow, H. B., \& Ostwald, T. J. Pecten of the pigeon's eye as an interocular eye shade. Nature, New Biology, 1972, 236, 88-90.

Benowitz, L. I., \& Karten, H. J. Organization of the tectofugal visual pathway in the pigeon: A retrograde transport study. Journal of Comparative Neurology, 1976, 167, 503-520.

BILGE, M. Electrophysiological investigations on the pigeon's optic tectum. Quarterly Journal of Experimental Physiology, 1971, 56, 242-249.

Binggeli, R. L., \& Paule, W. J. The pigeon retina: Quantitative aspects of the optic nerve and ganglion cell layer. Journal of Comparative Neurology, 1969, 137, 1-18.

Bloch, S., \& Maturana, H. R. Oil droplet distribution and colour discrimination in the pigeon. Nature, New Biology, 1971, 234, 284-285.

Blough, D. S. Dark adaptation in the pigeon. Journal of Comparative and Physiological Psychology, 1956, 49, 425-430.

BLOUGH, D. S. Spectral sensitivity in the pigeon. Journal of the Optical Society of America, 1957, 47, 827-833.

Blough, D. S. The shape of some wavelength generalization gradients. Journal of the Experimental Analysis of Behavior, 1961, 4, 31-40.

Blough, P. M. The visual acuity of the pigeon for distant targets. Journal of the Experimental Analysis of Behavior, 1971, 15, 57-67.

Blough, P. M. Wavelength generalization and discrimination in the pigeon. Perception \& Psychophysics, 1972, 12, 342-348.

Blough, P. M. Visual acuity in the pigeon. II: Effects of target distance and retinal lesions. Journal of the Experimental Analysis of Behavior, 1973, 20, 333-343.

BLOUGH, P. M. The pigeon's perception of saturation. Journal of the Experimental Analysis of Behavior, 1975, 24, 135-148.

Blough, P. M., Riggs, L. A., \& Schafer, K. L. Photopic spectral sensitivity determined electroretinographically for the pigeon eye. Vision Research, 1972, 12, 477-485.

BoAKEs, R. A. The bisection of a brightness interval by pigeons. Journal of the Experimental Analysis of Behavior, 1969, 12, 201-209.

BowmaKer, J. K. The visual pigments, oil droplets, and spectral sensitivity of the pigeon. Vision Research, 1977, 17, 1129-1138.

BRAUTH, S. E., \& KARTEN, H. J. Direct accessory optic projections to the vestibulo-cerebellum. A possible channel for oculomotor control systems. Experimental Brain Research, 1977, 28, 73-84.

BRIDGES, C. D. B. Visual pigments of the pigeon (Columba livia). Vision Research, 1962, 2, 125-137.

Brown, K. T. The electroretinogram: Its components and their origins. Vision Research, 1968, 8, 633-677.

CAmpbell, H. S., \& SMITH, J. L. The pharmacology of the pigeon pupil. Archives of Ophthalmology, 1962, 67, 501-504.

CATANia, A. C. On the visual acuity of the pigeon. Journal of the Experimental Analysis of Behavior, 1964, 7, 361-366.

CHARD, R. Visual acuity in the pigeon. Journal of Experimental Psychology, 1929, 24, 588-608.

ChaRd, R. D., \& Gundlach, R. H. The structure of the eye of the homing pigeon. Journal of Comparative Psychology, 1938, 25, 249-272.

Clarke, P. G. H., \& Whitteridge, D. The projection of the retina, including the 'red area,' on to the optic tectum of the pigeon. Quarterly Journal of Experimental Physiology, 1976, 61, 351-358.

Cohen, A. I. The fine structure of the visual receptors of the pigeon. Experimental Eye Research, 1963, 2, 88-97.

CoHEN, D. H. Visual intensity discrimination in pigeons following unilateral and bilateral tectal lesions. Journal of Comparative and Physiological Psychology, 1967, 63, 172-174.

CoHen, J. The synthetic-analytic character of color vision in the pigeon. Psychonomic Science, 1967, 9, 429-430.

Corballis. M. C., \& Luthe, L. Perception of lateral movement by monocularly viewing pigeons. Perception \& Psychophysics, 1973,
14, $41-44$

Cowan, W. M., Adamson, L., \& Powell, T. P. S. An experimental study of the avian visual system. Journal of Anatomy, 1961, 95, 545-563.

Cowan, W. M., \& Powell, T. P. S. Centrifugal fibres in the avian visual system. Proceedings of the Royal Society of London, B, 1963, 158, 232-252.

Crossland, W. J. Single unit analysis of color responses in the thalamic nuclei of the pigeon (Columba livia). MA thesis, University of Illinois at Urbana-Champaign, 1970.

CRossland, W. J. Receptive field characteristics of some thalamic visual nuclei of the pigeon (Columba livia). $\mathrm{PhD}$ thesis, University of Illinois at Urbana-Champaign, 1972.

DeBritto, L.B.G., Brunelli, M., Francesconi, W., \& Magni, F. Visual response pattern of thalamic neurons in the pigeon. Brain Research, 1975, 97, 337-343.

Delius, J. D., Perchard, R. J., \& Emmerton, J. Polarized light discrimination by pigeons and an electroretinographic correlate. Journal of Comparative and Physiological Psychology, 1976, 90 , 560-571.

Detwiler, S. R. Vertebrate photoreceptors. New York: Macmillan, 1943.

DodT, E., \& WIRTh, A. Differentiation between rods and cones by flicker electroretinography in pigeon and guinea pig. Acta Physiologica Scandinavica, 1953, 30, 80-89.

DoNNER, K. O. The spectral sensitivity of the pigeon's retinal elements. Journal of Physiology, 1953, 122, 524-537.

Dowling, J. E., \& Cowan, W. M. An electron microscopic study of normal and degenerating centrifugal fiber terminals in the pigeon retina. Zeitschrift für Zellforschung und Mikroscopische Anatomie, 1966, 71, 14-28.

Dubin, M. W. The inner plexiform layer of the vertebrate retina: A quantitative and comparative electron microscopic analysis. Journal of Comparative Neurology, 1970, 140, 479-505.

DufF, T. A., \& CoHen, D. H. Retinal afferents to the pigeon optic tectum: Discharge charactersitics in response to whole field illumination. Brain Research, 1975, 92, 1-19.

Fite, K. V. Two types of optomotor response in the domestic pigeon. Journal of Comparative and Physiological Psychology, 1968, 66, 308-314.

Frost, B. J. The effect of light adaptation on the d-wave of the pigeon ERG. Physiology \& Behavior, 1972, 8, 829-835.

Frost, B. J., \& DiFranco, D. E. Motion characteristics of single units in the pigeon optic tectum. Vision Research, 1976, 16, 1229-1234.

Galifret, Y. In R. Jung \& H. Kornhuber (Eds.), The visual system. Neurophysiology and psychophysics. Berlin: SpringerVerlag, 1961.

GaLIFRET, Y. Les diverses aires fonctionelles de la rétine du pigeon. Zeitschrift fur Zellforschung und Mikroscopische Anatomie, 1968, 86, 535-545.

Galifret, Y., \& CondÉ-Courtine, F. Influences centrifuges s'exercant sur la rétine du pigeon. Journal de Physiologie, Paris. 1968, 60, Suppl. 2, 445.

Goodson, J. E. Optokinetic responses in the pigeon. PhD dissertation, George Washington University, 1969.

Govardovskiř, V. I., \& ZuEVA, L. V. Visual pigments of chicken and pigeon. Vision Research, 1977, 17, 537-543.

GraF, V. A. A spectral luminosity function in the pigeon determined by flicker photometry. Psychonomic Science, 1969, 17, 282-283.

GRAF, V. A. De Lange characteristics for the fresh-water turtle Chrysemys picta picta, and the pigeon Columba livia. Vision Research, 1973, 13, 1815-1822.

Graf, V. A., \& NorRen, D. V. A blue sensitive mechanism in the pigeon retina: $\lambda \max 400 \mathrm{~nm}$. Vision Research, 1974, 14, 12031209.

Granda, A. M., \& Yazulla, S. The spectral sensitivity of single units in the nucleus rotundus of the pigeon, Columba livia. Journal of General Physiology, 1971, 57, 363-384. 
Granit, R. The photopic spectrum of the pigeon. Acta Physiologica Scandinavica, 1942, 4, 118-124.

GuNDLACH, R. H. The visual acuity of homing pigeons. Journal of Comparative Psychology, 1933, 16, 327-342.

GuNDLACH, R. H. The speed of pupillary contraction in response to light in pigeons, cats, and humans. Journal of Genetic Psychology, 1934, 44, 250-253.

Gundlach, R. H., Chard, R. D., \& Skahen, J. R. The mechanism of accommodation in pigeons. Journal of Comparative Psychology, 1945, 38, 27-42.

Gusel'Nikov, V. I., Mozenkov, E. D., \& Gutsu, I. P. Reaction of neurons of the tectum opticum of the pigeon to visual stimuli. Neurologia, 1971, 3, 78-83.

Guttman, N., \& Kalish, H. I. Discriminability and stimulus generalization. Journal of Experimental Psychology, 1956, 51, 79-88.

Hamdi, F. A., \& Whitteridge, D. The representation of the retina on the optic tectum of the pigeon. Quarterly Journal of Experimental Psychology, 1954, 39, 111-119.

Hamilton, W. G., \& Coleman, T. B. Trichromatic vision in the pigeon as illustrated by the spectral hue discrimination curve. Journal of Comparative Psychology, 1933, 15, 183-191.

Hamilton, W. F., \& Goldstein, J. L. Visual acuity and accommodation in the pigeon. Journal of Comparative Psychology, 1933, 15, 193-197.

HAYES, B. P., \& WebsteR, K. E. An electron microscope study of the retino-receptive layers of the pigeon optic tectum. Journal of Comparative Neurology, 1975, 162, 447-466.

HENDRICKS, J. Flicker thresholds as determined by a modified conditioned suppression procedure. Journal of the Experimental Analysis of Behavior, 1966, 9, 501-506.

Hodos, W. Color discrimination deficits after lesions of the nucleus rotundus in pigeons. Brain, Behavior \& Evolution, 1969, 2, 185-200.

Hodos, W. Vision and the visual system: A bird's eye view. In Progress in psychobiology and physiological psychology (Vol. 6). New York: Academic Press, 1976.

Hodos, W., \& Bonbright, J. C., JR. The detection of visual intensity differences by pigeons. Journal of the Experimental Analysis of Behavior, 1972, 18, 471-479.

Hodos, W., \& BONBRIGHT, J. C., JR. Intensity difference thresholds in pigeons after lesions of the tectofugal and thalamofugal visual pathways. Journal of Comparative and Physiological Psychology, 1974, 87, 1013-1031.

Hodos, W., \& Bonbright, J. C., JR. Intensity and pattern discrimination after lesions of the pretectal complex, accessory optic nucleus and ventral geniculate in pigeons. Journal of Comparative Neurology, 1975, 161, 1-18.

Hodos, W., \& Fletcher, G. V. Acquisition of visual discrimination after nucleus rotundus lesions in pigeons. Physiology \& Behavior, 1974, 13, 501-506.

Hodos, W., \& KARTEN, H. J. Brightness and pattern discrimination deficits in the pigeon after lesions of nucleus rotundus. Experimental Brain Research, 1966, 2, 151-167.

Hodos, W., \& KARTEN, H. J. Visual intensity and pattern discrimination deficits after lesions of ectostriatum in pigeons. Journal of Comparative Neurology, 1970, 140, 53-68.

Hodos, W., \& KARTEN, H. J. Visual intensity and pattern discrimination deficits after lesions of the optic lobe in pigeons. Brain, Behavior, \& Evolution, 1974, 9, 165-194.

Hodos, W., Karten, H. J., \& Bonbright, J. C., JR. Visual intensity and pattern discrimination after lesions of the thalamofugal visual pathway in pigeons. Journal of Comparative Neurology, 1973, 148, 447-468.

Hodos, W., Leibowitz, R. W., \& Bonbright, J. C., JR. Nearfield visual acuity in pigeons: Effects of head location and stimulus luminance. Journal of the Experimental Analysis of Behavior, 1976, 25, 129-141.

Hodos, W., Smith, L., \& Bonbright, J. C., JR. Detection of the velocity of movement of visual stimuli by pigeons. Journal of the Experimental Analysis of Behavior, 1976, 25, 143-156.

Holden, A. L. Two possible visual functions for centrifugal fibres to the retina. Nature, $1966,212,837-838$.
Holden, A. L. Receptive properties of retinal cells and tectal cells in the pigeon. Journal of Physiology, 1969, 201, 56P-57P.

Holden, A. L. The laminar organization of the pigeon optic tectum. Journal of Physiology, 1971, 214, 44P-45P.

Holden, A. L. Concentric receptive fields of pigeon ganglion cells. Vision Research, 1977, 17, 545-554.

Holden, A. L., \& Powell, T. P. S. The functional organization of the isthmo-optic nucleus in the pigeon. Journal of Physiology, 1972, 223, 419-447.

Huber, G. C., \& Crosby, E. C. The reptilian optic tectum. Journal of Comparative Neurology, 1933, 57, 57-161.

Hughes, C. P., \& Pearlman, A. L. Single unit receptive fields and the cellular layers of the pigeon optic tectum. Brain Research, 1974, 80, 365-377.

Hughes, J. T., Jerrome, D., \& Krebs, H. A. Ultrastructure of the avian retina. An anatomical study of the retina of the domestic pigeon (Columba livia) with particular reference to the distribution of mitochrondria. Experimental Eye Research, 1973, 14, 189-195.

Hunt, S. P., \& Künzle, H. Observations on the projections and intrinsic organization of the pigeon optic tectum: An autoradiographic study based on anterograde and retrograde axonal and dendritic flow. Journal of Comparative Neurology, 1976, 170, 153-172.

Hunt, S. P., \& WeBster, K. E. The projection of the retina upon the optic tectum of the pigeon. Journal of Comparative Neurology, 1975, 162, 433-466.

IKEDA, H. The spectral sensitivity of the pigeon (Columba livia). Vision Research, 1965, 5, 19-36.

JARVIs, C. D. Visual discrimination and spatial localization deficits after lesions of the tectofugal visual pathway in pigeons. Brain, Behavior, \& Evolution, 1974, 9, 195-228.

JASSIK-GERSCHENFELD, D., \& GUICHARD, J. Visual receptive fields of single cells in the pigeon's optic tectum. Brain Research, 1972, 40, 303-317.

JAsSik-GersChenfeld, D., Guichard, J., \& Tessier, Y. Localization of directionally selective and movement sensitive cells in the optic tectum of the pigeon. Vision Research, 1975, 15, 1037. 1038.

Jassik-Gerschenfeld, D., Minois, F., \& Condé-Courtine, F. Receptive field properties of directionally selective units in the pigeon's optic tectum. Brain Research, 1970, 24, 407-421.

JASSIK-Gerschenfeld, D., TeUlon, J., \& Ropert, N. Visual receptive field types in the nucleus dorsolateralis anterior of the pigeon's thalamus. Brain Research, 1976, 108, 295-306.

KARTEN, H. J., FITE, K. V., \& Brecha, N. Specific projection of displaced retinal ganglion cells upon the accessory optic system in the pigeon (Columba livia). Proceedings of the National Academy of Science of the USA, 1977, 74, 1753-1756.

KARTEN, H. J., \& Hodos, W. Telencephalic projections of the nucleus rotundus in the pigeon (Columba livia). Journal of Comparative Neurology, 1970, 140, 35-52.

Karten, H. J., Hodos, W., Nauta, W. J. H., \& Revzin, A. M. Neural connection of the "Visual Wulst" of the avian telencephalon. Experimental studies in the pigeon (Columba livia) and owl (Speotyto cunicularia). Journal of Comparative Neurology, 1973, 150, 253-278.

KARTEN, H. J., \& Revzin, A. M. The afferent connections of the nucleus rotundus in the pigeon. Brain Research, 1966, 2, 368-377.

Kelly, D. H. Visual responses to time-dependent stimuli. I. Amplitude sensitivity measurements. Journal of the Optical Society of America, 1961, 51, 422-429.

Kimberly, R. P., Holden, A. L., \& Bamborough, P. Response characteristics of pigeon forebrain cells to visual stimulation. Vision Research, 1971, 11, 475-478.

KING-Smith, P. E. Absorption spectra and the function of the coloured oil drops in the pigeon retina. Vision Research, 1969, 9, 1391-1399.

Kreithen, M. L., \& EISNER, T. Ultraviolet light detection by the homing pigeon. Nature, 1978, 272, 347-348.

Kreithen, M. L., \& KeEton, W. T. Detection of polarized light by the homing pigeon, Columba livia. Journal of Comparative Physiology, 1974, 89, 83-92. 
LAURENS, H. Studies on the relative physiological value of spectral lights. III: The pupillomotor effects of wavelengths of equal energy content. American Journal of Physiology, 1923, 64, 97-119.

LE GRAND, Y. Light, colour, and vision (2nd ed.). London: Chapman \& Hall, 1968.

LIEBMAN, P. A. Microspectrophotometry of photoreceptors. In H. J. A. Dartnall (Ed.), Handbook of sensory physiology (Vol. VII/1). Berlin: Springer-Verlag, 1972.

McGill, J. I. Organization within the central and centrifugal fiber pathways in the avian visual system. Nature, 1964, 204, 395-396.

McGill, J. I., Powell, T. P. S., \& Cowan, W. M. The organization of the projection of the centrifugal fibers to the retina in the pigeon. Journal of Anatomy, 1966, 100, 35-49. (a)

McGill, J. I., Powell, T. P. S., \& Cowan, W. M. The retinal representation upon the optic tectum and the isthmo-optic nucleus in the pigeon. Journal of Anatomy, 1966, 100, 5-33. (b)

Marshall, J., Mellerio, J., \& Palmer, D. A. Damage to pigeon retinae by moderate illumination from fluorescent lamps. Experimental Eye Research, 1972, 14, 164-169.

Marshall, J., Mellerio, J., \& Palmer, D. A. A schematic eye for the pigeon. Vision Research, 1973, 13, 2449-2453.

Maturana, H. R. Functional organization of the pigeon retina. In Information processing in the nervous system. Amsterdam: Excerpta Medica Foundation, 1964.

Maturana, H. R., \&. Frenk, S. Directional movement and horizontal edge detectors in the pigeon retina. Science, 1963, 142, 977-979.

Maturana, H. R., \& Frenk, S. Synaptic connections of the centrifugal fibers in the pigeon retina. Science, 1965, 150, 359-361.

MeIER, R. E., Minailovic̀, J., \& CuÉNod, M. Thalamic organization of the retino-thalamo-hyperstriatal pathway in the pigeon (Columba livia). Experimental Brain Research, 1974, 19, 351-364.

Mentzer, T. L. Comparison of three methods for obtaining psychophysical threshold from the pigeon. Journal of Comparative and Physiological Psychology, 1966, 61, 96-101.

Miceli, D., PEYrichoux, J., \& RePÉRANT, J. The retino-thalamohyperstriatal pathway in the pigeon (Columba livia). Brain Research, 1975, 100, 125-134.

Mirailovic̀, J., Perisic̀, M., Bergonzi, R., \& Meier, R. E. The dorsolateral thalamus as a relay in the retino-wulst pathway in pigeon (Columba livia). An electrophysiological study. Experimental Brain Research, 1974, 21, 229-240.

Mrles, F. A. Centrifugal effects in the avian retina. Science, 1970, 170, 992-995.

Miles, F. A. Centrifugal control of the avian retina. IV: Effects of reversible cold block of the isthmo-optic tract on the receptive field properties of cells in the retina and isthmo-optic nucleus. Brain Research, 1972, 48, 131-145.

Mrllodot, M., \& Blough, P. The refractive state of the pigeon eye. Vision Research, 1971, 11, 1019-1022.

Montgomery, K. C., \& Heinemann, E. G. Concerning the ability of homing pigeons to discriminate patterns of polarized light. Science, 1952, 116, 454-456.

MorRIs, V. B. Symmetry in a receptor mosaic demonstrated in the chick from frequencies, spacing and arrangement of the types of retinal receptor. Journal of Comparative Neurology, 1970, 140, 359-397.

Muntz, W. R. A. Inert absorbing and reflecting pigments. In J. J. A. Dartnall (Ed.), Handbook of sensory physiology (VII/1). Berlin: Springer-Verlag, 1972.

Norren, D. V. Two short wavelength sensitive cone systems in pigeon, chicken, and daw. Vision Research, 1975, 15, 1164-1166.

NYE, P. W. The binocular acuity of the pigeon measured in terms of the modulation transfer. Vision Research, 1968, 8, 1041-1053.

NyE, P. W. The monocular eye movements of the pigeon. Vision Research, 1969, 9, 133-144.

NYE, P. W. On the functional differences between frontal and lateral visual fields of the pigeon. Vision Research, 1973, 13, 559-574.

Ogden, T. E., \& Wylie, R. Avian retina. I: Microelectrode depth and marking studies of local ERG. Journal of Neurophysiology, 1971, 34, 357-366.

OnLeY, J. W. Brightness scaling of white and colored stimuli. Science, 1960, 132, 1668-1670.

Passe, D. H. Absolute scotopic thresholds in the pigeon determined by classical conditioning of directed motor action. $\mathrm{PhD}$ dissertation, Florida State University, 1977.

PAsternak, T. Delayed matching performance after visual wulst lesions in pigeons. Journal of Comparative and Physiological Psychology, 1977, 91, 472-484.

Pasternak, T., \& Hodos, W. Intensity difference thresholds after lesions of the visual wulst in pigeons. Journal of Comparative and Physiological Psychology, 1977, 91, 485-497.

Patel, A. S. Spatial resolution by the human visual system. The effect of mean retinal illuminance. Journal of the Optical Society of America, 1966, 56, 689-694.

Pearlman, A. L., \& Hughes, C. P. Functional role of efferents to the avian retina. I: Analysis of retinal ganglion cell receptive fields. Journal of Comparative Neurology, 1976, 166, 111-122. (a)

Peariman, A. L., \& Hughes, C. P. Functional role of efferents to the avian retina. II: Effects of reversible cooling of the isthmooptic nucleus. Journal of Comparative Neurology, 1976, 166, 123-132. (b)

Pedler, C., \& Boyle, M. Multiple oil droplets in the photoreceptors of the pigeon. Vision Research, 1969, 9, 525-528.

Perisic̀, M., Mihailovic̀, J., \& Cú́nod, M. Electrophysiology of contralateral and ipsilateral visual projections to the Wulst in pigeon. International Journal of Neuroscience, 1971, 2, 1-8.

Polyak, S. The vertebrate visual system. Chicago: University of Chicago Press, 1957.

Powell, R. W. The pulse-to-cycle fraction as a determinant of critical flicker fusion in the pigeon. Psychological Record, 1967, 17, 151-160.

Powell, R. W., \& SMITH, J. C. Critical-flicker-fusion thresholds as a function of very small pulse-to-cycle fractions. Psychological Record, 1968, 18, 35-40.

Powell, T. P. S., \& CowaN, W. M. The thalamic projection upon the telencephalon in the pigeon. Journal of Anatomy, 1961, 95, 78-109.

Pritz, M. B., Mead, W. R., \& Northcutt, R. G. The effects of wulst ablations on color, brightness and pattern discrimination in pigeons. Journal of Comparative Neurology, 1970, 140, 81-100.

REPÉRANT, J. Nouvelles données sur les projections visuelles chez le pigeon (Columba livia). Journal für Hirnsforschung, 1973, 14, 151-188.

Revzin, A. M. Unit responses to visual stimuli in the nucleus rotundus of the pigeon. Federation Proceedings, 1967, 26, 656.

Revzin, A. M. A specific visual projection area in the hyperstriatum of the pigeon (Columba livia). Brain Research, 1969, 15, 246-249.

Revzin, A. M. Some characteristics of wide-field units in the brain of the pigeon. Brain, Behavior, \& Evolution, 1970, 3, 195-204.

Revzin, A. M., \& Karten, H. J. Rostral projection of the optic tectum and the nucleus rotundus in the pigeon. Brain Research, 1966/67, 3, 264-276.

Riggs, L. A., Blough, P. M., \& Schafer, K. L. Electrical responses of the pigeon eye to changes in wavelength of the stimulating light. Vision Research, 1972, 12, 981-991.

ROBERT, F., \& CUÉNOD, M. Electrophysiology of the intertectal commissures in the pigeon. I: Analysis of the pathways. Experimental Brain Research, 1969, 9, 116-122. (a)

RoBert, F., \& Cú́nod, M. Electrophysiology of the intertectal commissures in the pigeon. II: Inhibitory interaction. Experimental Brain research, 1969, 9, 123-136. (b)

Rogers, L. J., \& MiLes, F. A. Centrifugal control of the avian retina. V: Effects of lesions of the isthmo-optic nucleus on visual behaviour. Brain Research, 1972, 48, 147-156.

Romeskie, M., \& YAGER, D. Psychophysical studies of pigeon color vision. I: Photopic spectral sensitivity. Vision Research, 1976, 16, 501-506. (a)

Romeskie, M., \& YAger, D. Psychophysical studies of pigeon color vision. II: The spectral photochromatic interval function. 
Vision Research, 1976, 16, 507-512. (b)

Samson, H. H., \& Young, M. L. The relation of flash intensity and background illumination to the photic evoked potential in the pigeon's optic tectum. Vision Research, 1973, 14, 253-262.

SCHNEIDER, B. Multidimensional scaling of color difference in the pigeon. Perception \& Psychophysics, 1972, 12, 373-378.

Schultze, M. Zur Anatomie und Physiologie der Retina. Archiv für Mikroskopische Anatomie, 1866, 2, 175-286.

SHORTESS, G. K., \& KLOSE, E. F. Effects of lesions involving efferent fibers to the retina in pigeons (Columba livia). Physiology \& Behavior, 1977, 18, 409-414.

Shumake, S. A., Hatfield, C. A., \& Smith, J. C. Brightness difference thresholds in the pigeon using the conditioned suppression technique. Psychonomic Science, 1966, 6, 313-314.

Siegel, R. K. Apparent movement detection in the pigeon. Journal of the Experimental Analysis of Behavior, 1970, 14, 93-97.

Siegel, R. K. Apparent movement and real movement detection in the pigeon: Stimulus generalization. Journal of the Experimental Analysis of Behavior, 1971, 16, 189-192.

Sillman, A. J. The visual pigments of several species of birds. Vision Research, 1969, 9, 1063-1077.

Stone, J., \& Freeman, J. A. Synaptic organization of the pigeon's optic tectum: A golgi and current source density analysis. Brain Research, 1971, 27, 203-221.

STORT, A. G. H. van GENDEREN. Über Form und Orstveranderungen der Netzhautelemente unter Einfluss von Licht und Dunkel. Albrecht von Graefes Archiv für Klinische und Experimentelle Ophthalmologie, 1887, 33, 229.

STRother, G. K. Absorption spectra of retinal oil globules in turtle, turkey and pigeon. Experimental Cell Research, 1963, 29, 349-355.

TANSLEY, K. Vision in vertebrates. London: Chapman \& Hall, 1965.

Voneida, T. J., \& MELlo, N. K. Interhemispheric projections of the optic tectum in pigeon. Brain, Behavior, \& Evolution, 1975, 11, 91-108.

WAELChII, G. Zur Topographie der gefarbten Kugelin der Vogelnetzhaut. Albrecht von Graefes Archiv für Klinische und Experimentelle Ophthalmologie, 1883, 29, 205-223.

WaLD, G. Retinal chemistry and the physiology of vision. Selig Hecht commemorative lecture. In Visual Problems of Colour (Symposium No. 8, National Physical Laboratory, U.K.). London: H.M.S.O., 1958.

WaLls, G. L. The vertebrate eye. Bloomfield Hills, Mich: Cranbrook Institute of Science, 1942.

WALLS, G. L., \& JUDD, H. D. The intra-ocular filters of vertebrates. British Journal of Ophthalmology, 1933, 33, 641-675, 705-725.

WeBster, K. E. Changing concepts of the organization of the central visual pathways in birds. In R. Bellairs \& E. G. Gray (Eds.), Essays on the nervous system: $A$ festschrift for J. $Z$. Young. Oxford: Clarendon Press, 1974.

WhITERIDGE, D. Tectum opticum: Introduction. In R. Jung \& H. Kornhuber (Eds.), The visual system: Neurophysiology and psychophysics. Berlin: Springer-Verlag, 1961. Pp. 210-211.

Williams, J. L. Evidence of complementary afterimages in the pigeon. Journal of the Experimental Analysis of Behavior, 1974, 21, 421-424.

Wolbarsht, M. J., Stopp, P. E., \& Godson, J. E. Ophthalmoscopy of pigeons using transillumination. Experientia, 1964, 20, 466.

Woods, E. J., \& Frost, B. J. Adaptation and habituation characteristics of tectal neurons in the pigeon. Experimental Brain Research, 1977, 27, 347-354.

Wright, A. A. The influence of ultraviolet radiation on the pigeon's color discrimination. Journal of the Experimental Analysis of Behavior, 1972, 17, 325-337. (a)

Wright, A. A. Psychometric psychophysical hue discrimination functions for the pigeon. Vision Research, 1972, 12, 1447. 1464. (b)

WrIGHT, A. A. Bezold-Brücke hue shift functions for the pigeon. Vision Research, 1976, 16, 765-774.

Wright, A. A., \& Cumming, W. W. Color-naming functions for the pigeon. Journal of the Experimental Analysis of Behavior, 1971, 15, 7-17.

WYLIE, R. M. Responses of neurons in the optic tectum of the pigeon. PhD thesis, Harvard University, 1962.

YAGER, D., \& RoMESKIE, M. On the proper control of luminance cues in pigeon color vision experiments. Journal of the Experimental Analysis of Behavior, 1975, 23, 293-295.

YAZULLA, S. Intraretinal differentiation in the synaptic organization of the inner plexiform layer of the pigeon retina. Journal of Comparative Neurology, 1974, 153, 309-324.

Yazulla, S., \& Granda, A. M. R. Opponent-color units in the thalamus of the pigeon (Columba livia). Vision Research, 1973, $13,1555-1563$.

\section{SUPPLEMENTARY BIBLIOGRAPHY}

Angaut, P., \& Repérant, J. Fine structure of the optic fibre termination layers in the pigeon optic tectum. A Golgi and electron microscope study. Neuroscience, 1976, 1, 93-105.

ARDEN, G. B., \& ERNST, W. Mechanism of current production found in pigeon cones but not in pigeon or rat rods. Nature, 1969, 223, 528-531.

Beale, I. L., \& Corballis, M. C. Beak shift: An explanation for interocular mirror image reversal in pigeons. Nature, 1968, 220, 82-83.

Beale, I. L., Williams, R. J., Webster, D. M., \& Corballis, M. C. Confusion of mirror images by pigeon and interhemispheric commissures. Nature, 1972, 238, 348-349.

BingGeli, R. L., Tschirgi, R. D., \& WenzeL, B. M. Effects of unilateral hemispheric and optic tectal ablations on visual discrimination learning in pigeons. The Physiologist, 1963, 6, 140.

Birch-Hirschfield, A. Der Einfluss der Helladaptation auf die Struktur der Nervenzellen der Netzhaut nach Untersuchungen an der Taube. Albrecht von Graefes Archiv für Klinische und Experimentelle Ophthalmologie, 1906, 63, 85.

Bloch, S., \& Martinoya, C. Are colour oil droplets the basis of the pigeon's chromatic space? Vision Research, Suppl. 3, 1971, 11, 411-418.

Blough, D. S. Stimulus generalization as signal detection in pigeons. Science, 1967, 158, 940-941.

BLOUGH, D. S. Visual search in the pigeon: Hunt and peck method. Science, 1977, 196, 1013-1014.

Brooks, B., \& Holden, A. .L. Suppression of visual signals by rapid image displacement in the pigeon retina: A possible mechanism for "saccadic" suppression. Vision Research, 1973, 13, 1387-1390.

Brooks, B., \& Holden, A. L. Centre and surround influences on the proximal negative response of the pigeon retina. Journal of Physiology, 1974, 239, 15-29.

Catania, A. C. Techniques for the control of the monocular and binocular viewing in the pigeon. Journal of the Experimental Analysis of Behavior, 1963, 6, 627-629.

Catania, A. C. Interocular transfer of discriminations in the pigeon. Journal of the Experimental Analysis of Behavior, 1965, 8, 147-155.

CLARKE, P. G. H. The organization of visual processing in the pigeon cerebellum. Journal of Physiology, 1974, 243, 267-285.

COHEN, D. H., \& KaRTEN, H. J. The structural organization of the avian brain: An overview. In I. J. Goodman \& M. W. Schein (Eds.), Birds: Brain and behavior. New York: Academic Press, 1974.

Corballis, M. C., \& Beale, I. L. Monocular discrimination of mirror-image obliques by pigeons: Evidence for lateralized stimulus control. Animal Behaviour, 1970, 18, 563-566.

Cowan, W. M. Centrifugal fibres to the avian retina. British Medical Bulletin, 1970, 26, 112-118.

Duff, T. A., \& Cohen, D. H. Optic chiasm fibers of the pigeon: Discharge characteristics in response to whole field illumination. Brain Research, 1975, 92, 145-148.

Duke-Elder, S. System of ophthalmology (Vol. 1). The eye in evolution. London: Klimpton, 1958. 
Erchenkov, V. G., Gusel'Nikov, V. I., \& Zaborskis, A. A. On efferent effects upon responses of the pigeon retina ganglion cells. Sechenov Physiological Journal, 1972, 58, 385-392.

FriedmanN, H. On the supposed visual function of the nictitating membrane in the domestic pigeon. Journal of Comparative Psychology, 1932, 14, 55-61.

GALIFRET, Y. Le système visuèl de pigeon. Unpublished doctoral dissertation, Université de Paris, 1966.

Galifret, Y:, Condé-Courtine, F., Repérant, J., \& Servière, J. Centrifugal control in the visual system of the pigeon. Vision Research, Suppl. 3, 1971, 11, 185-200.

Goodwin, D. Pigeons and doves of the world. London: British Museum of Natural History, 1967.

Graham, C. H., Kemp, E. H., \& Riggs, L. A. An analysis of the electrical retinal responses of a color-discriminating eye to light of different wavelengths. Journal of General Psychology, 1935, 13, 275-296.

Gray, E. G., \& HAMLYN, L. H. Electron microscopy of experimental degeneration in the avian optic tectum. Journal of Anatomy, 1962, 96, 309-316.

Gusel'Nikov, V. I., \& Voldlanskiŕ, A. N. Some data on the visual analyzer of the pigeon. Biological Abstracts, 1969, 50, No. $109106,45-52$.

Heaton, M. B., \& Harth, M. S. Developing visual function in the pigeon embryo with comparative reference to other avian species. Journal of Comparative and Physiological Psychology, 1974, 86, 151-156.

Hodos, W., \& Leibowitz, R. W. Near-field visual acuity of pigeons: Effects of scotopic adaptation and wavelength. Vision Research, 1977, 17, 463-467.

Holden, A. L. Antidromic activation of the isthmo-optic nucleus. Journal of Physiology, 1968, 197, 183-198. (a)

Holden, A. L. The centrifugal system running to the pigeon retina. Journal of Physiology, 1968, 197, 199-210. (b)

Holden, A. L. The field potential profile during activation of the avian optic tectum. Journal of Physiology, 1968, 194, 75-90. (c)

Holden, A. L. Types of unitary response and correlation with the field potential profile during activation of the avian optic tectum. Journal of Physiology, 1968, 194, 91-104. (d)

Holden, A. L. Receptive properties of centrifugal cells projecting to the pigeon retina. Journal of Physiology, 1970, 210, 155 p.

Holden, A. L. Proximal negative response in the pigeon retina. Journal of Physiology, 1972, 221, 173-188.

Holden, A. L. Extensive lateral transmission in the inner plexiform layer of the pigeon retina. Vision Research, 1977, 17, 665-666.

Huber, G. C., \& Crossy, E. C. The nuclei and fiber paths of the avian diencephalon, with consideration of telencephalic and certain mesencephalic centers and connections. Journal of Comparative Neurology, 1929, 48, 1-225.

Huizinga, E., \& VAN DER Meulen, P. Vestibular rotatory and optokinetic reactions in the pigeon. Annals of Otology \& Laryngology, 1951, 60, 927-947.

Hunt, S. P., \& Webster, K. E. Thalamo-hyperstriate interrelations in the pigeon. Brain Research, 1972, 44, 647-651.

Hunt, S. P., Streit, P., Künzle, H., \& Cún Nod, M. Characterization of the pigeon isthmo-tectal pathway by selective uptake and retrograde movement of radioactive compounds and by Golgi-like HRP labeling. Brain Research, 1977, 129, 197-212.

JasSiK-GERSChENFELD, D., LANGe, R. V., \& ROPERT, N. Response of movement detecting cells in the optic tectum of pigeons to change of wavelength. Vision Research, 1977, 17, 1139-1146.

JUNGHERR, E. Certain nuclear groups of the avian mesencephalon. Journal of Comparative Neurology, 1945, 82, 55-76.

KARTEN, H. J. The organization of the avian telencephalon and some speculations on the phylogeny of the amniote telencephalon. Annals of the New York Academy of Sciences, 1969, 167, 164-185.

KARTEN, H. J., \& Hodos, W. A stereotaxic atlas of the brain of the pigeon (Columba livia). Baltimore: Johns Hopkins Press, 1967.

KAzSUK, J. D. Some effects of limited pulse trains on critical fusion frequency for pigeon and human subjects. Dissertation Abstracts
International, 1970, 30(11-B), 5259.

KIDD, M. Electron microscopy of the inner plexiform layer of the retina in the cat and in the pigeon. Journal of A natomy, 1962, 96, 179-188.

KING-SMITH, P. E. Micro-electrode recordings from the pigeon lateral geniculate nucleus. Journal of Physiology, 1970, 210, 169P-170P.

LEVI, W. M. The pigeon. Sumter, S. C: Levi, 1957.

LEVINE, J. Studies in the interrelations of central nervous structures in binocular vision. I. The lack of bilateral transfer of visual discriminative habits acquired monocularly by the pigeon. Journal of Genetic Psychology, 1945, 67, 105-129.

LEVINE, J. Studies in the interrelations of central nervous structures in binocular vision. II. The conditions under which interocular transfer of discriminative habits takes place in the pigeon. Journal of Genetic Psychology, 1945, 67, 131-145.

LEVINE, J. Studies in the interrelations of central nervous structures in binocular vision. III. Localization of the memory trace as evidenced by the lack of inter-and intraocular habit transfer in the pigeon. Journal of Genetic Psychology, 1952, 81, 19-27.

Mariani, A. P., \& Leuré-Du Prée, A. E. Horizontal cells of the pigeon retina. Journal of Comparative Neurology, 1977, 175, 13-26.

MELlo, N. K. Interhemispheric reversal of mirror-image oblique lines after monocular training in pigeons. Science, 1965, 148, 252-254.

MelLo, N. K. Concerning the inter-hemispheric transfer of mirrorimage patterns in pigeons. Physiology \& Behavior, 1966, 1, 293-300.

Mello, N. K. A method for restricting stimuli to the frontal or lateral visual field of each eye separately in pigeon. Psychonomic Science, 1967, 8, 15-16.

Mello, N. K. The effect of unilateral lesions of the optic tectum on interhemispheric transfer of monocularly trained color and pattern discrimination in pigeons. Physiology \& Behavior, 1968, 3, 725-734.

Miles, F. A. Centrifugal control of the avian retina. I. Receptive field properties of retinal ganglion cells. Brain Research, 1972, 48, 65-92.

Miles, F. A. Centrifugal control of the avian retina. II. Receptive field properties of cells in the isthmo-optic nucleus. Brain Research, 1972, 48, 93-113.

Miles, F. A. Centrifugal control of the avian retina. III. Effects of electrical stimulation of the isthmo-optic tract on the receptive field properties of retinal ganglion cells. Brain Research, 1972, 48, 115-129.

Mori, S. Analysis of field response in optic tectum of the pigeon. Brain Research, 1973, 54, 193-206.

MorI, S., \& MitaraI, G. Late field responses in optic tectum of the pigeon. Brain Research, 1974, 65, 525-528.

MOWRER, O. H. The nystagmic response of the pigeon to constant angular acceleration at liminal and supra-liminal intensities. Journal of Comparative Psychology, 1935, 19, 177-193.

NYE, P. W. An examination of the electro-retinogram of the pigeon in response to stimuli of different intensity and wavelength and following intense chromatic adaptation. Vision Research, 1968, 8, 679-696.

Parker, D. M., \& Delius, J. D. Visual evoked potentials in the forebrain of the pigeon. Experimental Brain Research, 1972, 14, 198-209.

Pumphrey, R. J. The sense organs of birds. Ibis, 1948, 90, 171-190.

Runge, R. G., Uemura, M., \& Viglione, S. S. Electronic synthesis of the avian retina. Institute of Electrical and Electronic Engineers Transactions in Bio-Medical Engineering, 1968, BME-15(3), 138-151.

Samson, H. H., \& LAVINE, L. Effects of pentobarbital on the visual evoked response in the avian optic tectum. Physiology \& Behavior, 1972, 8, 1193-1196.

SCHLICHTE, H. J. The importance of optical parameters for homing in pigeons. Zeitschrift für Tierpsychologie, 1973, 32, 257-280.

SIEGEL, R. K. A device for chronically controlled visual input. Journal of the Experimental Analysis of Behavior, 1968, 11, 
$559-560$.

SkInNer, B. F. Pigeon in a pelican. American Psychologist, 1960, 15, 28-37.

SloANe, H. N. Stimulus generalization along a light flicker rate continuum after discrimination training with several subjects. Journal of the Experimental Analysis of Behavior, 1964, 7, 217-222.

SOMmer, F., \& Whitteridge, D. Compensatory eye movements in the pigeon. Journal of Physiology, 1957, 139, 19-20P.

Stort, A. G. H. van Genderen. Mouvements des éléments de la rétine sous l'influence de la lumière. Archives Néerlandaises des Sciences éxactes et naturelles, 1887, 21, 316-386.

URcuioli, P. J., \& Nevin, J. A. Transfer of hue matching in pigeons. Journal of the Experimental Analysis of Behavior, 1975, 24, 149-155.

WALKER, J. K. The bisection of a spatial interval by the pigeon. Journal of the Experimental Analysis of Behavior, 1968, 11, 99-105.

Wright, A. A. Psychometric and psychophysical theory within a framework of response bias. Psychological Review, 1974, 81, 322-347.

ZEIGLER, H. P. Effects of endbrain lesions upon visual discrimination learning in pigeons. Journal of Comparative Neurology, 1963, 120, 161-182.

ZeIgler, H. P., \& Schmerler, S. Visual discrimination of orientation by pigeons. Animal Behaviour, 1965, 13, 475-477.

\section{REPRINT PERMISSIONS}

The following figures and tables are reprinted with permission:

Figure 1. From Journal of Comparative Psychology, 25, Chard \& Gundlach, "The structure of the eye of the homing pigeon." Copyright 1938, American Psychological Association.

Figure 2. From Vision Research, 13, Marshall, Mellerio, \& Palmer, "A schematic eye for the pigeon." Copyright 1973, Pergamon Press, Ltd.

Table 1a. From Journal of Comparative Psychology, 25 Chard \& Gundlach, "The structure of the eye of the homing pigeon." Copyright 1938, American Psychological Association.

Table 1b. From Vision Research, 13, Marshall, Mellerio, \& Palmer, "A schematic eye for the pigeon." Copyright 1973, Pergamon Press, Ltd.

Table 2. From Vision Research, 13, Marshall, Mellerio, \& Palmer, "A schematic eye for the pigeon." Copyright 1973, Pergamon Press, Ltd.

Figure 3. From Vision Research, 17, Govardovskii \& Zueva, "Visual pigements of chicken and pigeon." Copyright 1977, Pergamon Press, Ltd.

Figure 4. From Zeitschrift für Zellforschung und Miknoskopische Anatomie, 86, Galifret, "Les diverses aires fonctionelles de la rétine du pigeon." Copyright 1968, Springer-Verlag Inc.

Table 3. From Nature, New Biology, 234 Bloch \& Maturana, "Oil droplet distribution and colour discrimination in the pigeon." Copyright 1971, Macmillan Journals Ltd.

Table 4. From Journal of Comparative Neurology, 153, Yazulla, "Intraretinal differentiation in the synaptic organization of the inner plexiform layer of the pigeon retina." Copyright 1974, The Wistar Institute Press.

Table 5. From Journal of Comparative Neurology, 153, Yazulla, "Intraretinal differentiation in the synaptic organization of the inner plexiform layer of the pigeon retina." Copyright 1974, The Wistar Institute Press.

Figure 5. From Journal of Comparative Neurology, 137, Binggeli \& Paule, "The pigeon retina: Quantitative aspects of the optic nerve and ganglion cell layer." Copyright 1969, The Wistar Institute Press.

Figure 6. From Progress in Psychobiology and Physiological Psychology, 6, Hodos, "Vision and the visual system: A bird's eye view.” Copyright 1976, Academic Press.

Figure 7. From Journal of Anatomy, 95, Cowan, Adamson, \& Powell, "An experimental study of the avian visual system." Copyright 1961, Cambridge University Press.

Figure 8. From Vision Research, 13, Graf, "De Lange characteristics for the freshwater turtle Chrysemys picta picta and the pigeon Columba liva." Copyright 1973, Pergamon Press, Ltd.

Figure 9. From Vision Research, 13, Graf, "DeLange characteristics for the freshwater turtle Chrysemys picta picta and the pigeon Columba livia. ' Copyright 1973, Pergamon Press, Ltd.

Table 7. From Vision Research, 17, Bowmaker, "The visual pigment, oil droplets, and spectral sensitivity of the pigeon." Copyright 1977, Pergamon Press, Ltd.

Figure 10. From Vision Research, 17, Bowmaker, "The visual pigment oil droplets, and spectral sensitivity of the pigeon." Copyright 1977, Pergamon Press, Ltd.

Figure 11. From Vision Research, 17, Bowmaker, "The visual pigment, oil droplets, and spectral sensitivity of the pigeon." Copyright 1977, Pergamon Press, Ltd.

Figure 12. From Vision Research, 15, Norren, "Two short wavelength sensitive cone sys̀tems in pigeon, chicken, and daw." Copyright 1975, Pergamon Press Ltd.

Figure 13. From Psychonomic Science, 17, Graf, “A spectral luminosity function in the pigeon determined by flicker photometry." Copyright 1969, Psychonomic Society, Inc.

Figure 14. From Journal of the Experimental Analysis of Behavior, 23, Yager \& Romeskie, "On the proper control of luminance cues in pigeon color-vision experiments." Copyright 1975, Society for the Experimental Analysis of Behavior, Inc.

Figure 15. From Vision Research, 17, Bowmaker, "The visual pigments, oil droplets, and spectral sensitivity of the pigeon." Copyright 1977, Pergamon Press, Ltd.

Figure 16. From Vision Research, 17, Bowmaker, "The visual pigements, oil droplets, and spectral sensitivity of the pigeon." Copyright 1977, Pergamon Press, Ltd.

Figure 17. From Perception \& Psychophysics, 12, P. Blough, "Wavelength generalization and discrimination in the pigeon." Copyright 1972, Psychonomic Society, Inc.

Figure 18. From Perception \& Psychophysics, 12, Schneider, "Multidimensional scaling of color difference in the pigeon." Copyright 1972, Psychonomic Society, Inc.

Figure 19. From Journal of the Experimental Analysis of Behavior, 15, Wright \& Cumming, "Color-naming functions for the pigeon." Copyright 1971, Society for the Experimental Analysis of Behavior, Inc.

Figure 20. From Vision Research, 16, Romeskie \& Yager, "Psychophysical studies of pigeon color vision, II: The spectral photochromatic interval function." Copyright 1976, Pergamon Press, Ltd.

Figure 21. From Vision Research, 8, Nye, "The binocular acuity of the pigeon measured in terms of the modulation transfer." Copyright 1968, Pergamon Press, Ltd.

Figure 22. From Journal of the Experimental Analysis of Behavior, 25, Hodos, Leibowitz, \& Bonbright, "Near-field visual acuity in pigeons: Effects of head location and stimulus luminance." Copyright 1976, Society for the Experimental Analysis of Behavior, Inc.

(Received for publication January 9, 1978; revision accepted August 15, 1978.) 